\title{
Beyond Marginalization: Youth Street Groups in Northern Africa
}

José Sánchez-García (Scientific Coordinator), Kamal Boucherf, Mustapha Omrane, Sihem Najar, Rachid Touhtouh, Carles Feixa (Dir.)

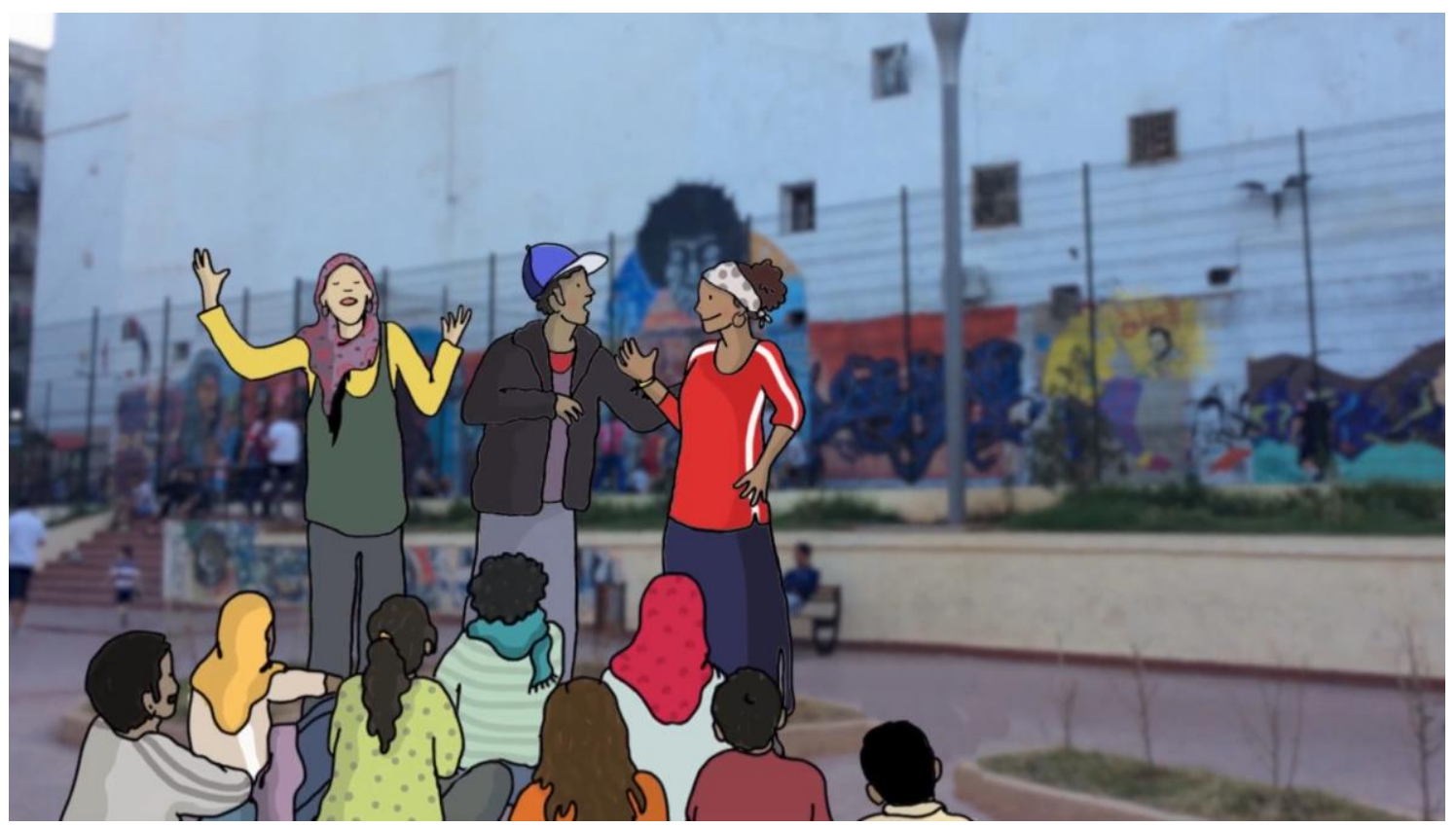




\section{Beyond Marginalization: Youth Street Groups in Northern Africa}

TRANSGANG Working Papers

Number: 5.1

SN: TRANSGANG_WP05.1/2021

Edition: July, 2021

\section{Authors}

José Sánchez-García (Scientific Coordinator), Kamal Boucherf, Mustapha Omrane, Sihem Najar, Rachid Touhtouh, Carles Feixa (Dir.)

Work distributed under CC licence

\section{(c) $(i) \Theta \Theta$}

\section{(C) TRANSGANG \& UPF}

\section{Recommended format for citation}

Sánchez-García, J. (Coord.), Boucherf, K., Omrane, M., Najar, S., Touhtouh, R., Feixa, C. (Dir.). (2021). Beyond Marginalization: Youth Street Groups in Northern Africa (TRANSGANG Working Papers 5.1). Barcelona: Universitat Pompeu Fabra \& European Research Council.

DOI: 10.31009/transgang.2021.wp05.1

ISBN: 978-84-09-21205-7

www.upf.edu/web/transgang

transgang@upf.edu

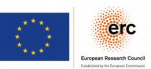

The TRANSGANG project receives funding from the European Research Council (ERC) under the European Union's HORIZON 2020 research and innovation programme under grant agreement $n^{\circ} 742705$ 


\section{Table of Contents}

\section{Introduction: Hip-hoppers, informal vendors and marginalized youths} José Sánchez-García ......................................................................................... 5

$1.1 \quad$ Researching youth street groups in the Maghreb...............................................

1.2 Mediation and youth groups in the Maghreb ...................................................10

1.3 Case studies: street vendors, hip-hoppers and marginalized youth.....................12

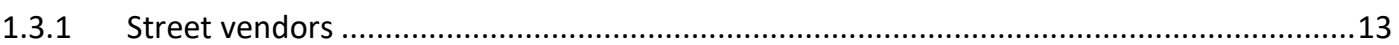

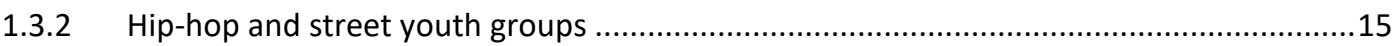

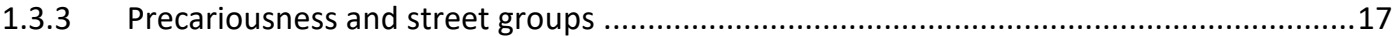

1.4 Border spaces and youth street groups in the Maghreb .....................................20

$1.5 \quad$ Then suddenly Covid-19 arrived ...................................................................21

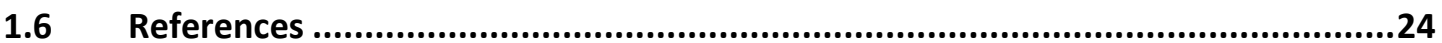

2 Researching Youth Street Groups in Algeria: Between the Universal and the Particular

Kamel Boucherf and Mustapha Omrane ........................................................... 26

2.1 Youth marginalisation and violence ................................................................27

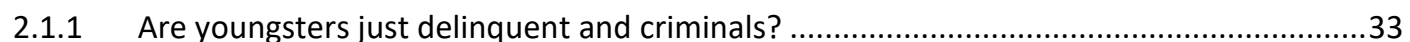

2.2 Empowering youth: Strengths and weaknesses ..............................................34

$2.3 \quad$ Women empowerment.......................................................................................40

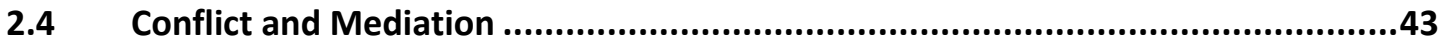

2.5 The concept of border space in the context of Algerian society ..........................48

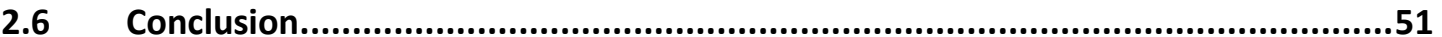

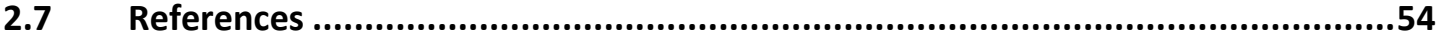

3 Researching Youth Street Groups in Tunisia: Violence, Empowerment and Mediation

Sihem Najar 58

3.1 Research on (trans)gangs in Tunisia..................................................................60

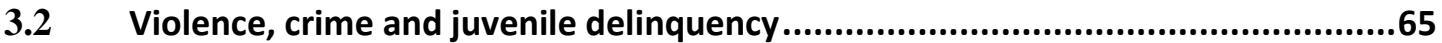

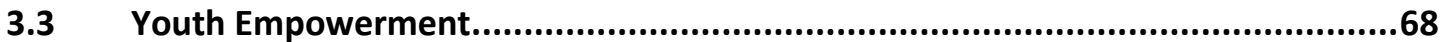

3.4 Conflict and mediation: a reading from Tunis .................................................71

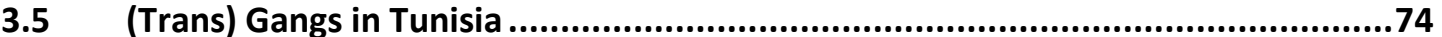

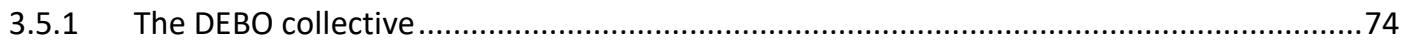

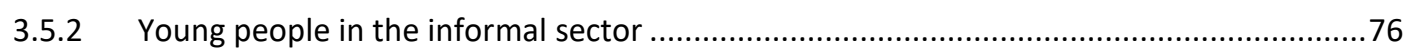

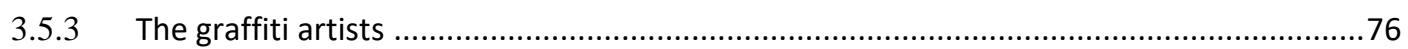




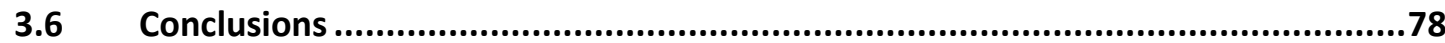

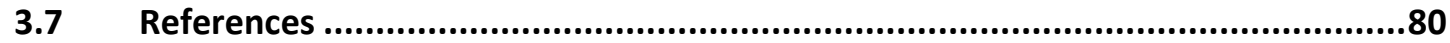

4 Street Youth Groups Cultures in Morocco: State of the Art and Research Perspectives

Rachid Touhtouh.

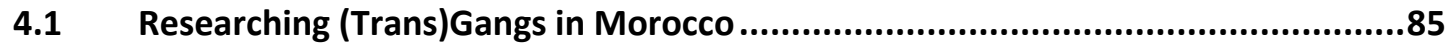

4.2 Beyond Violence: Empowerment, Conflict and Mediation in Morocco .................91

4.2.1 The Unemployed University Graduates Groups: Joblessness and precariousness .............93

4.2.2 The 2016 Rif Hirak: Marginalization and Incarceration ..................................................94

4.2.3 The Moroccan Boycott Movement of 2018: A Virtual Non-movement ...............................96

4.3 (Trans)Gangs in Greater Casablanca, Rabat and Sale........................................97

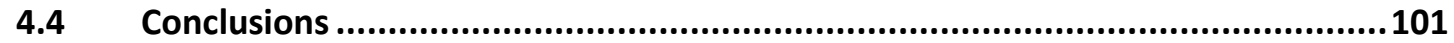

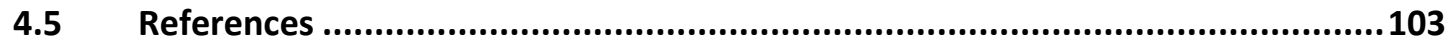

\section{Table of Illustrations}

Illustration 1. Entrance to the Borjd El Kiffan cultural centre ..................................................... 11

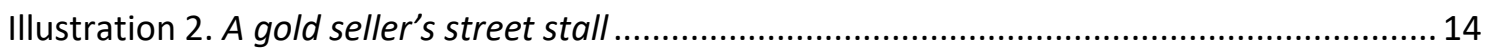

Illustration 3. Meeting room of the Tunisian cultural association............................................. 16

Illustration 4. Gentrifying the neighbourhood 18

Illustration 5. Yong people of the neighbourhood 18

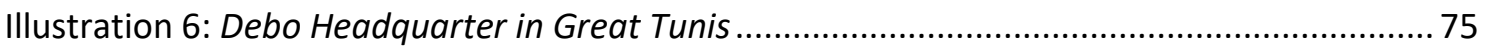

Illustration 7: "White wall, silent people" 78

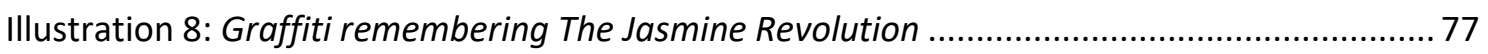

Illustration 9: A group of young people gathering to celebrate their bands in Casablanca

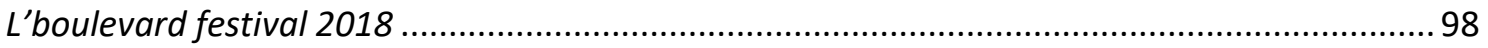

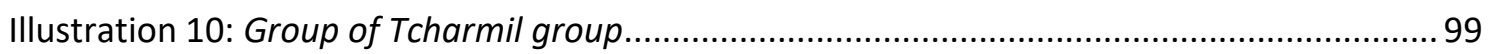

Illustration 11: One of the Raja's Ultras, the Green Boys, Tifo ............................................... 100 


\title{
1 Introduction: Hip-hoppers, informal vendors and marginalized youths.
}

\author{
Jose Sánchez-García
}

\begin{abstract}
How can a minority live within a majority that represses it? The merit of heavenly messages is normally measured by the prosperity they provide to man, having as their first mission to reach out to the oppressed (Naguib Mahfuz)
\end{abstract}

This volume presents the theoretical and methodological approaches that the research teams in Casablanca, Algiers, Djendel and Grand Tunis have carried out within the theoretical perspective of the TRANSGANG project. The texts are the result of bibliographic research, previous and on-going ethnographic experiences, and discussions focused on youth street groups in the Maghreb carried out during the first two years of the project. Different researchers are conducting field work with various youth street groups in these locations, collecting original data as the basis for the subsequent comparative task (regional and global), focusing their attention on the cultures of youth street groups and developing the theoretical-methodological perspective adopted in the project. The qualitative research carried out in Algeria, Morocco, and Tunisia has provided an understanding of the day-to-day practices, negotiations and decisions of youth street groups at the micro level while remaining in tune with the broader tensions associated with the paradoxes of globalization. In a youth research field dominated by an overdeveloped criminological approach, the critical approach adopted here makes it possible to address the issue of youth street sociabilities reversing the hegemonic Eurocentric model, or better, the North American-centric model (Feixa, Sánchez García, Ballesté, Cano-Hila, Massanet, Mecca and Oliver, 2019) $)^{1}$.

This is about putting young people at the centre of research and doing research with them. More than studying gangs, we interpret processes with blurred boundaries in different places with very different social, political and economic conditions. Each field location tells us something about how youth street groups navigate their lives, identities and choices in the light of global processes. Thus, although the theoretical perspectives

\footnotetext{
1'Eurocentrism, therefore, is not the cognitive perspective of Europeans exclusively, or only of the dominant groups of world capitalism, but of the group of those educated under its hegemony. And although it implies an ethnocentric component, it does not explain it, nor is it its main source of meaning. It is about the cognitive perspective produced in the long time of the whole Eurocentric world of colonial/modern capitalism, and that naturalizes the experience of the people in this pattern of power" (Quijano, 2000, p. 287).
} 
adopted allow a deep and comprehensive approach to daily life and the overall conditions, expectations and trajectories of the young members of the groups, to avoid a certain epistemological colonialism, the North African TRANSGANG research teams have developed these theoretical-methodological approaches from a local perspective, so that they can be used as appropriate lenses for North African contexts (Grosfoguel, 2011). Therefore, the work of conceptualization and 'translation' of the general theoretical perspectives of the project carried out by North African researchers will not lose in the process of comparative analysis the historical and socio-cultural specificities that affect the processes of emergence of these new sociabilities.

As a reading guide, it is necessary to understand that the Maghreb social structures in which youth street groups are inserted, the research itself and the researchers are all an expression in certain spatial coordinates of what Hodgson (1974) called Islamicate. ${ }^{2}$ Drawing on Hodgson, we propose to understand the term in its most inclusive sense to refer to the dynamic mosaic of social and cultural ways of life that exist not only in Muslim-majority societies such as Morocco, Algeria and Tunisia, but also of the Muslims of the diaspora, as in the case of Marseilles, also included in the project. This makes a controlled regional and transnational comparison in diasporic situations possible. As Sayyid points out, "the societies in the Islamicate share a set of experiences common to what used to be described as the Third World: colonization, unequal exchanges, institutionalization of cultural inferiority, anti-colonial struggles, formal independence" (Sayyid, 2012; pp. 1-2). The Islamicate is, therefore, a structural historical heterogeneity differentiated from Eurocentric modernity, but which, at the same time, contains Eurocentric forms in dispute with its own elements (Feixa et al., 2019; Quijano, 1989) $)^{3}$.

In this presentation, we will trace the shared signals that, from each of the locations (Casablanca-Rabat, Algiers, Djendel and Tunisia), allow us to establish spaces for comparison both at regional and global levels of the relationships of youth groups with their environment (other street groups and social and institutional agents), and to observe the identifications (ideological, religious, political, musical, sports) of the members through their practices (economic, leisure, ritualistic), without forgetting their subjectivities and specificities that are particular to the region. A careful reading of the texts leave out a complex image in which some cross-cutting elements stand out: the scarcity of research on the 'gang' phenomenon in the region (Najar, Chapter 3); the marginalization of large groups of the youth population who react by being part of

\footnotetext{
${ }^{2}$ The term islamicate was originally coined by the North American historian, Marshall GS Hodgson, who used it in The Venture of Islam, to describe "the social and cultural complex historically associated with Islam and Muslims, both among Muslims themselves and among non-Muslims" (Hodgson, 1974, p. 59).

${ }^{3}$ Quijano (1989, p. 122) refers the historical-structural heterogeneity to "all social existence, or 'society' or 'culture' or 'civilization' as a configuration of elements that come from very different histories and geographies, or 'space/time' and relate to each other, even in a conflictive way, but forming an active structure" in a particular context. (Quijano, 1989, p. 132)
} 
youth street groups (Touhtou, Chapter 4 and Boucherf \& Omrane, Chapter 2); the way of understanding violence and mediation processes (Boucherf \& Omrane, Chapter 2); the signification of the concept of "street" and "neighbourhood" in relation to what we have termed as border areas and places/stages where sociabilities of youth street groups are produced in Algeria, Morocco and Tunisia (Boucherf \& Omrane, Chapter 2); and finally, each of the chapters includes the dimensions that violence acquires in relation to youth street groups in the region. A fundamental question appears as a corollary of the texts: How do youth street groups form and operate within the multiple constraints/limitations and opportunities of being young, Muslim, marginalized and subject to the social control that exists in the Maghreb?

\subsection{Researching youth street groups in the Maghreb}

The rapid demographic change of the last decades in the Maghreb has favoured the development of a youth population that is producing a significant change in the social composition of the different states. According to data obtained from the questionnaire on the socioeconomic status of the youth population (15-24 years old) as part of the Sahwa project ${ }^{4}$, they are situated between $43 \%$ in Algeria, $21 \%$ in Morocco and $23.4 \%$ in Tunisia ${ }^{5}$. These demographics imply that young people are gradually occupying a central place in the politics and culture of these societies as a combined result of the neoliberal globalization, geopolitics of the neo-imperialism, the emergence of a discourse of civilization in which Islam is positioned in opposition to the West, coupled with ever-widening levels of college graduates without jobs. Thus, the "youth question" is often framed as a paradox, as both a problem and an opportunity. As a problem it is related to security, anxiety about the increase in youth unemployment, inequality, civil and regional conflicts, drug use, extremism and violence of youth street groups, which creates a moral panic against “deviant” young people (Queirolo, 2017).

Hence, in recent years, a plethora of publications from academia, government and nongovernmental organizations and international institutions have examined the conditions and behaviour of young people as well as their practices and cultural expressions. In many of these, young people are treated as a group that needs to be understood and trained for purposes of political containment, ideological monitoring, and economic reform. Despite continually referring to their agency, young people are often treated as objects rather than agents of social change. According to Kamat, this approach "does no favours for the genuine concerns of young people seeking a better world; these publications do not offer hope in this direction and, instead, position young people as a

\footnotetext{
${ }^{4}$ SAHWA Project was funded by EU Horizon 2020 from 2012 to 2014 . The project brings together fifteen partners from Europe and Arab countries to research youth prospects and perspectives in a context of multiple social, economic and political transitions in five Arab Mediterranean countries (Morocco, Algeria, Tunisia, Egypt and Lebanon).

${ }^{5}$ For more information see: http://sahwa.eu/Media/Sahwa/Youth-Survey
} 
valuable resource that nations can take advantage of to build competitiveness in the global economy" (Kamat 2007, p. 1216).

In several academic publications, we find reflections on issues related to the difficulties of professional integration, criminality and risk behaviours, often framed in the context of the general question of youth. This literature is presented in two forms: grey literature (reports prepared by government institutions or by national, regional or international organizations that seek solutions to the various problems that concern the youth population); and studies and research from the social sciences produced by research or academic institutions to contribute to the debate on the various issues related to "youth" as a socially constructed category. Thus, in the chapter dedicated to Tunisia, a reflection on the social construction of youth is proposed that will allow us to understand the specificities of this social category that researchers in the region face.

A review of the literature on youth street groups reveals that different issues have been analysed in relation to the problems of violence, criminality and juvenile delinquency, generally from a perspective dominated by the North American criminological tendency, as indicated in the chapters that follow. Sihem Najar warns that, although these studies shed light on the criminalization process and on the emergence of violence, they do not allow us to understand the dynamics of the groups, their relationships with other street groups, with the State and its institutions, and, even less, their reactionship to being denied social recognition as well as the precariousness in which they find themselves ${ }^{6}$.

Thus, in the case of Maghreb societies, the location of young people on the margins of the hegemonic political, economic and social discourses allows them to deploy an agency in their day to day lives to get around or avoid the institutional structures of societies marked by their adult-centrism and guided by the so-called "judges of normality" (Ghannam, 2013). In this way, young people's actions are recognized as a creative process based on significant symbolic and material practices that can, in many cases, be classified in more than one way, and can be recognized as strategies of resistance and resilience (Feixa et al., 2019). Reciprocity, solidarity and communalism are the fundamental mechanisms of youth street groups, which are formed mainly in relation to place of residence. The dynamism of the networks constructed in this way allows young people to be included in strategic ways in escaping from social margins, be they economic, cultural and/or political. It is due to these social restrictions that becoming a member of a youth street group is a way of escaping from marginalization for young people in North Africa, and is a source of recognition and dignity. As Jean and John Comaroff point out, "one of the hallmarks of the present moment, the era of

\footnotetext{
${ }^{6}$ Paradoxically, in the three chapters, the majority of bibliographic references are in French and mostly by French authors. Thus, the field of research on young people in the Maghreb appears "colonized" by the former metropolis.
} 
globalization and postcolonialism, is the decline of the ability of the governments-if not the forces of the market they foster - to control the bodies, energies and intentions of young people. The nation-State harbours forces that it can no longer adequately control" (Comaroff \& Comaroff, 2005, p. 22).

In this sense, the work carried out has been a challenge and an opportunity to establish narratives and discourses that come from the youth street groups themselves, setting up an original and non-Eurocentric perspective. In our framework, post-subcultural studies and decolonial perspectives meet critical criminology, focusing on questioning traditional conceptions and uncovering false beliefs about crime and criminal justice. As a result, crime is seen as a product of the oppression of subaltern groups within society, such as young people, women, and ethnic minorities, because young members "have no choice but to resist this relationship of domination" (Brotherton, 2015, p. 80). This perspective emphasizes the creative and assertive capacity of the members of the street groups, their cultural productions and their forms of sociability and resistance practices, which are of course contradictory and ambiguous, against a set of discriminatory processes determined by their social age (Sánchez-Montijano \& Sánchez-García, 2019).

Thus, one of the main obstacles has been to accommodate cultural differences in the research design. The Eurocentric trend to use North American experiences as heuristics for experiences in other parts of the world means criminalizing the youth groups by using the term gang. By framing our understanding of street gangs and youth groups through debates on postcolonialism and critical subcultural studies, we understand that this trend can be reversed, especially in the Maghreb, where there is no tradition of research on gangs. In particular, we focus on the different exchanges between researchers, on the definition of youth street groups from a local perspective, proposing functional definitions to avoid western points of view and the coloniality of knowledge (Mignolo, 2010).

In the Maghreb case, the term gang is ignored due to its colonial origin. The general term used to refer to "criminal youth groups" is iṣhāba, while the term shila is used to designate a group of street youths (Feixa et al., 2019). As we will see, however, there are other related terms from the national and local contexts and those expressed in colloquial Arabic, such as hittistes (Algeria) ${ }^{7}$ or tcharmils $\left(\right.$ Morocco) $^{8}$, which are used

\footnotetext{
${ }^{7}$ In Algeria, literally "those leaning against the wall", is used to name young people who spend the day on the street looking for means of subsistence in Algeria. They go in groups and stop at strategic thoroughfares, which allows them to stay informed of the entire life of the district, taking advantage of this situation.

${ }^{8}$ Tcharmil is an expression in Dariya (Moroccan Arabic dialect) that traditionally indicates a range of spicy marinated flavours for meat dishes that include garlic, olive oil, and parsley. Currently it is also used to name a type of youth subculture, adopted by groups of young people from the poor neighbourhoods of the main cities of the country. Although they emerged in Casablanca, the groups quickly spread to Fes, Meknes, Agadir, Rabat, Salé and Marrakech.
} 
to denominate different street groups. In addition, another challenge has to do with the naming process associated with the research into "youth gangs". Although the process of assigning characteristics to gang groups helps determine how conflicts and social problems are framed, if we focus on gangs only as a social problem we ignore fundamental structural issues such as racism, poverty and social inequality. Without this sensitivity, we could fall into the difficulty of not being able to capture the fluidity and contradiction inherent in the identification of youthful street sociabilities, creating an artificial sense of similarity between different cultural contexts. The image of "the gang" as socially dangerous or harmful prevents gangs from becoming prosocial organizations or more organized criminal entities, often leading to the intervention of state control agents. Hence, the researchers have not adopted the term "gang" because they do not accept using the label because the imaginary and symbolic fields that the concept opens are very far from the realities of street youth who sell gold or seek a precarious living in the streets. By not using this term it is possible to prevent their criminalization and stigmatization. We thus change the way we talk about these groups, obviating the term "gang", an empty signifier over which a continuous struggle operates that is also outside the North African cultural forms.

What, then, is the situation of the members of youth street groups in the Maghreb? A combination of a growing youth population, unemployment, marginalization and a general sense of deprivation has given young people exceptional status as harbingers of radicalism and a threat to stability. Although most young people in Maghreb societies and communities share many common social, political and economic misfortunes they exhibit markedly different responses to their situations. One response is the spontaneous grouping in the neighbourhood streets, which allows young people to escape from this marginalization.

\subsection{Mediation and youth groups in the Maghreb ${ }^{9}$}

During one of the ethnographic trips in Algeria, we headed to Bordj El Kiffan ${ }^{10}$. There we met with members of associations that do community work with young people from the neighbourhood to present the project to them. The meeting took place in the cultural headquarters of the municipal government. When we arrived, we were greeted by the representative of the local Ministry of Sports and Youth. We went to a warehouse for old computer parts. Seated around a table, we began to present the project by Kamel Boucherf and Mustafa Omrane. All those present showed great interest in the proposal both due to its novelty and to the possibility of making their work visible in the

\footnotetext{
${ }^{9}$ The ethnographic scenes presented are part of the field diary of the ethnographic coordinator and were obtained during the field visits carried out during 2019.

${ }^{10}$ Bordj El Kiffan is a coastal municipality located east of the wilaya of Algiers and part of the Algiers conurbation. Territorially widespread, it has undergone strong and anarchic urbanization of its rural areas during the last decade. Thus, in addition to the city of Bordj El Kiffan, it includes the urbanized areas of Ben Mred, Dergana and Ben Zerg of recent construction.
} 
neighbourhood. Finally, Omrane presented the idea of mediation. The social activists were surprised, it was the first time that they had heard the term. Omrane tried to explain it in terms that our interlocutors would recognise, who, after this explanation, began to give examples of practices that can be considered mediation, which, although not institutional, are rooted in the social practices of Algerian society. They described the importance of local shayks in disputes, of school authorities beyond the institution itself, and also of people with social prestige, usually due to their religious practices, who become mediators in everyday disputes. Therefore, I understand that mediation is established through local cultural forms, even if they are not called mediation.

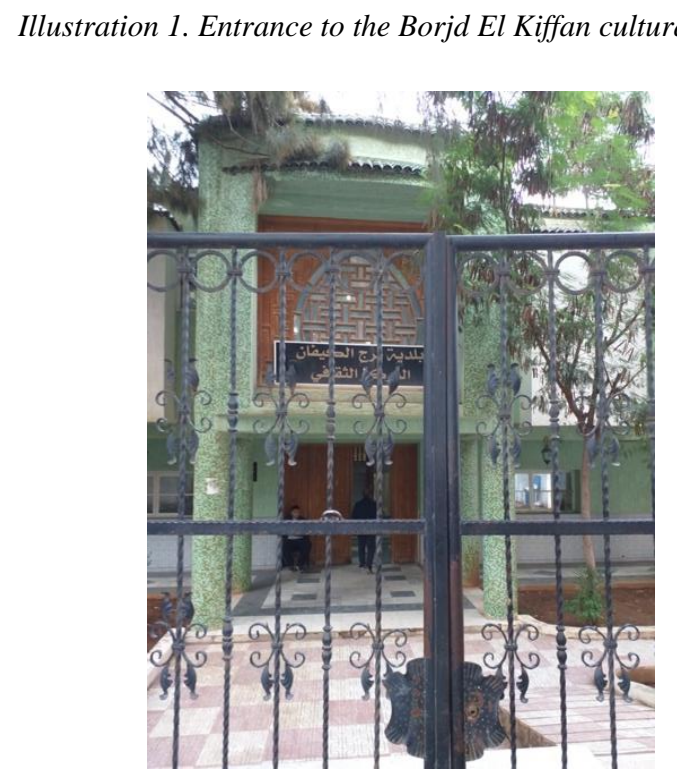

Source: José Sánchez-García

This excerpt from the diary of the first ethnographic trip in Algeria situates us in another of the challenges proposed by the project in North Africa: the small amount of research, evaluations and implementations of institutional forms of mediation between youth groups and other groups and institutional agents, beyond arbitrary repressive work, and, often, also mediation by police officers. In each of the chapters a look at mediation is proposed that coincides with the importance of those defined as natural mediators in our theoretical approach in the absence of institutional mediation channels, as pointed out by Boucherf and Omrane for the Algerian case. However, the lack of mediation channels between young people and state structures and the impasse at which this task is located, very often pushes young people to react in a violent way to give voice to their complaints and eventually make a change.

Nevertheless, institutional mediation processes are increasingly common, as Najar (Chapter 3) points out in Tunisia. The transition after the 2010 revolution has made it possible to implement forms of restoration and reparation of damages from the conflicts that arose from the uprisings against the Ben Ali dictatorship. However, at the local level there are often shortcomings that make repression one of the only ways to alleviate 
the consequences of some conflicts. In this sense, the cultural groups presented in this chapter, whether they are music producers or graffiti artists, are gradually becoming natural "mediators", claiming these cultural forms legitimized by youth populations, which are often illegal from the point of view of legislative codes. In the case of Marruedos, Touhtou discusses the presence of mediation processes in Moroccan neighbourhoods, but also in the centre of Rabat in the case of Heavy Metal fans (Touhtouh, Chapter 4).

In conclusion, addressing the issue of mediation processes with and between youth groups in the Maghreb is a difficulty and a challenge. It represents a challenge since, from the little-developed empirical research in the region, we will proceed to the presentation of effective forms of mediation and, above all, the promotion of the members of the groups participating in the research themselves as natural "mediators". However, it also poses a difficulty as, in some cases, it is a concept that is foreign to cultural practices in the region. If in the Western case mediation processes are carried out by professional workers trained specifically in mediation techniques, at these locations, as shown by the three chapters, the figure of the natural mediator, informal mediator and traditional mediator is especially relevant. This type of mediation is carried out by people who do not have specific training in mediation, but who have natural abilities and symbolic capital to mediate in a conflict and, generally, a social position respected by their community, on many occasions, represented by religious figures or elderly people. This figure of the mediator is questionable from the Western conception of mediation because "invariably the parties try to bring their relatives or elderly people from the neighbourhood without taking into account the bias and conflict of interest that the person may have" (Ibid., p. 8). However, consistently with our theoretical framework and our intention to avoid Eurocentrism as far as possible, it is essential not to downplay these types of mediation processes, among which we also include youth groups themselves as Sihem Najar points out. Furthermore, various research works on traditional mediation processes for conflict management and resolution in the Arab-Islamic culture reveal the significant contrasts between established Western mediation approaches and Arab-Islamic mediation approaches, especially the primacy of the community-oriented approaches, and explicit references to religious ideals, sacred texts, stories and moral examples, as well as local history and customs (Irani, 1999).

\subsection{Case studies: street vendors, hip-hoppers and marginalized youth}

As noted in the different chapters, if the youth group responses in the four selected cities (Casablanca, Algiers, Djendel and Grand Tunis), understood as ethnographic scenarios, have something in common, it is marginalization, the stigma and the exclusion of youth groups, whether for political, ideological, generational, cultural, socio-economic or spatial reasons. According to the analysis process proposed in the 
methodological manual of the project (Feixa, Sánchez García, Soler-i-Martí, Ballesté, Hansen and Brisley, 2020) the comparison is between core cases (Rabat-Salé) and contrast cases (Algiers, Djendel and Grand Tunis) located in urban environments because cities play a crucial role in cultivating a particular awareness of youth, as proposed by the subcultural perspectives (Bayat, 2010). The public parks, the commercial centres, markets (souk), the corners or cafes provide key locations for the formation of youth street groups as elements of identity. Added to this is the expansion of information and communication technologies (ICT), the spread of fashion trends and global consumer products and a tendency towards the nuclear family, which are all transforming the social structure and political economy of the research field (Touhtou, Chapter 4).

Street groups are, then, strategies for escaping from these situations, and generate action spaces, cultures of resistance and social protest that challenge the established social order as a whole. Thus, the youth street groups can be seen as a generation gap and also as a strategy for benefitting from their marginalized, and according to the institutional actors, "deviant" position. In summary, "we consider the gang [street groups in the region] as a dynamic cultural formation in a context of exclusion and social transformation" (Feixa et al., 2019, p. 46) that can evolve towards more associative, cultural or sports forms, or may specialize in some type of criminal activity. We made the final selection of case studies for the comparative process based on this operational definition. Therefore, after the ethnographic visits and the methodological meetings, it was decided by consensus that the ethnography of the youth street groups would concentrate on the main areas of marginalization (economic, political and cultural) in the region that lead to the appearance of this type of sociability; the three groups studied are informal street vendors, urban culture associations, and subalternized youth groups.

\subsubsection{Street vendors}

In an excerpt from the researcher's field diary we can read, "in a Tunisian informal market (souk), the police officers have their own way of buying a cheap mobile phone. The police officer shows up, takes a quick look at the merchandise, selects a mobile phone with a good price, and asks the young salesperson about the serial number and all vendor-related information listed in the seller's book. Finally, the policeman offers to 'buy' the mobile phone to forget about the 'violation' of the rules. The seller does not have many options, but is negotiating with the agent who will always find ways of accusing them of selling stolen goods, so they end up giving the agent the mobile to keep themselves safe from the whims of the police. The protagonist of the scene is a young man, who, like many other street vendors, is facing economic difficulties as a result of deficiencies in the labour market, grouped with other street vendors, not without conflicts, around a market (souk)". 
It is also the case of an Algerian street gold seller, who with a degree in business management and a master's degree in international trade, prefers to spend his days in his neighbourhood souk selling gold pieces, obtaining an income much higher than his friends who work in companies. The business works as long as the police do not interrupt, although not without certain conflicts with other street vendors to place themselves in the best locations in the neighbourhood, or with women who are looking to "take" a piece. Informal selling is a risky activity since it is illegal, although socially legitimized, it occurs in practically all Maghreb cities. The state strategy about what is informal but tolerated (because it is legitimate) and what is informal but not tolerated at all (because it is illegal) is sustained within its relationships with the law (Boucherf \& Omrane, Chapter 2).

\section{Illustration 2. A gold seller's street stall}

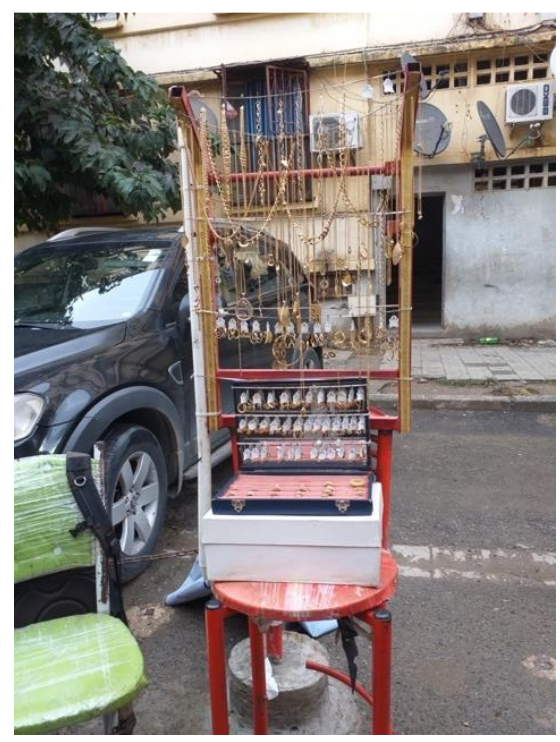

Source: Jose Sánchez-García, November 2019

To access adult life according to the life-cycle model, these young people, like many others in the Maghreb, have to move quickly from the state of childhood to the world of work, responsibility and parenting, all indicators of adulthood. However, work and economic difficulties exclude them from this transition, hence they look to informality for their way of life and subsistence. According to Najar, the boys leave formal education to join an established regional or family network where they receive the necessary socialization to adequately assimilate the practical aspects of the "profession and form a network [wasta'], revealing their own social world that allows young people to stand up to the state and fight against social injustice and economic marginalization" $(\text { Najar, Chapter } 3)^{11}$. These young people live in an almost closed community and are both agents and witnesses of acts of violence in the markets.

${ }^{11}$ Wasta' is an Arabic term to name an individual's social media system in the different dimensions of a person's life. In the current situation, the significant role of these networks is taken for granted, 
Therefore, including these types of street sociabilities is relevant as there is a generalized inclination to sum up this phenomenon as a crime condemned by the State without recognising the economic and political challenges involved. In addition, throughout the Maghreb, the informal sector is a very sensitive terrain, which is both uncertain and complex, representing over $60 \%$ of economic activity in the region. It is a practice that requires some secrecy for the formation of these social networks. As noted by Boucherf and Omrane in the chapter on Algeria, although from a certain perspective the arbitrariness of the State in this area serves to reduce, to some extent, the consequences of youth unemployment, at the same time, the State is allowing the development of these activities that are often criminalized. The attitude of officials depends on social and political circumstances depending on the specificities, at all levels, of each situation. Therefore, the State makes use of its power and judicial instruments to benefit from a flexible policy that translates into the use of its right or left hand, in the terms of Bourdieu (2011). It is a situation that requires good relationships in the street, a good wasta' network, to continue resisting the arbitrariness of police power. Despite this, in terms of mediation, youth groups in the informal sector enjoy considerable legitimacy, allowing them to intervene in potential conflicts between the communities in question, on one hand, and between the communities and State institutions, on the other. Second, membership in these groups, either by kinship, or origin and/or shared residence (the two main sources for acquiring membership in the region) obliges members to enter into conflict with security forces.

Indeed, youth sociabilities that emerge from the economic needs of young people can be framed within the operational definition previously presented of a youth street group. In addition, informal sales pose security issues to public authorities for being part of the often transnational merchandise trafficking networks, and the conflicts between the vendors themselves and buyers require, in some cases, the intervention of mediators.

\subsubsection{Hip-hop and street youth groups}

In Tunisia, in a street adjacent to the Ministry of Internal Affairs, protected with concrete walls and wire in the city's central district, is the headquarters of a youth association that produces music videos and promotes concerts around the country. The office is no more than $70 \mathrm{~m} 2$. It consists of four rooms to carry out the activities. There is a room used to prepare projects, with a large central table, there is a passage area to rest with a sofa, and a music recording and visual editing studio. It is also possible to sleep in some of the rooms, although they are crammed with objects. It then becomes a space that allows the transgression of Tunisian social norms, in a society where youth emancipation always passes through marriage. A safe space from the social world that

constructed through professional, family and/or neighbourhood relationships to find good jobs and other types of social benefits. Consequently, good connections are a source of inclusion for young people, and street groups belong to this type of relationship. 
criminalizes them: an aware countercultural movement of educated young people and accommodating social groups that try to take urban culture to the remotest corners of the country and that sometimes has to face the intransigence of adult institutions.

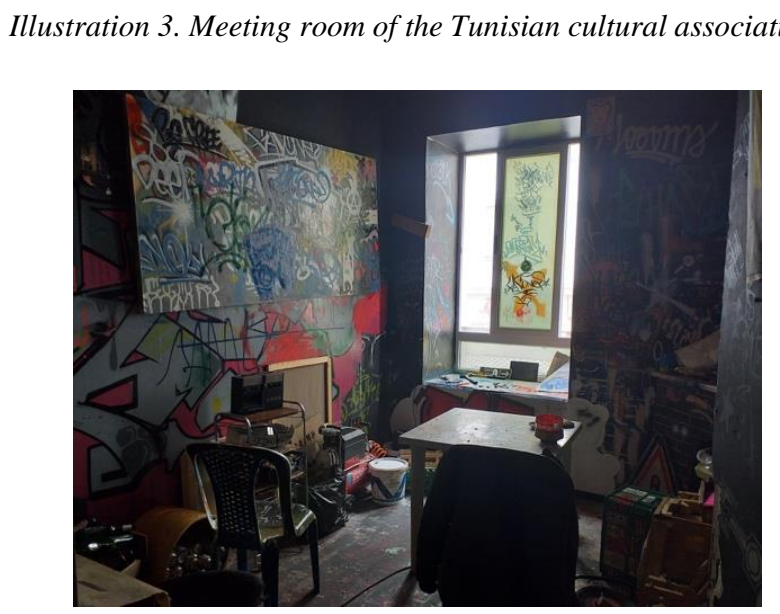

Source: Jose Sánchez-García, March 2019

It is evidence that Maghreb youth, like their global counterparts, have come of age during a technological revolution. The new information and communication technologies (ICT), from the mobile phone to the Internet, have changed the learning, culture, sociability and political commitment landscape of young people. Folk arts, and among these hip-hop, as seen in Tunisia, grassroots movements and cyber communities are some of the avenues in which young people are adopting a more proactive stance, generating awareness and an alternative action on issues of citizenship, justice and multiculturalism (Sánchez García \& Feixa, 2017). By experimenting, they forge new avenues of cultural expression, openness, and awareness as their economic opportunities and possibilities for securing a future are shrinking.

Based on these premises, we selected street associative groups that through their practices are claiming their right to experience youth, becoming mediators between official instances and other street groups, resisting their criminalization by the institutional sectors (Sánchez García \& Feixa, 2017). Thus, we have included two groups in Tunisia as case studies: one dedicated to audio-visual production and the other to graffiti mural painting, two activities that are also susceptible to being criminalized from hegemonic discourses and often identified as illegal. These groups experiment with 'anti-Islamic' cultural products and lifestyles as they listen to rap music and dress according to global fashion, although at the same time, in some cases, they identify with the 'global Ummah' (Piscatori, 2019).

These groups cause conflictive situations that can be a stimulus that leads to some social change (Feixa et al., 2019). As they are considered to be "outside the law" they are regularly in dispute with state representatives and, by extension, with the legislation (Sánchez-García, 2019). As Najar and Touhtou point out, this conflict impacts the 
economy and politics and is repeated over and over again due to a lack of confidence in the government, but also the lack of mediation channels. In a similar situation, which also occurs in Algeria where there are instituted forms of mediation, we are witnessing the emergence of informal groups that act as mediators between the government and the political system, and also between various youth groups. An example is the case of the DEBO group and the graffiti artists in Tunisia, who have located their activities and events in an institutional framework, thus making known countercultural practices that continue to be illegal and subject to criminalization.

\subsubsection{Precariousness and street groups}

In the streets of an outer Moroccan suburb, an avenue separates the neighbourhood from the sea, a group of young people struggle to "watch over" the recently parked car. For a few coins they assure the owner that when he returns, it will still be intact. Next to the car park are three artificial grass indoor football fields. The few informal settlements remaining in the neighbourhood, on the other side of the street, are being replaced by apartment buildings and residences to accommodate tourism that is hoped will arrive when the entire country has been updated. The youth of the neighbourhood spend their days going around, looking for a way to make some money. As they say, they spend their day doing enabiqi, a term they use to describe their activities to earn a little money. "When I go from here to there to sell something, be it a canary or a mobile phone, I can go home and affirm my dignity", as a young man from the neighbourhood explained. They spend their free time in a cafe with the group members, consuming karkoubi $^{12}$, khat (a well-known stimulant that is chewed or drunk as tea with effects similar to amphetamines), and kala (hash oil) in secluded places that have become safe spaces. The neighbourhood adults, who have left the street, try to attract them to another life and mediate their conflicts through football and religion, so that they leave the street (Field diary, 2019)

\footnotetext{
${ }^{12}$ Mixture of psychotropics, cannabis, alcohol and cola produced in Morocco. https://parismatch.be/actualites/societe/120807/le-karkoubi-la-drogue-de-la-violence-qui-inquiete-le$\underline{\text { maroc }}$
} 

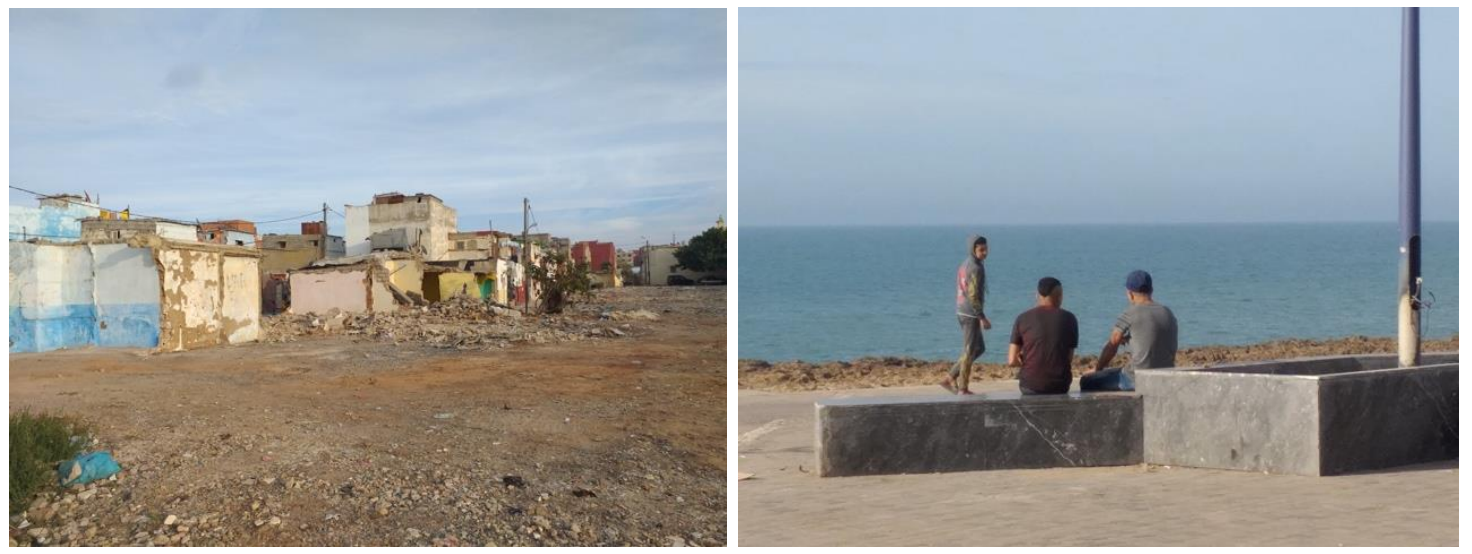

Source: Jose Sánchez-García, September 2019

This field diary entry focuses on the question of street sociability in peripheral urban areas: the need to belong to the neighbourhood group that offers identity, dignity and safe spaces. In these contexts, economic and social deprivation have led to the emergence of a phenomenon of street sociability with a high presence on the Moroccan and Algerian streets. As a result of job insecurity and the economic crisis, a broad spectrum of the youth population, as discussed in the chapter dedicated to the situation in Algeria, are excluded from social life. The deprivation of a livelihood not only affects the general welfare of the young people, but also has an undeniable influence on the expression of desires that are specific to young people, for example, to have enough money to acquire consumer goods, chasing dreams of youth and being free. For many young people, these simple goals seem hopelessly out of reach. Economic exclusion, political corruption, underemployment and deprivation prevail among a vast segment of young people, which means that the transition to adulthood is increasingly problematic (Boucherf \& Omrane, Chapter 2).

Therefore, membership in spontaneous associations established mainly based on place of residence seems to satisfy an immediate need to establish identity and claim dignity and, therefore, feel relevant and powerful. However, these groups, in the long term, do not transform structural forces or create the conditions that will lead to livelihoods, economic opportunities and secure futures. These sociabilities do not represent an alternative to a socioeconomic and political order, but rather a reaction to it, where dignity [karama] is increasingly sought in the capacity to consume (Mernissi, 2015).

The formation of street groups due to precarious situations is researched in two locations: Casablanca (Morocco) and Djendel (Algeria). Touthou discusses the tcharmil phenomenon in Morocco, which has also appeared in the Spanish press, while Boucherf and Omrane discuss the hittiste phenomenon in Djendel. These two groups show some similar characteristics. According to previous research, everything seems to suggest that gangs are forming in a similar way as in European city streets and neighbourhoods at 
the beginning of the century, in a situation similar to that described by the term "gangsin-process" referring to groups like the Netas and Latin Kings in Europe:

...there are networks like groups and behaviours at an early stage, even if the media tend to identify them with criminal organizations similar to the pattern of North American gangs. In this case, there are street-oriented groups, with names, symbols and enduring traditions, made up of young people from depressed social backgrounds. Some members have connections to illegal activities, even if those activities are not part of the group's core identity. (Feixa et al., 2008, p. 65)

The case of the hittiste in Djendel makes it possible to contrast the irruption of Moroccan street groups with a phenomenon of youth street sociability that is better known in academic literature and which has been around longer. As part of the project, in addition to understanding their daily practices, we focus on the way in which institutional circuits for integration are accessed, taking into account one of the prototypical and salient specificities of the region: the importance of Islam to understand conflicts and the mediation practices between these groups. Therefore, for some, Islam serves as a faith-based community that offers trust, support and networks, within which young people can improve their life opportunities and "get off the streets". This type of group, on the other hand, points to the existence of a vertical type of mediation space between institutions and street youth groups, considered problematic in the Maghreb ecosystem: the tcharmil, which are mainly radical Islamists and hooligans, as Touhtou states (Chapter 4). Thus, in addition to the ethnographic monitoring of the aforementioned groups, the research will provide a look at these forms of natural mediation and culturally situated social intervention with these two examples from different Moroccan and Algerian marginal neighbourhoods.

In conclusion, if we look at the indicators of "youth street group" operationalized in the theoretical perspective of the project, each of the groups selected in the Maghreb meets at least three of the five conditions proposed for defining the study object. First, the names, note that only groups engaged in cultural activities, such as the Tunisians, have given themselves a name, which ascribes their identity as a political act in authoritarian situations (Touhtou, Chapter 4). In contrast, the external labels for denominating groups are usually imposed from the dominant narratives and constructed by the media as in the case of Moroccan tcharmil and Algerian hittiste, with the intention of marginalization if not criminalization. The third of the conditions, the existence (or not) of an internal consciousness, is one of the questions that must be researched and traced from the conversations with the young members of the groups. Regarding ordinary activities, the fourth indicator, in all the selected groups we find practices that unite them in solidarity based on their place of residence (tcharmil, hittiste) or on common practices, as in the case of cultural associations and street vendors. Something more controversial, due to the peculiarities of the region, is the continuity in time for more than a year ${ }^{13}$. Specifically, the spontaneous Maghreb youth street groups come together

\footnotetext{
${ }^{13}$ As analysed in the chapter dedicated to Algeria, one of the causes of the flexibility of the groups, in
} 
due to common interests, especially street vendors and the tcharmil and hittiste, thus we are facing flexible groups, in which members continuously enter and leave without establishing defined hierarchies. Only associative groups that perform cultural mediation practices are stable in both time and membership.

As we see, the selection of cases can include youth groups with behaviour classified as "deviant", often illegal or delegitimized in the region, such as the urban culture proposals. However, this selection makes it possible to distinguish youth street groups from organized crime or from transnational criminal organizations, including terrorist cells, but also from informal groups without a stable organization, grouped exclusively around leisure.

\subsection{Border spaces and youth street groups in the Maghreb}

This presentation of the main topics covered in the chapters that follow testifies that young members of street groups navigate in difficult circumstances caused by poverty, fragile economies, authoritarian and corrupt governments in conflict, globalism and intergenerational struggles. Young people are extremely critical, frustrated, and sometimes overwhelmed by their impotence. In this context, each of the groups presented, combining the possibilities of the global and the local, construct spaces, in a physical and symbolic time, which give them livelihoods, cultural practices, scenarios for political disruption, identity ascription and individual dignity (karama) as a human being. The centre of the Tunisian cultural association, the Algerian and Tunisian souk, and the neighbourhoods (especially the spaces they construct in their neighbourhoods, such as the houma in Algeria) occupied by the tcharmil and hittiste are safe spaces where youth groups build their strategies to achieve their objectives, whether economic, cultural or political.

This spatialization of youth street groups, which often do not renounce occupying the central spaces of the city or passively accept their marginalization (as in the case of the followers of Heavy Metal in the centre of Rabat) is a fundamental variable when exploring the conflicts and mediations that are generated in governance contexts that are, to a greater or lesser degree, authoritarian. These border spaces are located on the margins of the social world, also physically, so that subjects can think of themselves as subjects between two worlds. In this way, youth street groups constitute border spaces that use strategies from both the global world and local memory and practices, conferring power to that space that young people re-signify as response spaces, which in the Maghreb, as Boucherf and Omrane point out for the Algerian case and Touhtouh in the Moroccan case, are always constituted as a disruptive or defiant political space. There is, therefore, a social, political and cultural occupation on the border that takes on a conjugation of different positions in the social structure, in the political space and also

many cases, is the vital horizon of migration to Europe, therefore the composition of the groups is not stable or long lasting. 
in the processes of cultural hegemony and counter-hegemony (Feixa et al., 2019, p. 70). As Mignolo points out, border space is not exclusively a question of visible borders (nation-state), but, more importantly, it is a political and social positioning within the modern/colonial world that seeks to break, consciously or unconsciously, with decreed and also unique epistemic and ontological forms (Mignolo, 2015).

Thus, according to the theoretical perspective of the TRANSGANG project (Feixa et al., 2019), we understand these spaces of sociability of youth groups as border areas between the subaltern produced by modernization and colonization processes and the marginalization suffered that considers the members of youth groups as separate subjects who do not accept the options or conditions that (from power) are presented or imposed on them (Mignolo, 2015).

To finish this presentation, taking into account all the issues discussed, reading the chapters contained in this volume raises some fundamental questions. Are the moral panics of the Maghrebi adult-centric dominant society and those who hold power over the Maghrebi youth and their forms of sociability justified? When faced with a population that is perceived as problematic, we must ask ourselves, problematic for whom? Who defines the problem? What political, economic, cultural or moral order perceives this group as disturbing? Thus, the "problem" of youth street groups cannot be researched solely by dissecting the alleged objects of the problem, that is, the members themselves, but rather by turning them into constructors of shared knowledge.

\subsection{Then suddenly Covid-19 arrived ...}

At the end of February and mid-March, the coronavirus interrupted the daily lives of youth groups and the activities programmed in the region. At the same time, the political management of the pandemic modified the situation in the Maghreb and forced an accelerated "adaptation" of both the groups and the researchers. Ethnographic research requires face-to-face contact with the participants in urban locations in order to secure confidentiality to address delicate and sensitive issues, such as the activities of street groups and the conflicts that occur both with other groups and with state authorities (Feixa, Sánchez-García \& Brisley, 2020). In this sense, one of the biggest obstacles has been the physical distancing measures introduced by the authorities in Morocco, Tunisia and Algeria that have led to a closed control of the populations on the street and increased surveillance by technological means.

In neighbourhoods where different data collection tasks are carried out, the daily activities of the youth street groups, bearing the mark of the "transient", are being repressed, and these groups have become the most exposed to the disease and the repressive measures. As Sihem Najar points out, "this category of young people is the most exposed to the risk of contamination because they live in an environment where confinement is not respected. On the economic level, their socioeconomic conditions 
will be even more critical because most of these young people (or their families) are in the informal sector, which has difficulties functioning during confinement" (Sihem Najar, TRANSGANG Tunisia).

Despite the pandemic, the researchers consider that the street continues to be the central space for these groups to solve the deficiencies magnified by the current situation. Thus, a greater dependency on support networks other than family support is observed, and not being able to access them can decrease the ability to handle the situation. Rachid Touhtou states "for them the street is their home, so confinement has no meaning ... social distancing is really difficult for them ... they share small rooms in social housing or in a poor city ... they share the same joints when smoking ... the group provides them support, so distance is a problem (...) It is affecting them now because the street is the centre of their lives and existence ... it will affect them first to lose the support of their friends" (Rachid Touhtou, TRANSGANG Casablanca). In this case, for young people from street groups, physical distancing means social isolation, marginalization and precariousness. While youth groups understand the street as the central place for social exchanges where trust and ties are established, also with researchers, the authorities understand the street as a public space that needs to be controlled to turn it into an aseptic space, form of governance hyperbolized by the pandemic.

For all these reasons, this irruption has turned the Covid-19 pandemic into a difficult variable to control that is modifying the forms of sociability and social relations between street groups. Thus, for example, the group Debo understood that the intimate, safe space is their headquarters, confining themselves together there and continuing with their usual activities despite physical distance and extreme use of social networks for communication. However, this communication has been significantly hampered by the monitoring and surveillance of cyberspace, so that it is not safe for young people to communicate through these channels. The researcher Anis Belgacem from Tunisia observes, "some of the young people can be reached through social networks, but often it is not feasible for two reasons: the first is the possibility that the interview is interrupted or stopped and (the second) is that people who still don't know you have a hard time talking to you freely through social networks and answering your questions, it's quite difficult" (Anis Belgacem, TRANSGANG Tunisia). The group that is suffering the greatest difficulties is, due to their actual activity, informal street vendors. As Kamel Boucherf, researcher in Algeria, says "There are groups here that sell products on the street and when asked about them staying in the street, their response is that they prefer to be affected by the virus and go to the hospital to get support from the State. There are groups that isolated themselves and no longer do so. Other groups do not seem to avoid Covid-19 but rather to avoid the police by meeting very late at night." (Kamel Boucherf, TRANSGANG Algeria).

Some questions that guide the research as a result of the pandemic, are becoming relevant: Have public virtual spaces become essential for ensuring communication 
during the pandemic among the members in a seemingly safe and anonymous way, similarly to the communication exchanges that can take place in city centres? Does the neighbourhood continue to be the key mechanism for the formation of groups and informal economic associations? How does the new social control of what has been called the "new reality" affect youth street groups in the Maghreb? What implications does social control by physical distancing have on the street logic of young people from marginalized neighbourhoods? 


\subsection{References}

Bayat, A., \& Herrera, L. (2010). Introduction: Being Young and Muslim. In L. Bayat, Asef; Herrera (Eds.), Being Young and Muslim. Oxford \& New York: Oxford University Press. https://doi.org/10.1093/acprof:oso/9780195369212.001.0001

Brotherton, D. C. (2015). Youth street gangs: A critical appraisal. London: Routledge. https://doi.org/10.4324/9780203727782

Comaroff, J. \& Comaroff, J. (2005). Reflections on Youth: From the Past to the Postcolony in Africa. In P. Honwana, Alcinda; De Boeck (Ed.), Makers \& Breakers: Children \& Youth in Postcolonial Africa (pp. 19-30). Trenton, NJ \& Asmara, Eritrea: Africa World Press.

Feixa, C., Sánchez, J., Soler-i-Martí, R., Ballesté, E., Hansen, N. \& Brisley, A. (2020). Methodology Handbook: ethnography and data analysis. Barcelona: Universitat Pompeu Fabra \& European Research Council.

Feixa, C. (Dir.), Sánchez-García, J. (Coord.), Ballesté, E., Cano-Hila, A. B., Masanet, M.-J., Mecca, M., \& Oliver, M. (2019). The (Trans) Gang: Notes and Queries on Youth Street Group Research (TRANSGANG Working Papers No. 2.1). Barcelona: Universitat Pompeu Fabra \& European Research Council. DOI: http://dx.doi.org/10.31009/transgang.2019.wp02.1

Feixa, C., Canelles, N., Porzio, L., Recio, C., \& Giliberti, L. (2008). Latin Kings in Barcelona. In F. van Gemert, D. Peterson, \& L. Inger-Lise (Eds.), Street Gangs, Migration and Ethnicity (pp. 63-78). Devon: Willan Publishing.

Feixa, C., Sánchez-García, J. \& Brisley, A. (2020). Gangs, Methodology and Ethical Protocols: Ethnographic Challenges in Researching Youth Street Groups. JAYS 3, 5-21 (2020). https://doi.org/10.1007/s43151-020-00009-1

Ghannam, F. (2013). Live and die like a man. Gender dynamics in urban Egypt. Stanford: Stanford University Press.

Grosfoguel, R. (2011). Islamofobia epistémica y ciencias sociales coloniales. Astrolabio, 6, 43-60.

Hodgson, M. (1974). The Venture of Islam: Conscience and History in a World Civilization, vol. 1: The Classical Age of Islam. Chicago: University of Chicago Press.

Irani, G. E. (1999). Islamic mediation techniques for Middle East conflicts. Middle East Review of International Affairs, 3(2), 1-17.

Kamat, S. (2007) "Populism Repackaged: The Word Bank’s Perspective on Equity and Youth." Development and Change 38(6): 1209-1218.

Mernissi, F. (2015). Comment ajuster la publicité à la karama (dignité) après la révolution sur les 642 télévisions panarabes FTA (Free to Air)? In F. Mernissi (Ed.), Réflexions sur la 'violence' des jeunes (Editions L, pp. 9-48). Rabat: Editions Le Fennec.

Mounia, B.-C. (2010). Moroccan Youth and Political Islam. In L. Bayat, Asef; Herrera (Ed.), Being Young and Muslim (pp. 63-76). Oxford \& New York: Oxford University Press.

Piscatori, J. (2019). Conceptualising the Umma: An Introduction. Muslim World, 109(3), 193-208. https://doi.org/10.1111/muwo.12286 
Queirolo Palmas, L. (2017). ¿Cómo se construye un enemigo público? Las 'bandas latinas'. Madrid: Traficantes de Sueños.

Quijano, A. (1989). Modernidad. Identidad y Utopía en América Latina. Quito: Ediciones el Conejo.

Quijano, A. (2000). Colonialidad del Poder y Clasificacion Social. Journal of World-Systems Research, 342-386. https://doi.org/10.5195/jwsr.2000.228

Sánchez-García, J., \& Feixa Pàmpols, C. (2017). Youth policies in leisure education: "Peer socialisation" as firewall for youth exclusion in the AMCs. SAHWA Policy Report, (4), 1-34. https://doi.org/10.24241/swpr.2017.4.1

Sánchez-García, J. (2019). Legal Considerations concerning Youth Street Groups in TRANSGANG regions (TRANSGANG Working Papers No. 3.1). Barcelona.

Sánchez-Montijano, E., \& Sánchez-García, J. (2019). Youth demarginalisation strategies in the Arab Mediterranean countries. In E. Sánchez-Montijano \& J. Sánchez-García (Eds.), Youth at Margins: Perspectives on Arab Mediterranean Youth (pp. 222-240). London and New York: Routledge.

Sayyid, S. (2012). Empire, Islam and the postcolonial. MnM Working Paper no 9. Adelaide. 


\section{Researching Youth Street Groups in Algeria: Between the Universal and the Particular}

\section{Kamel Boucherf and Mustapha Omrane}

When we consider all the problems that endure a significant part of the social category of youth in Algeria (school dropout, unemployment, violence, illegal emigration...) we are led to resign that there is a real and complex problem of social inclusion. For this purpose, it should be noted that, although in terms of demography, youth is very important in Algeria and all that this implies, to take in charge the issues related to the breach and shortcomings concerning the social integration into society of this category, the theme of youth street groups in the literature relating to youth is non-existent, by virtue of the social representations of the matter and local specificities.

It is a good opportunity for us, as members of the TRANSGANG scientific research project, to observe the youth street groups in Algeria and analyse the behaviour and culture of their members as young people gathering in informal organisation as forms of reaction or resistance to all processes of social exclusion and marginality. To this end, we will examine particularly the phenomenon of youth street groups in their diversity, highlighting, at first, the socio-economic, cultural and political conditions prevailing in society and which preside over the phenomenon of marginalisation of young people. In other words, from the structural point of view, the goal is to invest the classic spaces of socialisation, their characteristics, functioning and dysfunctions in order to base the reflection on the conditions and circumstances leading young people to the search for alternative social, economic and cultural forms of sociability. In a second step, we will present a detailed description of the emergence, organisation, functioning conditions, and diverse practices of youth street groups. In the third place we will be analysing the place of conflict and the way mediation is practiced.

In the wake of our research objective, we rely for the construction of our background paper on the TRANSGANG theoretical framework as well as the conceptual tools produced with the aim of relating them to the local specificities as a contribution to the questioning, interpretation and understanding of the social logics on which young people's behaviours and their desire to regroup under the impact of determined context conditions they depend. To reach this objective, we have divided our paper into four chapters, according to the project research questions and the underlying concepts: the first concerns the process of marginalisation of young people and the basis of their violent behaviours. The second is related to the issue of youth structure of empowerment in Algeria, to shed light on both its strengths and its weaknesses. The third chapter is concerned with the central question of conflict with could emerge in the youth street groups, in a broad sense. Then is tackled the question of how conflicts are 
solved. In other words, we aim at understanding the social mechanisms and logics of mediation, in a formal and informal way. The fourth chapter is devoted to the territorial aspect of the general project problematic. The question of territory is taken in a very large sense, to tightly fit the meaning of border space concept. This means a reading of youth strategies in this context of the role that spatial symbolism plays (border space) in the search for social identity and recognition (houma).

We finish our introductory part of the paper with a presentation of the legal aspect of the youth street groups and gangs in Algeria.

\subsection{Youth marginalisation and violence}

Violence in all its forms is a phenomenon of society whose explanation returns, in the first place, to the disciplinary and theoretical posture in force. According to a sociological approach, the socio-economic factors are at the origin of violence such as the density of the population, the conflicts of generation, the industrialisation, the religions, the privations. According to the systemic approach, this is due to the gap between the standard of living and the hoarding of wealth by a group (Abboud, 2017).

In Algeria, after a decade of terrorism that has killed at least 100,000 people as a result of a political crisis, the country is experiencing a resurgence of urban violence in two main forms: youth violence between rival youth street groups and political violence during protests directed towards the authorities in order to demand better living conditions. The first is now part of life in cities and towns, especially in the less affluent neighbourhoods. This is most often the case of social housing allocated by the state to households with modest incomes. Through this policy is created the link between high urban density and derisory amenities and comforts. In these neighbourhoods, drugs are a widespread scourge among young people and from that emerge violent conflicts of territory, leadership, etc. Thus, because of the capitalist economy creating a context marked by precariousness, uncertainty and instability, the mechanisms of state governance must be ensured, must be standardised through imperative adaptation. However, the pursuit of this goal (austerity) tends to impact populations that stigmatisation qualifies as populations at risk among which we find the young, working classes (Feixa et al., 2019, p. 25).

As for political violence, it occurs when people do not feel listened to by the authorities in relation to a need of daily life: housing, drinking water, health services, etc. Situations of repeated frustration trigger protests, often violent mainly by young people. The use of violent means of protest reflects the loss of trust between them and authorities at the local level (Sari, 2008; Omrane, 2019).

We must also specify that the uncomfortable situation of a large part of young people in Algeria vis-à-vis the main conditions of social inclusion, reveals their degree of their marginalisation in the sense that the social structure as a whole does not grant them the 
essential conditions so to enjoy a status and a role, as practices, allowing them to have the position of citizen that is theirs. What made Professor Mebtoul say: "whatever the social field apprehended in my field research; I was in the presence of a citizenship not found" (Mebtoul, 2018, p. 15). If he cannot build his future peacefully, to do the Tawil (optimal material conditions of social inclusion, especially through marriage), the young person is led to react violently by means of riots and revolts, or standing against anything that could represent or symbolise the authority governing the social structure as a whole or the institutional order. They are conscious acts that take a violent pace after the administrative and legal channels have been exhausted. Such reactions follow the feeling that their rights have been violated. Hence, it is a feeling that could lead them to delinquent behaviour to react against marginalisation in society.

The juvenile reactions to the established order are also manifested by the fateful decision to leave the place, for heavens supposedly more lenient and understanding of the specific situation of what is designated by the term young and which consequently push them to "... opting resolutely for the risky departure towards Europe, running away from a social and political system that does not open up any field of possibility for them to become active part of society" (Ibid, p.21). As they can look for some kind of substitute group in which they identify individually with its members, because sharing the same concerns, the same objectives and in which there is a listening and a voice: the group of youngsters. For all these reasons, the TRANSGANG research team at the Pompeu Fabra University in Barcelona has successfully synthesised the process by saying that: "It is because of these social constraints that becoming a member of a youth street group constitutes a special way of escaping marginalisation for young people in North Africa" (Feixa et al., 2019, p. 68-69).

Nonetheless, we should emphasize the fact that age of youth corresponds to the preparation of being adult which also means the preparation for a social situation necessary for the beginning of the period of empowerment. More precisely, this situation prevails in the Arab societies of North Africa, whereas the idea of empowerment according to the TRANSGANG approach, it concerns the young person as such, without necessarily linking it to the specific economic and socio-cultural circumstances of an adult would be.

For this, it should be added that it is the economic status of the individual that bases his social status. By deduction therefore, employment is in the very centre of the project of edification of the situation and social position of the young person. But it must be specified also that there are several ways in which the individual makes himself a place in the economic sphere (self-employment, entrepreneurship, wage labour...). Perhaps one should mention that the focus on wage labour is determined by the rate of this category of worker in society. In Algeria, 2/3 of the active population are wage-earners. In any case the employment / unemployment issue will be largely discussed in next chapter as a major empowerment factor, among others. 
For now, let us remind that the Algerian economy remains dependent on hydrocarbon revenues, failing to take off its economy through an efficient and profitable operation of its production tool. Thus, the major position of the state is identified with a role of uneven redistribution of the oil rent whose effects on the social aspect in the formal processes and the devices of creation of employment represent a necessary and insufficient condition for the sustainability of social peace.

Despite this, it cannot be denied that in Algeria enormous efforts have been made for the benefit of young people by the public authorities in the field of education and training, health and work and to a lesser degree in the fields of sports, leisure and recreation in order to manage their free time well (Meraihi, 2009, p. 51). Given the totality of budgetary resources allocated and achievements made, it is not right to deny the existence at the state level of a youth policy. The objective is to meet the specific needs, which are not economic only, of this category of the population known for its sensitivity and impulsivity; but because of its antisocial behaviour which identifies it in many cases, it is often the victim of stigmatisation, to say the least, controversial.

When one thinks of this phenomenon among young people in Algeria, if on the one hand it is a subject of extremely hot debate and endless controversy, on the other hand, it cannot in any way dispel the inadequacy and inefficiency of what can be taken for youth policy in Algeria.

We are confronted with a contradiction of such strength and socio-political and cultural depth that the President was led to recognise this in a speech he delivered at a working meeting with the Walis (governors) and whose meaning prompts us to take up an important passage. The President of the Republic, mentioning the phenomenon of Harragas (illegal migrants) said: "Despite the important work done for the creation of an environment conducive to the development of youth and its active integration into society, serious problems threaten the new generation today. The problems that fuel delinquency, violence and flight to other horizons are even more difficult to resolve as this category of the population has been directly confronted with the evils of the crisis that has affected the country. It must be recognised that national policies have not always lived up to the expectations of our young people. In particular, they have been inefficient and inconsistent due to the lack of operational mechanisms for consultation and coordination of the various institutions dealing with youth issues".

The surveys carried out on the expectations of youth confirm this illustrative finding of the disconnection of the relationship between young people and the action of public authorities (Labdelaoui, 2009, p. 10). Recognition of the gap between state action and the needs of our young people is the means by which it becomes possible and easy for us to grasp the way in which governments manage the concerns and demands of young people. Indeed, failing to implement the mechanisms that would be able to bring "supply and demand" closer to one another between our two protagonists, the decisionmakers of the institutions in charge of the youth issue show an exacerbating 
authoritarianism by means of arsenals "appropriate" legal grounds to justify a policy of securing society, at a time when youth is thought to pose a threat to the stability of the nation and social cohesion (Hadjidj, 2011, p. 214). Then, it becomes so easy to qualify young people as public enemy, when the major state decisions are taken for the benefit of the richest and wealthier and at the same time excludes young people from any space to effectively participate to decision-making and make their voices heard. Here are the ingredients inherent in a system of governance that marginalises young people from the spheres of decision-making. In other words, young people are confronted with an "insoluble" problem of social recognition. The relationship between institutional practices and the phenomenon of youth violence is remarkably synthesised by the researcher Lakjaa (2017) for whom, the practice of violence is the reflection of the social deregulation, it is linked to the deficiencies in the function of social and cultural framing of institutions. A situation which calls for the state strategy in the sense that it makes use of power relations reflecting the big gap which exists between the societal cultural and values system and the very functioning of the various institutions. A perspective which makes a modernisation project rather problematic. Then to preserve its domination the state makes use of its right-hand showing power, domination and penal tools. Then, one can easily imagine the sources of conflicts over those matters and searching for channels of mediations youth street groups can activate.

The lack or missing of listening to young people, a means of approaching the authoritarian attitude bordering on contempt, is at the origin of the crisis situation that characterises the relationship of young people to the holders of power and decisionmakers. For the latter, the treatment inflicted on the largest category of the population, is derived from the rule of infantilization of the people and its strongest category, in this case the youth, by treating it immature and aggressive (Serres, 2013). In this context, young people come up against a set of paralysing and inoperative bureaucratic organisations carved out of institutions and decision-making centres. As a result, any attempt at mediation is systematically banned because it is rejected by the "golden rule" of opacity and subjective functioning. Thus, there is a break in the relationship of mutual trust necessary for the links between the rulers and the governed.

This is a situation that is qualified, at the very least, as deadlocked, since the majority "social actor" is excluded from a possible mechanism for participation in decisionmaking. The explosive and aggressive nature of youth relationships to decision-makers at the local or national level is the reason for which two strategies are implemented. A first strategy, that of young people, which consists in systematically refuting all which represents or symbolises the State authority or emanates from its institutions. And, by other side, the remaining issue of mediation will be widely described and analysed in third chapter.

Now, concerning the relations youth/state and for the reasons showed above and with suspicion and unshakeable doubt, they develop a violent behaviour in their way of 
expressing their needs and "to make their demands heard" (Sari, 2008; Hadjidj, 2011). For this, young people tend to take the spaces that offer stadiums as a gathering place, to express their discontent to the state and its representatives. In this sense, the stadium is no longer, or simply exceeds, its definition of a space for the unfolding of sports competitions to transform itself into a tribune or openly expresses the conflicting relationships between young people and the state in a general sense, to the point where during a football match broadcast on television, the young people posted a huge tifo painting showing the photo of the Saudi King next to the President of the United States of America, accompanied by a writing signifying an unhealthy complicity in the politics domain. A poster that was at the origin of a diplomatic incident that happened between the Algerian authorities and those of Saudi Arabia. This doesn't mean that the young people concerned represent a gang, because they are not identified neither called as such (they are mainly described as immature, violent and manipulated), but it exists within the population of fans a core of Ultras made of ancient, very dynamic and permanent youngsters who lead, organize and manage the relationships with the "outsiders".

For its part, the state has for a long time put in place a strategy of impunity (Peyroulou, 2006) whose objective is the preservation of social peace or to conceal the underpinnings of highly compromising political scandals. However, the strategy of impunity advocated by the Algerian state is not without having perverse effects on the very foundations of public order and social cohesion. The most striking example is the position of the state vis-à-vis the informal practices of young people, especially in the economic field. If from a certain perspective the impunity of the state in this area serves to loosen the grip, somewhat, on the consequences of youth unemployment through the offer of a chance to enjoy a certain income, the other side of the coin shows the shortfall in the field of taxation but especially the development of informal economic activities to more than $50 \%$ of the entire economy and its effects on the organisation of national economic activity whether it be production or services. Yet, the price to pay is exorbitant and dangerous at the same time because as noted Mebtoul: "To maintain the status quo, - he said - the public authorities have helped to make visible and "normal" the kingdoms of the informal" (Mebtoul, 2018, p. 20). Of course, first, the state strategy concerning what is to be informal but tolerated (because legitimate) and what is to be informal but not tolerated at all (because illegal) is sustained within its relations to the law. Second, even the youth informal activities (which are considered legitimate) like the Street Vendors for example could be not tolerated sometimes. The officials' attitude depends on the real social and political circumstances depending on the specificities, at all levels, of each conjuncture. So, the state makes use of its power and judiciary instruments to take benefits of a flexible policy which is translated through the use of its right or left hand in Bourdieu's terms. From the dominated side the goal of survival pushes them to resist desperately.

In any case, the lack of channels of mediation between young people and the state structures and the impasse in which it is located, pushes them to react very often 
violently in order to voice their claims and eventually bring their claims to a successful conclusion. Their actions take the form of riots where all actions are good to get the message of their distress and their fed up. Having no means to put pressure on the decision-makers in their institutions, they go as far as to disturb the public order to "move" the leaders and the elected representatives at the level of their locality. And then they will require law enforcement officials to unblock the situation by asking for work meetings to find solutions to their problems (Sari, 2008, p. 276). Abboud, in turn, expresses the way young people react by noting that "young people have learned to communicate only through violence" (Abboud, 2017, p.13). The violent behaviours of young people, especially students, this time, take place by the demonstration of force through brutally immobilising the university institution through the requisitioning and closing of the gateways.

Moreover, the spread of violent behaviour in all its forms has made it a real worrying social scourge to the point where the public authorities have had to retaliate by setting up a national committee to coordinate actions to combat crime (Toumi, 2009). The communication channels being non-existent or inoperative, they give way to the most radical forms of expression in the crucible of a deep "incomprehension" between the protagonists. The result is that "our cities are becoming more and more the spectacle space of all possible forms of violence" (Toumi, 2009, p. 137), because violence among young people in Algeria is essentially an urban phenomenon. Most of these extended forms of violence among young people express the reaction (resistance or violence from the bottom) to the state violence materialised in all means to discipline marginalised people living in precariousness and poverty. So the hegemonic power relation of the state institutions (violence from the top), about which "the production of changes to expand neoliberalism and not leaving an option to resistance generates the appearance of an oppressive violence that departs from the powers and is structured through the state..." (Feixa et al., 2019, p. 37), tends to penalise the reactions against all forms of social inequalities by means of stigmatisation of the poorest and the young brandishing the security reason (Feixa et al., 2019, pp. 32-34).

For his part, Abboud made the same observation. For this author, the violent behaviour reached a point where it was brought to sound the alarm by warning that "the society is in disarray. Educational structures are failing, they no longer manage the excesses and deviance of young people" (Abboud, 2017, p. 13). The search for the causes of deregulation is oriented towards meditation around the blatant mismatch between institutional values and societal culture (Lakjaa, 2017, p. 13). This is how the social gap is immense in terms of the social behaviour of young people, to the point where a national symposium titled "Figures of Violence in Algeria" was held in 2017 at the University of Bejaia bringing together specialists in the field to try to identify the causes and think about the remedies. Though, we must add that the young people's riots that take place, have no political colour (Mokhefi, 2015), in the sense that they are aimed at meeting material needs in order to deviate, somehow, bad life, but also as a reaction 
against all forms of corruption, inequality and nepotism. What is meant here is that the riots taking place are not explicitly politically oriented or openly influenced by any particular political organisation, at least through the slogans they hold or their claims, but from a socio-political stand point, the act of riot in itself has a definite and obvious political meaning insofar as it asks the governance system and the state institutions.

By linking the youth policy advocated by the public authorities with the demands of these same young people, we can only observe an enormous gap between the two entities, to leave room for a sort of acute antagonism that reflects the extent of the marginalisation of which its victims the young people to which they remain only the rejection of the "official policy" to which they substitute sometimes entirely informal forms of interest in the public life (voluntary work, works of solidarity, actions charities...) and sometimes violent behaviour in various forms or organise in delinquent groups.

\subsubsection{Are youngsters just delinquent and criminals?}

The distinction between a gang and a group of youngsters is closely linked to their respective normative dynamics (Mohammed, 2007). We note in the literature a recurrent approach among researchers that consists in distinguishing between two types of groups. Like Mohammed (2007) for the case of France, or Hagedorn (2005) in the United States, Tournebize distinguishes the street youth group (bande) from criminal groups. In the first case, the youth street group (YSG) is above all a place of conviviality where delinquency is not the primary motivation of the group. In the second, groups are formed to carry out delinquent and criminal activities. From one group to another, the type of organisation and the acts committed are not the same. Individuals involved in organised crime are older than youth who participate in youth street groups (2006). In this respect, in line with TRANSGANG research objectives and its theoretical perspective, the privileged option is that which is based on an open and large definition to take into consideration a localised meaning of youth groups. Hence the term of youth street group is rather a generic one and which is applied empirically as a continuum comprising among others leisure and economics activities (Feixa et al., 2019, p. 43). In the same order of ideas, Delmas (2001) identifies two types of groups: a) unorganised YSGs that come together to manage the constraints of everyday life; and b) the groups involved in violent acts are the gangs.

When applied to the Algerian context we notice that this distinction is considered, from an institutional point of view. When dealing with youth street groups we note that the law is flexible according to the prevailing social and political conjecture, territory and even media impact, provided that the first category of YSG is not systematically linked to violence and crime. Though, in many aspects the idea of danger and insecurity sticks to the groups (stigmatisation). But when it comes to violent groups, they are rather put in crime record. 
Let us add that the distinction between gangs and other groups (youth street groups) of young people by their delinquent behaviour reflects the situations observed. Mohammed (2007) as well as the TRANSGANG theoretical framework, they highlight several elements in the gang definition task. They first recall that the term is associated with the deviance, crime and drug trafficking world-wide propagated by North American film and music production (North American centrism). We note, consequently, that the consensus on the variable "deviance-delinquency" has shifted theoretical divides to the place and meaning of transgressions in gangs.

We can conclude this section by saying that in accordance with TRANSGANG'S definition, the phenomenon of YSG (bande in French) can in no way be systematically assimilated to crime, deviant behaviour and delinquency of young people insofar as the constitution of youth groups is described and identified in accordance with the modes of concrete reaction to the dialectics of marginalisation / inclusion and socialisation. The investigation we propose, and which concerns two youth street groups: The Gold Sellers and the Hittist group, is built upon the hypothesis that these are groups which are not systematically organised around delinquency and crime matters.

This said, now it is obvious to try to provide a discourse about the place and role of youth empowerment in the Algerian society. It is relevant to try to answer the following questions: how is the youth empowerment process done, in a society known for its adult-centrism (and mismatch between tradition and modernity)? and what is the place of the gender issue in such questioning?

\subsection{Empowering youth: Strengths and weaknesses}

At a theoretical level, the concept of empowerment encompasses different definitions, from one discipline to another, from one context to another and from one society to another. There are many definitions that emphasise the ability of the individual to make decisions that affect him, to have his resources, etc. So, those are clearly human rights issues. That is, the freedom for every individual to be able to decide on his personal life and to be able to choose and act. Some authors analyse empowerment at several levels: personal, which involves personal abilities and self-confidence; relational, which involves the ability to negotiate and influence decisions; and collective because certain capacities are realised in groups as for example in the associative or political field (Rowland, 1997). At the political level, very often the focus is on the issue of inequality and how to reduce it. The United Nations highlights inequalities in political and economic participation and decision-making on economic resources (UNDP, 2009).

In the scientific literature, empowerment is often analysed with other concepts such as socialisation, autonomy, independence, adulthood, etc. Autonomy is a subjective dimension, in relation to self-esteem, a positive perception of oneself; it is a category of identity. While independence "is defined from objective categories: it is a state in which the individual finds himself, when he has sufficient resources to manage his life without 
financial, material or parental support" (Ramos, 2011, p. 11). Another key concept: adulthood, becoming an adult is part of a process of personal development. This may be at the end of studies or at the time of employment, for example (Galland, 1997). Becoming an adult means that the young person has acquired a new social status, and this implies new social roles. This period in the life of the individual is the result of a combination of personal, institutional, and social conceptions, not just a series of steps ordered and lived in a linear manner (Van de Velde, 2008). Given the work that has been done on this issue, the transition from childhood to adulthood is very complex given the multiple factors that come into play. In all societies, the young person clearly needs to be accompanied in this process to successfully enter adult life. Although the description of the life process gives objective reasons to take into account the sequencing of the age phases (youth - adulthood in this case), it should be said that empowerment of youngsters implies in the first place to get the necessary resources (material and immaterial) to be able to enjoy one's young's autonomy as such.

On the public policy and development agenda side, the concept of empowerment is commonly understood to refer to actions to strengthen the economic and social capacities of young people and women: education, information, training, employability, limiting social barriers, etc. This is a process that is supposed to lead to individual autonomy. On the other hand, data from the SAHWA survey show that, in Algeria, about $90 \%$ of young people live with their parents. This shows how high the need for autonomy and independence is. This desire for emancipation is known among young people, especially when family control is very strong, as is the case in Algerian society, known for its traditional functions. Logically, young people's desire to become emancipated runs up against the problem of unemployment. For a job, even with low wage, gives young people a certain degree of financial autonomy, and strengthens the status of the person - including girls - within the family group (Omrane, 2019).

Health is a very important component of the empowerment process as well. It is the basis for the development of empowerment. People need to be healthy, to have a quality education, to be well prepared for jobs and to be useful to society.

Since its independence, Algeria has consistently placed the health of the population, along with education, among the government's top priorities. The State policy is to establish a health system accessible to the entire population, offering quality services and free of charge in all regions of the country. Thus, the health sector has always had a considerable part of the State budget. Today, health coverage has reached the entire population. Public investment concerns all medical services and at all levels, starting with primary health. In this part of the document, we will focus mainly on education and employment, which are more related aspects to our research theme.

In the field of education, Algeria has made immense progress. Public investment in this sector has borne fruit, and as a result the country is experiencing a real generalisation of access to school for both sexes, this is true at all levels of school. It should be noted that 
the education sector receives the largest share of the state budget. The country is realising its goal of universal access to education as a human right. According to a 2012-13 national survey, 98\% of primary school-aged children attend primary school. For the middle and high school cycles, the net school attendance ratio is in the order of 79\% (UNICEF, 2012 - 2013; 2015).

At the higher education level, 107 institutions exist in the country in 2019 and offer students (especially girls in their area of residence) the opportunity to access university education. Let us remember that the vast majority of students benefit from government support for accommodation in university residences, catering, university transportation and scholarships.

Also, the university is accessible to people who do not have the baccalaureate by offering them training in certain specialties. More recently, masters are open online allowing students to take courses without moving up to university. Concerning adult education, there is in Algeria the Office for Adult Literacy. This government agency provides a literacy program throughout the country.

Nonetheless, weaknesses in education represent significant challenges for the country. For example, the data reveal regional disparities in early childhood access for children (MICS Report, 2012 - 2013, 2015). Children living in certain regions are less likely to attend preschool education, and this creates inequalities between children who, no doubt, will not be at the same level once admitted to primary school. It seems imperative to see access to preschool as a right for all children in the same way as primary education. It is therefore essential for the Ministry of Education to undertake a serious reflection on the issue in order to provide the necessary answers. Regarding the baccalaureate, which is the essential diploma for access to post-graduation studies in Algeria, there are strong regional disparities as a number of wilayas show low success rates in baccalaureate and other examinations each year.

At the level of university education, Algeria achieved in a relatively short time, a great performance, that currently have more than one hundred higher education institutions, located throughout all regions of the country. But there is a demand for quality education and its conformity with the economic dynamics, especially with the labour market. Reforms are needed to accompany the transformations of the world economy marked by the strengthening of the service economy and the emergence of new information and communication technologies.

In the last register which concerns employment/unemployment, we observe that in most countries of the world, unemployment is a problem that governments are trying to solve. In developing countries, where population growth is often accentuating the problem through the massive influx of young people of working age, access to employment is becoming a major issue both politically and socio-economically. Currently and according to the latest available data, the Algerian population of working 
age has reached $62.5 \%$ whose share of young people aged 15 to 29 amounts to $10,272,396$ or $25.16 \%$ of the total population (ONS, 2018).

In this regard, in Algeria, the unemployment rate was of $11.1 \%$ in 2018, when it reached $26.4 \%$ for the category of young people between the ages of 16 and 24 after reaching the threshold of 30\% in 2015 for the first time (ONS 2018; CNES 2016: pp.104). It is clear that it is the age group of young people that suffers the most from the lack of job opportunities, in the sense that youth unemployment is more than twice the unemployment rate including all categories of the population having the working age. We can understand this phenomenon by referring to Wacquant's concept of advanced marginality as a phenomenon intimately linked or part of the capitalist development in the sense that those who are characterised by precariousness and poverty so are marginalised, are involved in a large process of structural reproduction and which ensures and may develop various forms of privileges and inequalities. Maybe this new trend makes us wonder about the role of the state in socio-economic matters, in a country such as Algeria which is mainly mono-exporter and has known a long period of socialism.

Moreover, by looking at the structure of the unemployed population and beyond the important fact that it concerns more particularly the category of young people, we also observe that the unemployment rate of women aged between 20 and 24 is two times higher than that of young men in the same age group (CNES, 2016: pp.105). When the unemployment rate in Algeria reached 29,1\% in September 2018, for the 16-24 years population, it was of $24,6 \%$ for men and of $51,3 \%$ for women. A fact that invites us to wonder about the gender issue in the Algerian society.

However, the unemployment situation in Algeria, especially that affecting the category of young people may be amplified by adding the fact of precarious employment that takes shape following the proliferation in the labour markets of the non-permanent work formula and forms of work informality.

What then are the lessons that can be drawn from this situation that can be described, at the very least, as an unfavourable situation regarding the category of young people in particular? In attempting to synthesise the type of relationship that binds young people to the labour market, there are three negative impacts on the psycho sociological and behavioural level:

a) The situation of academic's unemployment has a negative impact on the desire and the will of young people to make the necessary efforts to continue successful studies (drop-out rates are simply overwhelming)

b) The unemployment rate of young people who have benefited from training courses, vocational training, or higher education, reveals the reality of inadequacy between the training system in general and the market demand of jobs. 
c) To focus on the national educational system and its social function to the detriment of its economic dimension, inevitably leads to the realisation of the system intrinsic limits which in turn leads to a threatening crisis for all the social cohesion system.

Obviously, the situation of unemployment or vacancy generally, influences a great deal about the management of social time by young people in the sense that the absence of the centrality of the time allocated to the work function, prevents the latter from playing the role of regulator and organiser of social time and therefore tends to transform the daily life of the youngsters in a burden difficult to bear and whose idleness is visible in the public spaces. Cities and the countryside are full of idlers all day long and during the year (Sari, 2008, p. 273; Toumi, 2009). All that remains to them is the search for alternatives forms of organisation (resistance behaviour) and "occupation" that can play the role of vector through which they give themselves the chance to avoid the nightmare of marginalisation and exclusion, by trying to accommodate society, or more precisely at the margins of society by linking their common destiny in a healthy setting offered by the group. To sum up, these are social, political, and cultural circumstances which deepen and widen the empowerment problematic of those who "are waiting to be adults" (Sánchez-Montijano \& Sánchez García, 2019, p. 1).

It is also relevant to note that unemployment increases with the rise in educational attainment. In other words, higher education graduates have the highest unemployment rate compared to other levels of education. In April 2018, it was around 16.8\%, while it was only $12.6 \%$ for vocational training graduates and only $8.9 \%$ for young people with no qualification degrees (ONS, 2018, p. 7). In terms of place of residence, the unemployment rate is higher in urban than in rural areas.

In fact, the deep feeling of frustration of youth can also be seen as the logical result of the functioning of society in the sense that the lack of perspective which concerns a large part of the youth as social category presents a kind of inequality to the extent that if society is characterised by an economic crisis that tends to continue, in an economy based on oil revenue, it is the young people who are most affected by these major economic dysfunctions (Toumi, 2009, p. 137). In other words, the large and complex dysfunctions at the level of institutional arrangements and coherence are so flagrant that it is difficult to ignore the impacts. Indeed, in their social trajectories, young people adhere to the philosophy of institutional logics by integrating them as the essential sediment of their social success. For this, they "consent" to acquire learning and the conditions of socialisation included in a relatively long process of social inclusion and whose acquisition or the benefit of a significant economic role represents the unifying element of the set of dimensions that contribute to the construction of the social position of the individual. 
However, unemployment and the exacerbating lack of employment opportunities result in a painful situation of disenchantment that quickly dispels expectations, aspirations, and dreams of young people. They are suddenly confronted with a reality that, if it does not limit their chances of acquiring a job because of the economic crisis, then they will be caught up by the predominance of the criteria of social networks and relations of different kinds who chairs their recruitment. Anxious, therefore, to be inserted into the workforce, young people try, somehow, to adapt to the conditions imposed by the reality of the situation, by trying to solicit their social relations to get a job (Ragi, 2001). This is not the only perspective to react to the lack of jobs; young people show a high degree of challenge and resistance by creating, legitimately, their own economic perspective when the inclusive mechanisms on that matter are desperate and hopeless. The Gold vendors represent a valuable example of youngsters that challenge the state authority when this latter is enabled to ensure their inclusion. For the Hittists group, as far as they are jobless people, formally speaking, the output of our investigation is to observe the nature of their diverse activities during their everydayness.

In this regard, the state which, in Algeria, was the main employer, the main planner and decision-maker, has had to radically change its economic policy since the crisis of the late 1980s. The economic crisis which began at the end of the year 1986 coincided with the drop in oil prices, whose income impact can easily be imagined for a mono-export economy like Algeria. Exposing the reality of the fragility of the Algerian economy has transformed the crisogenic situation into a multidimensional crisis that has resulted in the major political decision of economic liberalisation, and will carry out fundamental structural reforms (1994-1998) under the pressure of the international financial institutions and this with the aim of restoring the macro-economic equilibrium of the Algerian society.

In the context of the major economic and political restructuration that have followed, the ensuing privatisation and the liberalisation of international trade have stifled small and medium-sized enterprises' projects in their "challenge" to international competition from developed and less developed countries. Moreover, the reality of the experience of most young people in Algeria tends, in many ways, to substantially reduce the effects of youth policy on the daily lives of these young people. A state of affairs that, although it does not inhibit the positive consequences of a hypothetical youth policy in Algeria, it tends in any case to highlight the inadequacies (Labdelaoui, 2009) to respond effectively to young people's requests. Indeed, by summoning the social phenomena by which is now described an important fringe of youth: suicide and self-immolation, the consumption of drugs that is of worrying proportions, violence and crime in all its forms that increase considerably and above all, illegal emigration (harga), which concerns all categories of young people and whose major risk characterises it, expresses the full extent of the distress felt (Labdelaoui, 2009; Meraihi, 2009). 
It seems clear that the Algerian government has become aware of the importance of integrating young people into society. This is not just an economic issue, but an issue of social peace. In fact, over the past 20 years, the government has placed the fight against unemployment at the centre of its policy. It has acted against unemployment on several fronts: vocational integration of first-time applicants, encouragement of entrepreneurship among young people, development of the various economic sectors, etc. Thus, we quote in the following the most important mechanisms put in place by the government in terms of employment assistance:

1. Youth employment support scheme: this scheme is managed by the Agence nationale de Soutien à l'Emploi des Jeunes (ANSEJ). It is intended for young people with projects between the ages of 18 and 35, who have a vocational qualification in relation to the planned activity. It is supported by a risk/credit guarantee fund for young promoters and concerns two types of investment: investment to create or expand activities producing goods and services. During the last two decades, about 1 million jobs have been created with this scheme.

2. Scheme to support the creation of activities by unemployed promoters aged 30 to 50: this scheme is managed by the Caisse nationale d'assurance chômage (CNAC). It is intended for these promoters who have a vocational qualification and who wish to set up a micro enterprise to produce goods and services. The scheme is supported by a Mutual Guarantee Fund to guarantee the risk of investment loans to guarantee the loans granted by banks to promoters. These two mechanisms, which have been in place for two decades, have contributed significantly to job creation, both among girls and boys, and to the decline in the unemployment rate, which was close to $40 \%$ among young people in the mid-1990s.

\subsection{Women empowerment}

In Algerian society, social barriers are no longer a problem in girls' access to education. Algerian society has changed profoundly in the sense of the principle of equal access to education. In truth, the social change is largely due to the efforts of the State, since independence, in the field of education through, in particular, the awareness of the population on the principle of equality between girls and boys, but also the very large investments made in the construction of schools across the country which, it must be remembered, is distinguished from a large area and the scattered residential areas. In legal terms, Algerian law requires compulsory schooling at the age of six and prohibits the exclusion of pupils before the age of sixteen. This legislation has certainly helped girls get into school. According to a national survey, nearly $93 \%$ of Algerian women aged 15 to 24 are literate. This proportion is $96 \%$ in urban areas and $87 \%$ in rural areas (MICS Report, 2012-2013, 2015). Once more, these numbers reflect the reality of regional disparities, which is clearly a weakness of government policy. On the other hand, girls are the majority in higher education, but that means that there is a real 
problem with boys. Therefore, the question is, is it a failure of the system or is there a socio-economic reason for it?

Despite the enormous importance of educational issue for women, one cannot understand the place and role of women in society without referring to the reality of public policy in terms of gender in Algeria. In this context we note that the human rights approach to empowerment naturally implies the right to dignity, that is, to be free from violence. Violence, whether verbal, physical or symbolic, hinders women's abilities and thus their empowerment prospects. From that perspective, addressing violence against women is a critical issue. Violence against women exists in all countries of the world. That is why there are mechanisms in place internationally to combat this phenomenon. Algeria has always been involved in these efforts, as evidenced by the ratification of the conventions at the international level. The Algerian State, for example, ratified with reservations the CEDAW (Convention on the Elimination of All Forms of Discrimination against Women) on January 22, 1996; Security Council resolutions 1820, 1888, 1960, etc.

At the national level, the Algerian government has been implementing its own policy to combat and prevent all forms of violence since 2007, including violence against women, children, seniors, and all vulnerable people. Legislatively, the Criminal Code, which was adopted in 2015, includes the criminalisation of all forms of violence against women. It is also worth noting other legislative measures such as the Family Code (adopted in 2005), the Nationality Act (2005), the Labour Relations Act (1990) and the Pension Fund for Divorced Women Act, adopted in 2012. The policy of the Algerian State does not consist only in the adoption or amendment of laws in the field of gender, but goes well beyond the strictly legislative framework, through concrete measures. In 2007, the Government Council adopted the gender approach in all national and local policies, programs. This is indeed a major step forward on the issue of gender given the political support at the highest level and it allows for a national impact of the decisions taken.

The economic dimension is indispensable in promoting the status of women in society. As a result, the Algerian government has adopted numerous initiatives to increase the participation of women in the economy. It should be remembered, however, that all the measures implemented by the Government which are intended to create jobs, particularly as regards entrepreneurship and investment, are available to women in the same way as men. In recent years there has been a remarkable increase in the number of businesses created by women, as shown by the available figures. According to data available in 2018, the share of credits granted to women under the framework of the Agence Nationale de Gestion du Micro Credit (ANGEM) reached more than $62 \%$ of all credits. This resulted in 785,549 jobs for women since 1999. 
In Algeria, there is no regulatory discrimination against women in terms of economic activity. Let us specify, however, a social change taking place in Algerian society in connection with the work of women. This seems to be a consequence of girls' massive access to all levels of education. This development is consistent with equality by facilitating access to higher education for all people, including girls. Performance has led to an almost paradoxical situation, with many girls in higher education. This should be emphasized, especially since it reflects a profound social change, in favour of the empowerment of women, therefore obviously conducive to the socio-economic development of society. Despite these advances in social, economic, legislative, and political terms, female employment accounts for $18 \%$ of all jobs in Algeria (ONS, 2018).

Politically, in 2012, Algeria introduced a 30\% quota for women in elected assemblies, as well as quotas for women in the organs of political parties. This initiative has enabled Algeria to increase the representation of women in the political process and in public life. On the social level, and despite the political, economic, or legislative measures taken, the reality nevertheless shows the existence of vulnerable populations and people developing socio-economic difficulties and precarity. This justifies resorting to eminently social actions to directly target people living in difficulty. In this context, the government launched programs in 1994 to support needy families and women in difficulty. This aid is paid directly by the State in the context of solidarity with the categories of disadvantaged people who have no income and who cannot work; it is therefore an assertive appeal on the part of the Government to left hand, according to Bourdieu's term (Bourdieu, Droit, \& Ferenczi, 1992).

In Algeria, socio-economic development policies do not discriminate against any category of the population. There are, however, obstacles, mainly of a social and cultural nature, which sometimes hinder women's empowerment and limit their access to socio-economic opportunities. Basically, a socio-cultural context which tends to exclude and marginalise a large part of the female population.

For this reason, advocacy, awareness-raising, and communication activities in the field of gender, aimed at the whole population, are important to remove these obstacles. In this sense, civil society organizations and the media are involved in gender efforts by the various government sectors. Politically, the government has taken proactive steps to specifically support women and youth. These initiatives make it possible to accelerate the promotion of these categories, through actions and mechanisms such as: 1) strengthening training opportunities for young people, especially those who have left school; 2) information campaigns for young people with the aim of encouraging them to take up vocational training. The Algerian government has put in place a series of actions and mechanisms to increase and strengthen the participation of women, particularly those living in rural areas. 


\subsection{Conflict and Mediation}

Mediation is a central and crucial concept in the theoretical construction of the TRANSGANG project. Youth street groups are seen as mediation agents. Mediation is related to the concept of conflict. In fact, the two concepts are closely linked; mediation is in a way the result of the conflict. In their work on the theoretical framework of the TRANSGANG project, Feixa and Sanchez-Garcia (2019) highlight the positive aspect of the conflict. It is true that this term is generally associated with social or political problems, and therefore has a negative connotation. The authors point out that conflict is an engine that allows society and organisations to change and evolve. Thus, the revolution makes it possible to obtain rights, conflicts in politics allow the alternation of power thus strengthen democracy. It is therefore essential to see conflict as an opportunity for progress and not as a problem (Feixa et al., 2019, p. 45).

The authors point out, based on different references (for example, Giménez, 1997; Minton \& Saunders, 1994) that depending on the parties involved, conflict can take different forms: between individuals, between individuals and groups, between groups, between groups and institutions, etc. Another central clarification in understanding the concept is that mediation deals more with conflict management than its resolution. The situations are multiple, and as a result mediation changes in each of the situations. Obviously, from one context to another even if the parties involved are the same, the nature of the conflict and the type of mediation may change.

Mediation is a broad concept, meaning that it can have different definitions. For this work, and in order to move towards coherence between the research work that is underway in the case of Algeria and the TRANSGANG project, the concept will be considered as a process focusing on its social dimension, in other words, social intervention. In the case of Algerian society, we will try to understand the cultural context in which mediation takes place in the event of conflict.

More specifically, this methodological approach will also lead us to discuss some models of analysis and see to what extent they can be applied to the context of Algerian society. Therefore, the reflection will focus on the concepts selected in the project such as intercultural mediation, co-mediation, etc. This is even more innovative and scientifically interesting because these models were built based on reflections made on other societies and in contexts certainly different from the Algerian context. The differences in contexts are numerous and at several levels: social relations, institutions, social values, culture, legal framework, religion (in the case of Algeria, Islam), etc. 


\section{Politics, conflict, and mediation}

Even at the highest levels of government, there is recognition of governance failures in terms of mediation. In fact, the recognition of this need implicitly proves the existence of a problem of communication, even of trust between individuals, groups, and the government. The history of managing socio-political crises in Algeria shows an initiative in the field of mediation in politics dating back to the mid-1990s, during the worst years of the armed conflict that had begun in 1992.

This conflict, which had a profound impact on society, broke down the electoral process and led to the victory of a political party based on religion. The Regime has created a new official body whose head is the Mediator of the Republic (1996). Its mission was to convey the requests and grievances of citizens to the high authorities of the country. This means that the state structures were not able to assume this function. It was established that trust was broken between the citizens who voted for that party and the political power of the day that did not accept the results of the vote. In 2007, the former President made this statement in an unofficial speech: "serious problems today threaten the new generation. These problems that fuel delinquency, violence, and flight to other horizons... It must be recognized that national policies have not always lived up to the expectations of our young people... The surveys carried out... confirm the illustrative finding of the disconnection between the relationship between young people and the action of public authorities" (Labdelaoui, 2009).

However, despite this increase in government lack of confidence, the lack of a mediation mechanism is highlighted: "Nothing is done on the ground to establish any kind of mediation body, so there is no established policy" (Hadjidj, 2011, p. 214). This lack of a formal mediation mechanism did not prevent the emergence of a type of mediation between citizens and local authorities. In the event of a social crisis, particularly in the case of strong popular dissatisfaction or riots, the latter call on active associations (especially football associations), representatives of neighbourhood residents to act as mediators between themselves and the rioters in order to establish contact and initiate negotiations. The first objective of this mediation is to stop the riot because it risks causing a spread, especially with the development of new communication technologies and increased use of social networks. This type of quasiformal mediation seems to emerge only in the event of a crisis but does not exist as an officially recognized mechanism.

The emergence of Hirak, a popular movement of demonstrations since February 22nd, 2019 to demand a radical change in the regime, shows that this lack of confidence is still there. Currently, the political power (the Regime) has set up a mediation and dialogue commission. Almost three decades have passed between the beginning of the armed conflict in 1992 and the outbreak of the Hirak in 2019, and the problem of the relationship between citizens and the state is still a source of conflict. This type of 
conflict, between individuals and institutions, is one of the most important in the case of Algeria. This failure in the system of governance between institutions and citizens is undoubtedly a determining factor in the fact that society is obliged to innovate and create its own mediation mechanisms.

On the social level, the literature on mediation in Algerian society is very poor. Very little work, at a general level, has been done on this issue, but in a secondary way. Based on this observation, our research work will be exploratory in nature, building on the theoretical construction of the TRANSGANG project. The diversity of conflicts in society and especially in the case of youth street groups, probably presupposes the existence of mediation. It will therefore be interesting for the Algerian project team to carry out a search on this mediation and to analyse it using the methodological tools and concepts developed in the project. This will no doubt facilitate an international comparison perspective.

\section{The burning issue of youth emigration}

By continuing on the path of young people's position in society, to shed light on the ways youngsters react and resist to their marginalisation, in this chapter we seek to identify the main writings on youth migration in Algeria. We aim, through the assessment of a short review of the literature on the topic, to reach explanations on the reasons behind the desire for migration that formulate the young. The investigation of the issue of migration within the population of young people is not an end in itself; in fact, the question is raised only because it is perceived according to its impact on social inclusion of young people.

The desire to leave is the title of the article by Rarrbo (1995) concerning the phenomenon of youth migration, in which he hypothesised that for young people, wanting to leave for another country is an extreme reaction to their situation of excluded and marginalised (Rarrbo, 1995, p. 21). Thus, in the migration strategy, they believe that going abroad to live and be able to settle there is a decisive and successful project.

The author also points out that the disarray and discomfort felt by young people are caused, to a large extent, by a kind of "cultural confusion" which is due to the wide gap between their daily lives and another "reality" of life mirrored by the new information and communication technology. A confrontation that tends to create a kind of frustration that they want to get rid of when leaving the country.

In his study, Rarrbo achieved a very significant result through which he believes that today the migratory phenomenon in Algeria has changed. Today it is very much about the elite of society in the sense that it finds more opportunities to be able to express itself better on many levels. 
The psychologist Khaled Nourredine (2013), tells us about the results and the reading he made of the data of the survey he conducted among 165 young people between 14 and 26 years old, of which $62 \%$ are minors. In this sample, the youngest are potential candidates for illegal emigration while adults have already tried the Harga (it means in colloquial Algerian Arabic, to cross the border illegally).

In his analysis, the author adds an important precision in which he refutes the idea, quite widespread, that the Harga is an act of desperation in the sense that young people are, in all conscience, extremely serious. He believes that such an explanation is reductive from the moment when for him the phenomenon should be explained as "an extreme and ultimate attempt at self-realisation" (Nourredine, 2013, p. 699). What is perceived as despair is driven by hope.

Brought back to the scale of society, the phenomenon of Harga is part of the sociopolitical history of Algeria. This is not a new fact in the sense that it "fits into a global context characterised by a tradition of emigration that is widespread for all segments of the population" (Nourredine, 2013, p. 701). Nevertheless, the insufficiency of such an explanation given the fact that socio-economic and cultural conditions have changed and therefore the causes of emigration are not necessarily the same. Conscious of this imperfection, the author contextualises the phenomenon by clarifying that if the Harga exists and grows among the social category of the young, it is due to the fact that they no longer have confidence in the political system and tend not to lose hope.

Also, in his reflection, the author does not fail to highlight a new piece of data of paramount importance to the development of illegal emigration in Algeria: The Harga is an urban phenomenon which tends to affect the youngest, that is to say, whose age varies between 14 and 15 years.

In this study, the data collected are also used to examine young people's representations of the act of leaving the country clandestinely for other skies at the cost of fatal risks. He remarks in this respect that their reasoning is built on a logic between the lived situation of departure and that of arrival, that of hope. Indeed, for young people lived situation is characterised by very difficult conditions of life, whereas the desired situation as imagined, told or seen is the one of which they dream. Thus, the appreciation of the relationship between the two poles incites to run the risk.

However, this position of young people is "rescued" or supported by an element that they use for their benefit: the tradition of emigration. $42 \%$ of the youth who he interviewed had at least one member who experienced emigration. For young Harga candidates, this is the example to follow, a model of success. However, young people who praise Harga's project produce, at the same time, a disjunctive and selective discourse, when at no time is the reference made to Harga's experiments that have had a dramatic end. 
What is interesting to note is that the Harga even if in many cases it remains on the scale of a desire, a dream, even an illusion, given the enormous difficulties in meeting the necessary conditions, especially financial, for the realisation of the "life project", it remains nonetheless that psycho-sociologically, in some circles and for many young people "the Harga has become a subculture, a rite of passage to adulthood" (Nourredine, 2013, p. 707), because living one's youth in these conditions also means living with the hope of leaving.

For his part, the researcher Labdelaoui, in his paper "Harga or the current form of irregular emigration of Algerians" (2009), offers a reflection on the theme of illegal emigration through the highlighting of the gaps and the inadequacies of the Algerian youth policy and the reactions of those at the highest level of the hierarchy whose task is to manage the youth sector.

To do this, and wanting to know first of all who the young Harrag is, the author observes that they are young people (91.28\% of the Herrags are under the age of 35) and are single, with a medium level of education and are unemployed.

In profiling the Herrag in Algeria, Labdelaoui believes that the first reason that pushes young people to take the huge and dangerous risk of irregular emigration is unemployment, which is the basis of any social perspective on which the young can build serenely his future. He also points out that within Algerian society the idea of Harga is quite common among the youth population. In this regard, $43.10 \%$ said that there are many people around them who would like to leave Algeria even illegally, despite the risks they incur (Labdelaoui, 2009). Through the highlighting of these realities, the author would like to stress the magnitude of the problem and thus designate the extreme gravity of the situation despite the existence in Algeria of a major institutional mechanism in charge of the youth population.

The author of this article follows the logic of his curiosity to question the position and the explanation of this heavy and worrying shift by the youth policy makers in Algeria and to note their recognition of the extreme inefficiency structures of the public authorities, because the essential problem which tends to be at the origin of all the evils which knows the social category of the young people: unemployment.

Yet officials in charge of the youth issue and researchers have relativized this general diagnosis. First, the position of the head of national solidarity who states that the desire for migration is not exclusively material conditions and youth unemployment to the extent that students, public servants, and other professionals are among the group. This means that there is a deep sense of malaise or dissatisfaction among young people. An identical result (Hammouda, 2008; Boucherf, 2017; Souaber, 2019) was reached by the data processing of the large SAHWA survey. Indeed, it is mentioned in its report that the proportion of young people wishing to emigrate was in the order of $25.7 \%$ of all young people between the ages of 15 and 29, making a total of 2,700,000 young people. 
Souaber, 2019, p. 171). In wanting to know what the pull factors were in these countries; lifestyle is in first place. This shows that the desire for migration for the young people is not driven solely by material considerations.

At the end, the analysis would only be complete once the phenomenon has been brought to the scale of society in the sense that young people try to emigrate by taking extreme risks. This necessarily involves the public authorities in charge of public policies that rightly target the social strata prey to casualization and poverty provider, mostly young Herraga. Obviously, what is appropriate to note in this regard is that the public authorities, failing to put in place effective devices that can serve as a safety net for the most deprived, those who populate the Herraga, the State uses his right hand to criminalise the illegal migration, while the most repressive measures taken in this respect have had no effect, worthy of mention, on the reduction of the phenomenon of illegal emigration.

We cannot close this chapter without referring to the relationship between irregular emigration and the YSG. The relationship takes shape when, now of the loss of any social perspective, young people leave, desperately, in search of any niche likely to represent a lever on which to build a saving future. To do this, they do not hesitate to join the youth groups in which they can penetrate the networks and clandestine organisations ensuring the processes of illegal migration. Thus, the relationship between groups of young people and illegal emigration occurs when the group becomes the shaper of the attitude favourable to emigration, especially for young people experiencing social difficulties. In this process, the group's encouragement and influence on the young is realised, as the Harga tells itself (successful adventures), it is transmitted within the YSG to become the action of a group because it is very often, if not always, a collective act.

Encouragement by the youth group nowadays takes on a virtual dimension insofar as the incentive is ensured by the complicated processes of social networks where groups virtually organise illegal international mobility in a very lucrative context.

\subsection{The concept of border space in the context of Algerian society}

Through the TRANSGANG theoretical framework, we find the notion of border space including a broader definition than the concept of space that we know in French language work, which is mainly limited to the notion of physical space. While the concept of border space has different dimensions and components: social, cultural, political, historical... Indeed, a brief reflection on the notion of border space and its components leads us to adopt such a concept, especially when applied to the context of Algerian society. As for the political dimension, it is readily apparent in the activities related to the demands of Algerian society. These are political movements, because they are really requesting to government officials at the local level. These claims take place 
in a very limited space, that inhabited by the group of individuals who feel concerned by the subject-matter of the claim.

Very often, young people challenge recruitment and integration procedures and consider themselves victims of the Hogra, an Arabic term that means injustice. The allocation of social housing is also a pretext for revolt. Some riots are the work of street vendors whose business space has been banned by the government. These protests take place in an area whose borders are known to the inhabitants. This space can be called "neighbourhood", "city", "Douar", "houma", or another normal term depending on the language of the region. It is possible that the protest is initiated by a group, usually young people, from a single neighbourhood and that will lead other groups of protesters from other spaces when its residents feel they have the same claims.

In working-class neighbourhoods, sharing the same demands reflects the shared sense of marginalisation caused by the government, which is designated as the main responsible party, which explains a collective action that aims to paralyse a public service (a road or an administration) in order to get a response from the government. The public space becomes for marginalised individuals (especially young people, including Hittists and Street Vendors) a theatre of political expression. Hence, there is the "physical" dimension of space (Houma, neighbourhood, city or Douar); the social dimension (sharing a perception of marginalisation); and a political dimension (riot). These dimensions are like Mignolo's definition of "border space", (cited by Feixa et al., 2019). However, it is very rare to find a protest that involves an entire city, as this will require greater mobilisation, while the city's residents are not structured to act for the city, but this is possible in a smaller space where mobilisation is based on social relations: the protesters know each other and interact daily. They are usually young people who spend a lot of time on the street where they are in a group.

The only experience of large-scale mobilisation is that related to events across the country since February 22, 2019, protests erupted in all regions of the country. These demonstrations surprised academic and political elites by their scale, peaceful character and degree of organisation. These events, which are certainly changing the country profoundly, have denied the recurring assertions about the inability of Algerian society to organise and participate in political life peacefully.

\section{Border space: an example of the political dimension}

In Algeria, the protests movements sometimes take the form of riots, especially when the number of participants is large. Very often, the substance of these protests relates to complaints directed at local authorities because individuals believe that this is the only way to be heard. The inhabitants of space are aware that the higher their number, the more their voice will be heard. It is therefore a show of force with very often a cut road, sometimes a highway, and the more essential the road is in traffic the greater the impact of the protest will be. It should be noted, however, that riots are not necessarily the work 
of young offenders. Therefore, delinquency and rioting are not necessarily linked, but at the same time express a social predisposition to violent behaviour (Omrane, 2019).

One of the main ideas of this theoretical approach is to go beyond the strictly physical aspect of space and consider its social dimension. Indeed, space is the terrain of social life in all its dimensions, in all its aspects. Thus, the perceptions, actions, relationships of individuals will be interpreted in the context of this social space, including when these individuals are members of groups, such as street youth groups. From this point of view, the neighbourhood becomes an important concept in the theoretical construction of the project and it is not only a socialisation factor but also an actor (Harvey, 2007, quoted by Feixa et al., 2019). According to the authors, the neighbourhood is linked to the question of the well-being of the individuals residing there, to their perception and expectations.

It is in the neighbourhood as a space and territory that the young man builds relationships with his peers, his relations of friendship and solidarity and it is also in the neighbourhood that he marks his benchmarks on all levels for he can evolve into "security", not to be perceived as "the foreigner" too. That said, there is nothing to exclude youngsters from joining youth groups beyond the geographic boundaries of their neighbourhood too. For all these reasons, the territory in the urban space and the neighbourhood in its sociological definition and space of belonging, represent the point of proximity and meeting of the young people who live there.

The space called El-Houma (neighbourhood), as Semmoud pointed out, represents the real and symbolic space at the same time, which allows all forms of sociability (Semmoud, 2009, p. 6). As a result, it becomes the first space that houses or "shelters" youth street groups. Thus, in its relation to the youth grouping phenomenon, the territory is an essential dimension in the problematic of youth street groups. All the studies that we have been able to consult (Kokoreff, 1993, Chobeaux, 1994; Rarrbo, 1997; Pol \& Valera, 1999; Delmas, 2001; Semmoud, 2009; Mohammed 2012) include this variable (neighbourhood) into the analysis of the phenomenon. The territory is one of the components of the group's identity, the place of residence and activity and a place of sociability par excellence. To use Tournebize's metaphorical description (2006), it is the identity cement of the youth group, as it becomes the extension of the private space. It should be remembered here that these are popular areas, where communities live modest, and sometimes poor. In these neighbourhoods, where there is often a lack of recreational facilities, teenagers and pre-teens have spaces of freedom both geographically and temporally. Group delinquency, including gang formation (casual or stable) is part of these spaces left in social life. They live their particular forms of sociability, which represent for some of them the main learning of group life (EsterleHedibel, 2007).

As shown by Duhau \& Giglia (cited by Feixa et al., 2019), this space can be contested. A priori, this idea is very interesting in the Algerian case because conflicts due to space 
are frequent, especially in urban areas. Our accumulated knowledge of Algerian society leads us to formulate two main hypotheses on this subject. One of the causes of these disputes is the control of a space in which to exercise an economic activity, often illegal, in our case gold sellers. The second is much more related to young people who are wandering (Hittistes) and who have as their main place of meeting and activity the street. It is therefore a part of this public space that is at the same time shared with other residents of the neighbourhood, hence the cause of disputes or conflict. These disputes erupt when young people behave in ways that residents dislike: noise, fighting, crowding too close to homes, drug trafficking, etc. Of course, in the Algerian society disputes over space can turn into conflicts, hence the need to see if there is a mediation, in which case it should be analysed. These disputes can arise between individuals, individuals and groups, groups and other groups, groups and institutions of the State.

\subsection{Conclusion}

At the end of the presentation of the youth street group's position in the Algerian society, it appears that youngsters suffer a problem of recognition at all levels, to which they are moving towards the invention of new forms of sociability.

In this sense, the objective we are aiming at is particularly the deciphering of the mechanisms of de-socialisation/marginalisation, in order to find out and describe the emergent alternative forms of sociability, or even inclusion, through the appropriation of practices and territories for which the neighbourhood plays a vital role.

For the youngsters, their constitution of alternative "organisations", to resist all forms of institutional or social structure domination, is mainly interpreted through the legal arsenal and value system. In this regard, the public authorities have the power and the margin of manoeuvre to establish the decisive border between the legitimate and the illegal actions. It is in this specific context that the reality of the street groups' life in Algeria reveals the state of the means of expression of young people and of democracy in general.

In this vein, there is a rejection of the state official forms and channels through which young people can express their needs, aspirations, and dreams. In all these forms, structures and means dominated by the state, often young people lacking alternative power or "counter-power" react violently against their marginalisation, because convinced that the institutional arrangements and rules that allow them to act are dictated by the law of hegemonic domination where a latent power struggle is established between the two entities.

In another respect, the investigation of the processes governing the emergence and composition of youth street groups shows that this is a phenomenon that particularly concerns the poor and popular sectors of urban areas of society. In this sense, the forms of solidarity and mutual aid that characterise youth groups express the relationship 
between their position vis-à-vis the "rules of the game" of life in society and forms of reaction to these same rules source of their marginalisation.

This means that the phenomenon of social, economic, political, and cultural alienation tends to create conflict situation and eventually search for mediation. In this context we should, say that in Algeria, for historical, socio-cultural, political, and religious reasons the phenomenon of "gangs" has not grown to the size of European or American societies. In this regard we have to emphasise the fact of the local specificities related to street groups that emerge into society because of two conflicting reasons: a) the effect of globalization and b) the structuring effect of communitarism that characterises Maghreb societies in general and its corollary the weakness of individualism. Consequently, we are called up to analyse the particularities of the social mechanisms of mediation as a decisive criterion.

Thus, despite all the state programs that are part of the youth policy in Algeria and which are geared to their empowerment, young people seize every opportunity and space offer to them to express their dissatisfaction, their discomfort and to look for other spaces of sociability, including groups of young people. This is why it urges to ask the question of what constitutes precisely the social malaise of young people in addition to material conditions of existence, it is in fact to try to know what form of sociability refer to young people not to feel excluded and marginalized and who at the same time question the social logic that underlies the system of socio-cultural values of the Algerian society.

By considering the specificities of Algerian society and to produce a localised knowledge, it becomes interesting to compare, as an output of the ethnographic fieldwork, the concepts of advanced marginality and border space with the economicpolitical and socio-cultural particularities of Algeria society.

As if to show concretely the means of resistance or resilience to forms of marginalisation and domination of state structures, young people activate, "move" and "navigate" outside official structures and organisations. A world or space that is held to be informal on the verge of transgression and subversion and therefore poses "a threat to public order". For this purpose, the official structures and some media tend to demonize all forms of sociability youngsters create between them, identified as gangs and public enemy. The relevance of the point tends to demonstrate that the challenge of youth social inclusion (from an economic and political point of view) moves towards the division between institutional actors and academic researchers on the definition of youth street groups. So to say, the groups in their relation to society appear in a transgressive attitude in the sense that they tend to shake up the organization system of society through the presentation of an alternative "order" when the classical structures of socialization particularly the family and school but also employment are failing. For this youth street groups are usually equated with delinquency and deviance and even crime. 
Also, when it comes to ask the question of gender in relation to the problematic of youth street groups, it should be noted that this relationship logically fits into the sociocultural particularities of Algerian society which determine and affect the gendered roles.

On the basis of all the issues mentioned through the construction of the Background paper, we find ourselves confronted to a sort of challenge from an academic (theoretical and methodological) point of view, in the sense that it allows us to ask questions to see to what extent the TRANSGANG theoretical perspective is valid for the Algerian explorative case. 


\subsection{References}

Abboud, H. (2017). Dynamique de la violence fondamentale à travers quelques

approches, Actes du colloque national : figures de la violence en Algérie : Aspects psychologiques et sociologiques. 10 et 11 mai 2016, Université de Bejaia, Faculté des sciences humaines et sociales. https://www.uni-

bejaia.dz/fac_sciences_humaines_sociales/images/PGR/recherches_scientifique/actes colloque_figures de la violence en Algerie.pdf

Boucherf, K. (2017). The impact of socio-economic conditions on the perception of migration issues among young people. Sahwa Project [Online] https://www.euneighbours.eu/en/south/stay-informed/publications/impact-socioeconomicconditions-perception-migration-issues-among

Bourdieu, P., Droit R. P. \& Ferenczi T. (1992). The Left Hand and the Right Hand of the State: Interview with Pierre Bourdieu. Variant Issue 32.

Chobeaux, F. (1994). L'identité collective des jeunes en difficulté d'insertion sociale, in Hommes et migrations, ${ }^{\circ} 1180$, octobre 1994. Quêtes d'identités, 23-29. https://www.persée.fr/doc/homig_1142-852x_1994_num_1180_1_2300

Conseil national économique et social (CNES / PNUD) (2016). Rapport national sur le développement humain. 2013-2015; Quelle place pour les jeunes dans la perspective de développement humain durable en Algérie ? Chapitre 9. Participation sociale et engagement de la société dans une culture de relève. PNUD Algérie. http://www.dz.undp.org/content/dam/algeria/docs/RNDH\%202013-2015.pdf

Delmas, P. (2001). Qu'est-ce-qu'une bande? Archive 30.01.2001. http://www1.rfi.fr/actufr/articles/013/article_5827.asp

Esterle-Hedibel, M. (2007). Controverses théoriques autour des bandes de jeunes. In Mohammed, M. et al. (Eds.), Les bandes de jeunes, La Découverte, «Recherches » (pp. 85 - 96). ISBN 9782707153456. https://www.cairn.info/les-bandes-de-jeunes--9782707153456-page-85.htm

Feixa, C. (Dir.), Sánchez García, J. (Coord.), Ballesté, E., Cano-Hila, A. B., Masanet, M.-J., Mecca, M., \& Oliver, M. (2019). The (Trans) Gang: Notes and Queries on Youth Street Group Research (TRANSGANG Working Papers 2.1). Barcelona: Universitat Pompeu Fabra \& European Research Council. DOI: http://dx.doi.org/10.31009/transgang.2019.wp02.1

Galland, O. (1997). Sociologie de la jeunesse, Armand Colin, Paris : Collection « U ».

Giménez, C. (1997). La naturaleza de la mediación intercultural. Migraciones. Publicación Del Instituto Universitario De Estudios Sobre Migraciones, (2), 125-159.

Hadjidj, D. (2011). Le paradoxe de l'espace public dans la ville algérienne, Afrique et développement. Vol XXXVI, $\mathrm{n}^{\circ} 2,207-218$.

Https://www.ajol.info/index/ad/article/viewfile/74108/64768 
Hagedorn, J. M. (2005). The Global Impact of Gangs, Journal of Contemporary Criminal Justice, Vol. 21, nº. 2, May 2005, 153-169, DOI: 10.1177/1043986204273390. http://mobile.gangresearch.net/Archives/hagedorn/articles/globalimpact.pdf

Hammouda, N. (2008). Le desir de migration chez les jeunes algeriens. Analyse microéconometrique. Note d'analyse et de synthese - module démographique et économique. CARIM-AS 142.

Kokoreff, M. (1993). Territoires, identités et mobilité, in Les annales de la recherche urbaine, $\mathrm{n}^{\circ} 59-60,171-179$.

Labdelaoui, H. (2009). Harga, ou la forme actuelle de l'émigration irrégulière des algériens, CARIM, Notes d'analyse et de synthèse 2009/18. Module socio-politique. European university institute.

Lakjaa, A. (2017). Quand l'échec des institutions produit la violence : le cas de l'école, Actes du colloque national : figures de la violence en Algérie : Aspects psychologiques et sociologiques. 10 et 11 mai 2016, Université de Bejaia, Faculté des sciences humaines et sociales.

Meraihi, H. (2009). Existe-il une politique de la jeunesse en Algérie?, Revue Sciences humaines, n³2, décembre 2009, Vol A, 47-54. Université Mentouri, Constantine, Algérie. https://www.revueumc.edu.dz/index.php/h/article/view/625

Mohammed, M. (2007). Des «bandes d'ici » aux «gangs d'ailleurs » : comment définir et comparer? In Mohammed, $\mathrm{M}$ et al. (Eds.), Les bandes de jeunes, La Découverte, « Recherches » (pp. 265-285).

https://www.cairn.info/les-bandes-de-jeunes--9782707153456-page-265.htm.

Mohammed, M. (2012). La bande est outil de compensation sociale. L'humanité. 13 avril 2012.

Mebtoul, M. (2018). Algérie : la citoyenneté impossible? Alger: Koukou.

Mokhefi, M. (2015). Introduction : L'Algérie. Blocages internes, instabilités externes, in Politique étrangère, 2015/3 (Automne), 10-16. DOI : 10.3917/pe.1530010. URL: https://www/cairn.info/revue-politique-etrangere-2015-3-page-10.htm

Nourredine, K. (2013). Adolescents harragas: risquer sa vie comme seule possibilité de realisation de soi, Adolescence, 2013/3 (T.31n³), 699-709. https://www.cairn.inforevue-adolescence-2013-3-page-699.htm

Office national des statistiques (ONS) (2018). Activité, emploi et chômage en Algérie, N819,27. https ://www/ONS.dz/ING/pdf/emploi_chômage_avril_2018.pdf

Omrane, M. (2019). La participation civique et politique des jeunes en Algérie : problématiques et enjeux. In Benhaddad, Boucherf, Hammouda, Souaber (Eds.), La jeunesse algérienne ; vécu, représentations et aspirations, CREAD / SAHWA, 2019, Alger.

Peyroulou, J.-P. (2006). Amnistie en Algérie : quand le pouvoir se reconduit dans l’impunité, Esprit, n³25 (6), juin 2006, 6-12. https://www;jstor.org/stable/24257713 
Pol, E. \& Valera, S. (1999). Symbolisme de l'espace et identité sociale. Villes en parallèles. $\mathrm{n}^{\circ}$ 28-29. Décembre 1999. Ville et environnement. Approche psychosociologique, 12-23. https://www.persee.fr/doc/vilpa_0242-2794_1999_num_28_1_1269

Ragi, T. (2001). Qui sont les jeunes ? in Agora débats/jeunesses, 25. Vers un nouveau pacte générationnel ?, 4-7.

https : www.persée.fr/doc/agora_1268-5666_2001_num_25_1_2393

Ramos, E. (2011). Le processus d'autonomisation des jeunes, in Cahiers de l'action, Institut national de la jeunesse et de l'éducation populaire, 2011/1 N³1, 11-20.

Rarrbo, K. (1997). La galère de la jeunesse algérienne, Agora Débats/jeunesse, 10. Se faire de l'argent, 117-128.

Https://www.persée.fr/doc/agora_1268-5666_1997_num_10_1_1573!

Rarrbo, K. (1995). Le desir de partir, Confluences, ${ }^{\circ} 14$, printemps 1995, 21-26 https://www.Revues-plurielles.org/_uploads/pdf/9_14_3.pdf

Rowland, J. (1997). Questioning Empowerment, Working with Women in Honduras, Oxfam, 192 p. ISBN 0855983620.

Sari, D. (2008). Le jeune et ses révoltes incessantes. In N. Benghebrit-Reamoun \& M. Haddab (Eds.), L'Algérie 50 ans après. Etat des savoirs en sciences sociales et humaines 1954-2004 (pp. 269-280). Orán: CRASC.

Sánchez García, J. \& Sánchez-Mantijano, E. (2019). Youth at the margins: Perspectives on Arab Mediterranean youth. Europa Regional perspectives. London: Routledge.

Semmoud, N. (2009). Nouvelles significations du quartier, nouvelles formes d'urbanité. Périphérie de l'Est d'Alger. Inssaniyat, [en ligne], 44 - 45/2009.

Https://journals.openedition.org.inssaniyat/406;DOI:10.4000/inssaniyat/406

Serres, T. (2013) La "jeunesse algérienne" en lutte. Du rôle politique conflictuel d'une catégorie sociale hétérogène. Revue des mondes musulmans et de la méditerranée. $\mathrm{n}^{\circ} 134$. Décembre 2013, 213-230. Https://www.journals.openedition.org/remmm/8401

Souaber, H. (2019). Le désir de migration des jeunes. In Benhaddad, N., Boucherf, K., Hammouda. N. \& Souaber, H. (Eds.), La jeunesse algérienne : vécu, représentations et aspirations, Alger : CREAD / SAHWA.

Toumi, R. (2009) Marginalisation et violences urbaines en Algérie. Pour une approche multidisciplinaire. Revue de LAPSI, ${ }^{\circ} 6,123-144$. Constantine : Université Mentouri. https://www.researchgate.net/publication/277004041

Tournebize, É. (2006). Les phénomènes de bandes en France. Puteaux : Les éditions Lalo.

ISBN : 2-913181-28-7- EAN : 9782913181281.

UNDP (2009). Envisioning Empowerment, A Portfolio of Initiatives for Achieving Inclusion and Development, United Nations, $87 \mathrm{p}$. 
UNICEF (2013). Multiple indicator clusters service report: Algeria. https://mics.unicef.org/surveys

UNICEF (2015). Multiple indicator clusters service report: Algeria. https://mics.unicef.org/surveys

Van de Velde, C. (2008). Devenir adulte: Sociologie comparée de la jeunesse en

Europe. Paris cedex 14, France: Presses Universitaires de France. doi:10.3917/puf.vande.2008.01. 


\title{
3 Researching Youth Street Groups in Tunisia: Violence, Empowerment and Mediation
}

\author{
Sihem Najar ${ }^{14}$
}

The research carried out in Tunisia (in Grand Tunis) on youth gangs will focus on three groups that act within different spaces and engage in various spheres of activity. The choice of these groups was no accident, and several criteria were decisive in identifying the groups to study:

- Type of action/activity (economic, cultural, etc.);

- Type of space: physical; cyberspace; market; territorial anchorage (market, space of expression and identification, etc.);

- The development of social criticism and forms of resistance;

- The durability of the group's activities.

The three groups identified are the following: graffiti artists; musical clans (the DEBO group); and young people in the informal sector (at Moncef Bey souk). The observation strategies will be adapted to the group studied (observation on social media networks with the agreement of group members; scheduled observation centred on specific group activities, etc.). These observations will make it possible to identify the key players within each group with a view to interviewing them (interviews and life stories).

But to what extent is studying groups of young people (particularly street groups) relevant today, in the current context of socio-political transformation in Tunisia, with all that implies at an economic, cultural and symbolic level?

Seeking to answer this question, we have used studies of young people carried out since the revolution as a basis for showing that three critical areas require substantive intervention and action: young people's marginalisation, access to employment and civic engagement. With regard to access to employment, a report by the UNFPA reveals that $18 \%$ of young people are inactive and, in neither employment, work, nor training (UNFPA Tunisia, 2016). This category of young people is the most concerning and affects more women than men. This situation is all the more critical as the informal sector attracts more and more young graduates due to the withdrawal of the state and its institutions. In addition to this, 26.8\% of young people aged 15 to 29 work in lowskilled trades (ILO and the Observatoire National de l'Emploi et des Qualifications, 2014).

\footnotetext{
${ }^{14}$ This text was drafted with joint contribution of Hamida Trabelsi Bacha and Hamida Jridi.
} 
In terms of young people and civic engagement, various studies have focused on the depoliticisation and civic disengagement of young people due to the crisis of trust in political institutions. A study conducted by the World Bank and the Observatoire National de la Jeunesse revealed that $91.2 \%$ of rural youth and $68.7 \%$ of young people in urban areas say they do not trust political institutions (World Bank, 2014). However, it is our belief that far from being disengaged, young people have turned their backs on politics, its stage and its actors, because it is an instituted and instituting discourse, and have gone to act and speak elsewhere. They have gone to experience different discourse emerging from other territories, improvised, reconquered or quite simply reconverted to the causes of a new engagement. Apathy towards the conventional mode of engagement is very distinct from indifference towards public affairs. It is, as Martine Barthélemy has rightly shown, as if a logic of affiliation has replaced a logic of allegiance (Barthelemy, 2000).

With regard to the marginalisation of young people, the main idea underpinning our reflection on street youth groups is that our society (like other contemporary societies) increasingly produces marginalisation and exclusion. A report on social inclusion in Tunisia reveals that until 2010, the rate of employment in the informal economy was around $40 \%$. Informal activities developed after the revolution and today represent almost $50 \%$ of GDP and employ $40.2 \%$ of the workforce (Institut Tunisien de la Compétitivité et des Etudes Quantitatives, 2017, p. 17). In line with the analysis of François Dubet we assume that our society has chosen marginalisation and exclusion in its relationship to youth (Dubet, 2014). This marginalisation and exclusion cuts across the different forms of social belonging: economic, generational, gender, educational, cultural and regional, among others. It should also be emphasised that, as Guy Rocher has correctly shown, marginalisation constitutes a new "reservoir of contestation" (Rocher, 1971). In this sense, marginalised young people are developing modes of criticism and social protest - and even new forms of action - which allow them to express a "civic self".

It is by taking these three fields of intervention into account, which we consider priorities for addressing the youth question, that we plan to analyse the selected groups of young people.

As well the introduction and conclusion, this report is organised into four sections:

1. Research on (trans)gangs in Tunisia. In this section the emphasis is placed on the specificity of the youth groups in Tunisia. These groups adopt a global culture which, through ICT, allows members of the groups concerned to be open to the outside world.

2. Empowerment, conflict and mediation: this section keeps to the spirit of the Transgang Project, which goes beyond the dominant theoretical model focussing on gang crime. Instead, it envisages groups of young people as agents of mediation and analyses the obstacles that prevent these groups - perceived as problematic - from 
taking up mediating roles. This perspective goes against the grain of the "negativist" approach that emphasises cases of failure and social exclusion. It focuses instead on analysing successful cases of youth gangs and social inclusion (peace and mediation).

3. Transgangs in Tunisia: this section presents the different groups of young people selected, emphasising their natures and characteristics.

4. The legal framework: an examination of the legal system that governs the functioning of groups and the degree of freedom they have.

What follows is a review of the literature on youth groups in Tunisia. What are the most common fields of research on groups of young people? What types of young people have been targeted? Which are the main lines of thought that emerge from these different works?

\subsection{Research on (trans)gangs in Tunisia}

The literature on youth gangs in Tunisia is very limited. In the main, we find reflections on issues related to the difficulties of professional integration, criminality and risky behaviour, often framed in the context of the general youth question. This literature comes in two forms: grey literature (reports produced by government institutions or by national, regional and international organisations seeking solutions to the various problems that concern the youth population); and social science studies and research produced by research or academic institutions to contribute to the debate on the various issues relating to "youth".

Beyond "negativist" approaches sometimes based on the victimisation of young people, sometimes on their stigmatisation by categorising them as problematic, and in keeping with the theoretical direction of the Transgang Project, we will proceed to a critical reading of this literature. This reading is guided by the idea that the marginalisation of young people generates standards of conduct that conflict with the hegemonic rules society imposes that extend to more or less significant acts of violence and conflicts with the outside world.

What are the guiding ideas for our critical review of the literature on youth groups?

We begin with several theoretical foundations which will allow us to grasp the empirical realities specific to groupings of young people in their various modalities. These groupings form according to generational, spatial, socio-political, cultural and economic opportunities, among others. While these spontaneous groupings of young people were originally anchored in neighbourhoods or cities, thanks to globalisation and ICT new types are increasingly emerging that are part of transcultural and transnational entities. The literature on youth groups mainly relates to street groups anchored in localities (in this case neighbourhoods and cities), such as delinquents, young drug 
addicts and deviants, among others. As for the new forms of youth groups (ultras, graffiti artists, rappers, etc.), they have not yet been the subject of in-depth studies. That being the case, the following hypothesis will guide our analysis of the target youth groups:

The marginalisation, stigmatisation and exclusion of particular youth categories (for political, ideological, generational, cultural, socioeconomic and spatial reasons, etc.) may generate areas of action, social revenge and protest cultures, even of rebellion that may transform the established social order. These reactions of social criticism and resistance take root in various fields of action (economic, artistic, cultural, political, etc.) and range from protest to acts of violence.

We now turn to the critical review of the literature on youth groups. This critical examination will allow us to underline the interest of the theoretical position developed in the Transgang Project, which goes against the dominant and pre-established theoretical frameworks and thought. We maintain the spirit of the Transgang Project, which goes against the hegemony of the dominant theoretical model focused on gang crime, in order to encourage a perspective that is better able to study groups of young people as agents of mediation and to identify the obstacles blocking the mediating role of these young people, who are considered to be marginal and disruptive. In other words, our perspective is at the heart of the position developed by the Transgang Project, which consists of reversing the negativist approach which focuses attention on cases of failure and social exclusion (in times of war and conflict), and aims to study success stories among youth gangs and social inclusion (peace and mediation).

With regard to the literature on youth groups in Tunisia, it is important to distinguish three thematic axes of the prevailing approach. The first concerns studies of young people as a social category; the second concerns violence, criminality and juvenile delinquency; the third concerns groups of young people.

\section{Young people as a social category}

Numerous studies focus on youth as a social category often characterized by a specific culture, norms, values and lifestyle, which constitutes a significant vector of social transformations taking place in Tunisian society. For instance, A. Zghal (Zghal, 1984) offers us an interesting socio-anthropological reading of modes of youth construction in the Arab world. The aim of this study is twofold; first, it begins by questioning what is commonly called «the problem(s) of youth» especially when certain young people behaviors disturb the established social order (through political protests, delinquency...), they therefore become « a problem » to be resolved. Second, the author develops a "non-European-centric" analysis of the notion of youth taking into account the cultural and socio-historical context of Arab societies. Accordingly, he develops the notion of futuwa, considered as an institution «invented » by young people in Arab towns in the medieval era, "whose practice and ideology », he says, « are in conflict 
with the official ideology » and «whose traces remain to the present day ». This insight, seems to us, very instructive concerning our studies on youth groups in Tunisia. The futuwa, a set of ideal values assigned to the young man and is always presented against an essentially moral adult life, the muruwa. Somehow, the pair muruwa/futuwa assign valuations to individual actions according to the age and the social group of the person who performs them. Thus, young men must possess certain unique virtues assigned to their age group to be positively recognized as such. Thus, is considered in the Article 12 of Tunis' 2013 Constitution that recognizes that "youth are an active force in building the homeland". Among the male features are strength, courage, gallantry, bravery, honesty, intelligence, generosity, grace, verve, insight, etc. Skills and virtues that would be included in the term futuwa, contrasting with muruwa -understood as a model of control by the intellect of irrational passions and lusts (Sánchez García, 2010).

Another important piece of work carried out by the Center of Arab Women for Training and Research (CAWTAR) opens new perspectives on issues related to youth as a «social category» (Center of Arab Women for Training and Research, 2003). This work was conducted on a sample of adolescents of both sexes from seven Arab countries (Tunisia, Algeria, Morocco, Egypt, Lebanon, Bahrain, and Yemen). From a comparative perspective, this study underlined the specificities of the experiences, values, representations, identity negotiations and the empowerment of Arab adolescents in the covered countries. This study offers a deep and relevant analysis of adolescents' testimonies including their relationships with social institutions, especially with the family, school, religion... and their relationships with their bodies and their sexuality... In other words, this study presents key elements on the construction of an "adolescent culture" in the Arab World, which is difficult to implement.

In the context of this study carried out by the CAWTAR on adolescents (of both sexes) in the Arab world, a research was conducted in Tunisia by Dorra Mahfoudh-Draoui and Imed Melliti among a sample of young people aged from 15 to 18 years (MahfoudhDraoui and Melliti, 2006). The authors have developed an analysis that reconsiders the dominant paradigms on adolescents (psychological, demographic and epidemiological). Therefore, they structured their work around a central question that guided their reflection on the construction of this social category: to what extent the Tunisian societal transformations can lead to the crystallization of adolescence as a distinct age group? This issue could be further enlightened by a series of questions formulated as follows: Are the forms of control exercised by the family group and the adult society flexible enough to allow the adolescents to work on themselves and to fully experience their adolescence? How does this translate if we take into account the gender cleavage line? Can one be an adolescent in Tunisia, etc.? In order to address these different questions, the authors analyzed the processes of identity development among the concerned adolescents, their relationships with the family, the school, the peer group, their perceptions of the future, etc. 
Another important research, conducted by Sénim Ben Abdallah, questioned youth's social (familial and extra-familial) networks use during their transition to adulthood (Ben Abdallah, 2003). These networks allow young people to both override the determinism of their peer groups and respect the dominant culture. Actually, through the youth empowerment process, the author has shown that "the integration of youth in Arab societies is closely linked to their willingness to conform to group values and to respect the established order". It appears, on one hand, that the family is still considered as a "sure value" for young people during their transition. They also do not trust the "modern" public institutions. On the other hand, this study reveals that concerning the extra familial networks, boys tend to mobilize their sociability resources to overcome the difficulties they encounter in their lives; however, girls are more oriented towards family sociability due to the social control exercised over them.

The case of North Africa provides a useful comparison with other transnational communities. It highlights the specificity of the Maghreb context, which is distinguished by groups of young people in a single culture and a single space piecing together local and global sub-cultural traditions. This feature of the region is a product of the fact that these cultures grew out of exchanges and changes in practices and discourses caused by migratory flows that passed through several geographical and cultural areas before stopping in Tunisia and in the Maghreb. Several tools enabled this, particularly the mass media, but also direct contact with migrants influenced by gangs from the northern shores of the Mediterranean who had learned from Central and Latin American gang culture, which was influenced in turn by the gangs of New York and Chicago in the early $20^{\text {th }}$ century (Feixa et al., 2019).

From the perspective of subculture studies, which are prioritised in this project, the idea of youth cultures is supported, in particular, by works that aim to deduce a typology of them, to explore their genesis as well as the discourses they produce. In this vein, important work was done by Youssef Ben Romdhane on the socio-historical conditions of the emergence of the Tunisian youth culture (Ben Romdhane, 1996). The author distinguishes between two types of youth culture; a "spontaneous" one that takes place within peer groups through several forms of social resistance and protest (violence, aggression, drug addiction, deviance, etc.) and an "official" culture covered by the mass media. The author emphasized a certain number of aspects of the "official" one, such as the interlinkage between local culture and global culture, the diversity of this culture and its social control over young people...

Beyond this dichotomous vision, contrasting a spontaneous culture with an official one, our objective within the framework of this project consists of questioning the identitybuilding processes in the groups of young people identified. This identification process is rooted in local modes of social and territorial organisation where belonging to the community is the key mechanism for establishing networks linked to the social centrality of institutions such as the café, the market, religious spaces and informal 
economic structures (Sánchez García, 2016). In the literature on youth, a number of works focus on marginalised young people. In this vein, the work of Olfa Lamloum and Mohamed Ali Ben Zina on young people from Douar Hicher and Ettadhamen, two working-class neighbourhoods in Tunis, should be mentioned (Lamloum \& Ben Zina, 2016). This work examines the changes taking place in the mentality of young people in Douar Hicher. Its aim is to provide a counterweight to the prevailing media construction, which reduces Douar Hicher and Ettadhamen to hotbeds of "Salafist violence", by taking a new look at these young people, reproducing their social life in all its complexity and giving them the opportunity to introduce themselves. The work attempts to understand the way they live their lives and grasp the familial, territorial, social, political and religious logics that underpin their existence.

In the current Tunisian context, with neoliberalism established as the only possible economic paradigm in a state affected by international geopolitical changes on the one hand and post-revolutionary socio-political reconfigurations on the other, precariousness flourishes, imposing a difficult reality on the country's young people. Social and economic reference points are at risk: professional integration is slowing and periods of unemployment are lengthening. Elsewhere, Ridha Ben Amor offers us an interesting analysis of young people testimonies in the working-class neighborhoods of Tunis in order to understand their experience of precariousness (Ben Amor, 2007). In a context of accentuated precariousness linked to the liberalization of the economy and the extension of the unemployment period, the author states that "precariousness is the norm for a large proportion of the working population". Ben Amor questioned their future plans by focusing on two key concepts: strategy and competence. Relying on this analysis, he suggests two types of pathways: pathways into precariousness and pathways of resistance and/or exit from precariousness. This second type of pathway, of resistance - resilience and empowerment and/or self-empowerment in most cases - is of interest, given that one of the objectives of the Transgang Project is to present success stories of groups of young people and good practices with a view to adopting an approach focused on social inclusion and the mediating role of young people, without forgetting to take into consideration the barriers and obstacles that hinder the mediation process.

These young people find themselves on the periphery of society, the economic system and even their own personal choices. Relegated to this subordinate position, they seek to fight against the implementation of the market economy and to show its social paradoxes (Wacquant, 2008) by choosing different forms of resistance: cultural, artistic and sometimes even in the form of violence and delinquency. The precariousness imposed on these young people, which affects their discourse, mechanisms of empowerment and mediation, needs to be studied in the local Tunisian context as it forms a part of the transnational comparison aimed at in this work. 
New subjects of research on young people emerged after the revolution. The work by Imed Melliti and Hayet Moussa deals with the issue of youth representations of injustice and examines political legitimacy in Tunisia through the prism of social justice (Melliti \& Moussa, 2019). This work aims to reveal the political effects of the discrepancy between, on the one hand, the representations of the "just" and the "unjust" and the political and social expectations that result from them, and on the other hand, the perceptions individuals have of social reality and state intervention as a guarantor of redistribution and the common good. Several questions guided reflection on the representations of justice and the common good: Do young people's demands regarding access to employment and the right to "dignity", particularly among graduates, express the extent of the "frustrations" generated by the gap between an imaginary "paternalistic" guardian state, which is the subject of considerable expectations, and the currently limited effects of its intervention and its redistributive activity? Today, does the recurrent and violent return of the social and regional issue testify to the extent of the unfulfilled expectations, the effect of which is compounded by this demand, born out of the revolution, to reformulate the national pact between regions and territories? Which rhetorical and lexical categories are used for "injustice": "excess", "exploitation", "contempt", "humiliation", for example? Which spheres (family, work, school, territory) prompt the strongest feelings of injustice? Along which identity lines are the feelings and frustrations provoked in Tunisia most commonly played out: tribal group, social class, gender or region?

\subsection{Violence, crime and juvenile delinquency}

The issue of violence, criminality (and, particularly, criminalisation) is at the heart of the thinking that guides the Transgang Project. Social exclusion, the loss of social support from social protection and the weakening of shared spaces of recognition are a sine qua non condition for the development of violence, especially in the disadvantaged and peripheral parts of large cities and urban centres. Uncertainty about the future generates a climate of aggressiveness which results in three types of violence: violence from above (oppression), violence from below (resistance) and horizontal violence (stigmatisation) (Feixa, Sánchez-García, et al., 2019). This violence is a reaction to marginalisation and stigmatisation. Behind this climate of violence hides what Luca Queirolo Palmas calls a process of public enemy construction (Queirolo Palmas, 2012b, 2012a). As Henriette Asséo has shown, the enemy is always outside the borders, and is therefore always a foreigner; the enemy is the barbarian who does not possess our level of civilisation (Asséo, 2016). The criminalisation of young people is nothing other than the expression of a confrontation between rival social categories that establishes conflicting relationships that take different forms.

A review of the literature on young people in Tunisia shows that a number of issues have been analysed in relation to the problems of violence, criminality and juvenile delinquency. Such issues, which shed light on the criminalisation process and the 
emergence of violence, allow us to understand the dynamics of street youth groups and their relationships with the state and its institutions, with other social groups, with their reactions to the denial of recognition and with precariousness. An example is provided by the work a group of researchers carried out on criminality in young adults, which proposed to establish the profile of the young adult delinquent through the evaluation of eighteen years of psychiatric experience in criminal law (Feki et al., 2016). Based on a sample of 97 subjects, the authors found that in the majority of cases the accused was male and unskilled. The main offences were: theft (36.1\%), homicide or attempted homicide (25.7\%), assault and battery (11.3\%) and sexual offences (7.3\%). In nosographic terms, $49.5 \%$ suffered from antisocial personality disorder and $11.3 \%$ were schizophrenic. $29.9 \%$ were legally insane. At the end of this study, the authors raise the question of preventing and treating mental disorders as a prophylaxis for delinquency in young people. This is a legitimate form of preventing deviant behaviour in children, adolescents and even adults. However, it is important to emphasise that social injustice in terms of access to quality care, and inequalities and inconsistency in the supply of care generate a climate of violence and aggressiveness (Association tunisienne de défense du droit à la santé, 2016). The reasons given for violence and assaults on nursing staff, which have become frequent, essentially relate to the failings in the healthcare system and the provision of services. It is above all patients' companions acting violently because they find the functioning of these services "intolerable" (Remili, 2019).

On another level, Mustapha Nasraoui examines the understanding of the relationships between delinquency and values in Tunisia (Nasraoui, 2011). He shows that as structures they are neither parallel nor merged, but detach and overlap at certain relatively solid anchor points. According to the author, a distinction should be made between two sets of values with different effects on the behaviour of Tunisian delinquents. A first set takes root in the offender's primary emotional life and is rarely transgressed, while a second, which relates to material well-being and the socioeconomic situation, is diverted from its original meaning and stripped of the social consensus on which it was founded. It is at the same time reinvested with a new meaning that comforts the offender. The actor/observer bias often seen in this kind of situation arises not only in terms of the causes of the crime but also in terms of its function: the aim of the offence varies depending on whether one is an actor or an observer.

Souad Laroussi-Zahar investigated female criminality and social change in Tunisian society (Laroussi-Zahar, 1994). Her work analyses the results of a 1980 empirical field survey conducted on a sample of 200 common law female prisoners held at La Manouba women's prison (in an inner suburb of Tunis), updated using statistical data from the prison authority. The study attempts to highlight the various shortcomings in the social environment in which the women offenders lived and which determined their deviance, as well as attempting a typological and quantitative classification of the 
crimes and offences committed by these prisoners. In addition, the author conducts a psycho-social analysis of the phenomenon of female delinquency in terms both of its endogenous and exogenous causes, and the importance and frequency of recidivism, and makes proposals for reducing their effects.

The interesting work done by Abdelwahab Bouhdiba on crime and social changes in Tunisia, which makes a sociological analysis of criminality, should also be highlighted (Bouhdiba, Sebag, Camilleri, \& Ben Amor, 1965; Bouhdiba, 1965). To study criminality in Tunisia in the 1960s, the author examines the social changes underway, and notes the present traces of the bandits d'honneur of the 19th and 20th century in relation to the Beylical and then the colonial order. He thereby attempts to understand how, in what way and why certain forms of criminality may violate the legal and even sometimes the moral order, and yet enjoy incontestable popular legitimacy. The interest of this socio-anthropological work lies in the fact that it runs contrary to mainstream approaches to crime and analyses cases in which crime may enjoy a degree of social legitimisation.

Abdelkader Zghal's work on youth violence shows how young people in the 1960s in Tunisia assimilated the idea of the future and this was confused with the myth of progress (Zghal, 1985). This idyllic image of youth was gradually replaced from the end of the 1960 s by a rather murky image which almost automatically linked the notion of youth to that of violence.

In addition, the National Youth Observatory conducted a study on "Tunisian youth and verbal violence "»(Observatoire National de la Jeunesse, 2004). It was conceived within the framework of a political campaign aiming to fight the phenomenon of incivility among young people. This research was based on Focus groups and surveys with a national sample of 820 young people. The main questions of this study are as following: is verbal violence in general and incivility in particular a new phenomenon in Tunisian society, especially among young people? To what extent is this form of violence the reflection of a youth subculture based on the transgression of social norms and adult control? How do the different forms of incivility reflect a negative citizenship that is imposed in the public space? Are the expansion of verbal violence and the feminization of the public space correlated? etc. The survey is based on a different perspective to that emphasised by the Transgang Project. Indeed, as part of a political campaign, this research was conceived by the "promoters of morality", to use Howard Becker's expression (Becker, 1985), meaning the state and its institutions, where young people are seen as marginal, deviant, even delinquent, which has repercussions on their individual and collective behaviour.

Lastly, work has been done on cybercrime, such as that by Samir Dridi on data protection (Dridi, 2018) and Salma Khaled on cybercrime and the Tunisian revolution (Khaled, 2012). They concern the new forms of what the "promoters of morality" (the state and its institutions) consider to be criminality among Tunisian young people. And 
so it is, one notes, that whatever the nature of a youth group, the negative representation always spontaneously prevails. These groups are likened to "gangs" fomenting disorder, violence, deviance and criminality. Hence, in line with Pierre Bourdieu's analysis of the role of the state and Loïc Wacquant's reflections on the criminalisation of poverty (Bourdieu \& Wacqant, 1992; Wacquant, 1998), the Transgang Project (Feixa et al., 2019) seeks to grasp the marginalisation and criminalisation of young people by focussing on the "retreat of the state", in particular its "left hand", which protects (as opposed to the "right hand", which controls). The state's disengagement can cause despair among the people. In Wacquant's view, the neoliberal state considers the police, prison and the justice system to be elements of the state's "right hand".

\subsection{Youth Empowerment}

The concept of empowerment relates to the various stages and conjunctures of life. We speak, for example, of empowering a child, a young person, or even a child suffering from psychological disorders, or physical or mental disabilities. During youth (the age group our work focuses on), empowerment has been defined as the crossing of stages towards independence from the family, the ability to create one's own universe and to govern one's life by making relevant choices (Ramos, 2011).

Empowerment is therefore often related to the entry to adulthood, to autonomy and independence (Ramos, 2011). In the sociology of youth, entry into adulthood is generally considered to be a transition period formally marked by several events: leaving the parental home, gaining a stable job and forming a couple (Ramos, 2011). It is therefore defined by the acquisition of social statuses associated with the various thresholds of the transition to adulthood (Galland, 2001). ${ }^{15}$ Independence is defined based on objective categories linked essentially to the resources available to the individual to manage their life without parental financial or material support. Autonomy, on the other hand, concerns subjective categories. The individual sets their own rules and this is considered to be a positive self-perception, and towards which the individual is pulled. It is therefore an identity category that implies that the individual must participate more in the development of the world, in the universe in which they live. Autonomy results from the capacity reason gives a person to be able to live and act by themselves. It is the proper business of the human individual to decide for themselves from which representations and norms their critical reflection emerges, which they are then able to translate into strategies and acts (Servais, 2016).

\footnotetext{
15 According to the author, four thresholds are particularly significant, as they introduce new social roles that delimit the age boundaries: the end of education, the beginning of professional life, the departure from the parental home, and forming a couple. The traditional model was based on the synchronisation of these thresholds. The model of entry into adult life today is characterised by the desynchronisation of the thresholds: the different stages are not all crossed at the same age, or in the same order.
} 
Until the mid-twentieth century, the empowerment of young people and the transition to adulthood meant leaving home following the obtaining of a job and/or forming a relationship that leads to marriage and the starting of a family. Young people's pathways are currently undergoing major changes. These are due to university studies generally requiring them to live at some distance from the family home, the prolongation of these studies (Poulet, 1996), the delay in leaving home (Bozon and Villeneuve-Gokalp, 1995), later marriage (Sardon, 2005), the end of training, unemployment, and professional integration, among others (all referred in Ramos, 2011).

These stages are no longer linked in this linear fashion and are less joined-up. Young people's pathways are therefore less standardised and increasingly individual, and depend on different empowerment processes at several levels: the affective and relational, the economic, and the organisational (Danic \& Valdes, 2016). Each individual/young person chooses their own pathway according to their personal aptitudes and attitudes (confidence and self-esteem, their relationships with those around them, their determinism, etc.) but also according to the environment in which they live and have lived. Indeed, this process of empowerment varies from one society to another, from one culture to another and from one country to another. However, in the current context of globalisation, young people experience almost the same sequence and often face the same constraints. Hence the usefulness of this study attempting to examine this process in different countries of the Mediterranean basin. The process of empowering young people is closely linked to government policies in the field of youth and the challenges they face in supporting them in this process and facilitating their independence and "transition to adulthood".

Tunisia is a pioneer in the Arab world in terms of family policy. Indeed, shortly after the country's independence in 1956, President Bourguiba established the Code du statut personnel pour les droits des femmes, aimed at promoting equality between men and women. Women's participation rate nevertheless remains very low across the total population. They are very poorly represented in positions of power and are confronted with stereotypes about the roles they should fill in the world of work and the public sphere. With $24.5 \%$ of their population aged 15 to 29 , Tunisia has a high level of young people and adolescents. They tend to be educated and Tunisia's illiteracy rate is low, at $3.2 \%$ of the population. Paradoxically, school dropout remains very high $(106,000$ young people in 2015) (UNFPA Tunisia, 2016), despite the great efforts made in education since independence in 1956.

Employment is one of the major challenges Tunisian young people face. According to a survey carried out by the International Labour Organization in 2013 (UNFPA Tunisia, 2016), 55\% of young people aged 15 to 29 describe professional success as their main concern while the unemployment rate recorded in the same year, in the same age range, was $33.2 \%$. The unemployment rate varies from region to region, but is higher in the 
interior regions of the country than along the coast. The country's north-west and centre-west have the highest unemployment rates (UNFPA Tunisia, 2016).

It should also be noted that $18 \%$ of young people are inactive and are not in employment, work, or training (UNFPA Tunisia, 2016). This group of NEETs (not in education, employment or training) is of great concern as it includes disengaged and discouraged young people who are marginalised and who are no longer looking for a job. More women are affected than men. Young people in this group generally endure long periods of inactivity, which further complicates their reintegration into the job market: $38 \%$ of unemployed young people have been looking for a job for over two years. This is partly due to the fact that young people refuse certain jobs (a current example is a labour shortage in olive-picking). The results of the "Transition Vers la vie Active" (ETVA) survey carried out by the International Labour Organization (ILO) shows that one in nine unemployed young people has turned down a job. According to the same study, low wages are the main reason for refusal.

For higher education graduates, the unemployment rate in 2013 was $32.7 \%$. The latter begin their professional life doing temporary and low-skilled jobs as a transitional solution. The problem of unemployed graduates affects $43.5 \%$ of women as against $23.1 \%$ of men and is particularly high in the interior and in the south of the country, where the overall rate reaches almost $40 \%$. While this group is increasingly attracted to migration, NEETs are more and more marginalised, prone to irregular migration and attracted by illegal activities such as smuggling.

Several measures have been taken to support Tunisian young people on the issue of employment. The Ministry of Vocational Training and Employment (MFPE) has implemented measures to facilitate the integration of young people and the transition to the labour market through the programmes of the National Employment Agency and Self Employment such as the Programme actif du marché du travail (PAMT) or even the entrepreneurship programmes that prepare and support young people to set up on their own account. It gives them the benefit of various training courses on project management, soft skills, IT tools, and so on, but these programmes are more accessible to unemployed university graduates from urban areas. Hence, such programmes do not solve the problem for NEETs. In addition, the level of beneficiaries of these programmes is very low, meaning they have little credibility in the eyes of young people (Institut National de la Statistique de la Tunisie (INS), 2017b), who raise the following problems in particular:

- Mismatch between academic training deemed too theoretical and the market demand for more functional skills;

- Recruitment processes and hiring criteria are seen to be discriminatory and to promote favouritism, corruption and regionalism. There is lack of contact and a general lack of opportunities. In fact, according to an International Labour 
Organization study, young people rated the importance of relationships $(58.1 \%)$ higher than that of qualifications or level of study (53.5\%) and professional experience (17.8\%). (Institut National de la Statistique de la Tunisie (INS), 2017b)

Young people are also highly affected by underemployment, defined by the ILO as "a lack of "adequate" employment opportunities, with persons who have jobs often being compelled to use their skills less fully or to earn lower hourly wages or work less [sic] hours than they are willing and able to" (Laurie, 2017, p. 5). According to this definition, $68.2 \%$ of all young Tunisians in urban areas are identified as underemployed (Institut National de la Statistique de la Tunisie (INS), 2017a). Young people are also affected by informal employment. These kinds of jobs present risks of exploitation, as they are often of fixed duration and do not provide the employee with social security.

These integration problems faced by young Tunisians in search of change are real and complicate their empowerment processes. They are issues that clearly predate the period of democratic transition in the country (although they were accentuated by this situation) and result from the lack of educational and sociocultural supervision despite the efforts made by non-formal youth education institutions, such as youth and cultural centres. This transition period, which has brought about major changes in the country's economic and social structure, places young people at the heart of these changes. Thus, governance institutions and governmental, intergovernmental and non-governmental organisations have the responsibility to ensure young people are included in society and help them overcome the obstacles they face. In this context, several initiatives have emerged that aim to empower young people, particularly women deemed to be more vulnerable and dominated.

\subsection{Conflict and mediation: a reading from Tunis}

In the theoretical field, as in praxis, mediation is today considered either a tool for analysing communication processes, or as a tool that can be used to nurture/handle/improve relationships between peers, or between individuals and institutions. Indeed, the explosion of mediation practices, whether in the legal, administrative, social, school, family, therapeutic or cultural fields, is seen by specialists as a proposal for a new mode of social regulation, or even as a new model of relationship between individuals, as well as between individuals and the state (Servais, 2016).

The term "mediation" is also recognised as any intervention aimed at reducing the distance between two (or even more than two) poles that are in tension with each other (Coste \& Cavalli, 2018). The distance/tension to be reduced may be related to lack of knowledge, conflict, misunderstanding or the failure of one of the parties to adjust to the needs of the other. It covers various well-established processes in different sectors of 
the social sphere: legal mediation, social mediation, conjugal or family mediation, intergenerational mediation, urban mediation, diplomatic mediation, economic mediation, and so on (Coste \& Cavalli, 2018).

It is the social actor's capacity, perceiving otherness, to blend in and participate in a social group (p. 2), taking into account the two "natures" of mediation: cognitive, when there is a need for information, knowledge, skills, and relational, when it comes to facilitating interaction, taking into account emotional dimensions, cultural attitudes and habits (Coste \& Cavalli, 2018, p. 3).

Isabelle Audras, who examines the concept of mediation in language teaching, considers that mediation takes place above all through language and discourse. She considers that mediation acts on at least three distinct but complementary levels (Audras, 2018):

- (Inter)individual mediation, which is seen by the author as the intervention of people without specific qualifications or by professionals with a responsibility related to their role (a translator for the refugee, a marriage mediator for couples in difficulty, a family mediator in the case of intergenerational conflicts, a teacher facing a particular student, a trainer in a professional environment, etc.).

- (Inter)community mediation occurs, according to the author, at the level of social groups whose actors may be either representatives of the community or communities in question (for example, certain interfaith initiatives against religious fanaticism or terrorism) or external mediators, professional or otherwise (NGOs, voluntary associations, union representations, etc.).

- Institutional mediation involves the commitment - and therefore the responsibility - no longer of individuals or (representatives of) social groups but of institutions in their return to a pathway focussed around joint mediation, whether that be through a school, the prison system, psychiatric hospital, language centre for immigrants or even a refugee reception hot-spot (Audras, 2018; Coste \& Cavalli, 2018).

Our use of the concept of mediation in this research relates to the second of these categories. Mediation is a central and crucial concept in the theoretical construction of the Transgang Project. Smuggling groups and young people from the informal sector are considered as agents of mediation linked to conflicts. In their work on the theoretical framework of the Transgang Project, Feixa et al. (2019) highlight the positive aspect of conflict. In this vein, Christine Servais says that mediation can be used to settle conflicts between norms and values that are likely to arise as there are more universal and/or transcendent norms to which to refer. Thus, mediation is conceived as much as a symptom of a societal evolution as a remedy for its pathologies; it is both a theoretical perspective and a model of action, a way of saying and a way of doing (Servais, 2016). 
Similarly, the founders of this project emphasise that conflict is an engine that allows society and organisations to change and evolve (Feixa et al., 2019, p. 45). Thus, revolution makes it possible to obtain rights and political conflicts allow the alternation of power, which strengthens democracy. It therefore forms part of this project to consider conflict as an opportunity for progress and not as a problem, and to see the extent to which we can apply reflections and models of analysis developed in different contexts to the Tunisian case, relying on reflections based on direct observation, as well as on participants in two Tunisian youth groups.

In fact, these marginalised groups considered to be "outside the law" are regularly in conflict with state representatives and by extension the law. The failure of dialogue and mediation between these two parties is undeniable. Even at the highest levels of government, we recognise governance failures in terms of mediation. Indeed, recognising this need implicitly proves the existence of a problem of communication, and even of trust between individuals, groups and the government. In Algeria, the history of socio-political crisis management reveals political mediation efforts dating back to the mid-1990s, during the worst years of the armed conflict that began in 1992.

This conflict impacts the economy and politics and recurs over and again, due to a lack of trust in the government but also to a lack of mediation. Institutionally, Tunisia established this mediation role in the administrative field. Since 1992, a government position was created of "administrative mediator" (similar to the "Mediator of the Republic" that existed in France). But the role of this institution is limited to mediating in cases of citizens' conflicts with the administration, and it remains unknown by a large majority of citizens. Socially speaking, certain groups have informally come together to act as mediators between the government and the political system on the one hand and the different social actors on the other.

The DEBO group is one such case. It takes an anti-establishment position and above all an interest in the problems and concerns of marginal and marginalised young people whose rights it asserts via artistic expression. It is our view that due to its special relationship with the institution, DEBO could play a mediating role. Indeed, in this context, the importance of the relationship between gang and institution comes down to the fact that the members of DEBO have institutionalised their exclusion. By placing their activities and events within an institutional framework, the group manages to publicise the underground and therefore the illegal; it shines a light on elements that remain illegal in Tunisia (the anti-establishment attitude, drugs, violent discourse, etc.).

The group stands out because it takes action in the field - in the street, on the stage, within its localities, as well as on the internet. It has conflicts with other music groups (clans) that do not share the same ideological, political or cultural affiliations. It is also transnational, in the sense that it adopts a hybrid culture based on several musical genres that are heavily influenced by globalisation. 
In the economic sector, which cannot be separated from politics, the networks of young people in informal work also play a mediating role. In our case, specifically, these are young people from Moncef Bey souk. These youth networks overlap with a type of community that is often perceived as inaccessible to official institutions for two reasons. Firstly, these networks provide an economic dynamic which the state has failed to consolidate in certain regions since independence. Youth groups in the informal sector enjoy considerable legitimacy, which allows them to potentially mediate between the communities in question on the one hand and between communities and state institutions on the other. Secondly, these young people from the informal sector belong to these communities themselves, whether by kinship or by region and they very often come into conflict with the security forces. Conflicts also arise between sellers who belong to different clans and who are in competition. Observation of this group will cover all the stakeholders and actors who act within the market or who belong to the distribution network.

\section{5 (Trans) Gangs in Tunisia}

\subsubsection{The DEBO collective}

"Underground" Tunisian artists and alternative music are scarce in Tunisia. The DEBO collective has been a key clan in the artistic and social scene over the past few years. DEBO $^{16}$ was "officially" created in 2013. Its members are young people from several downtown districts of Tunis that represent a panoply of underground art forms. It unites rappers, dancers, videographers, composers and anyone who identifies with a culture in which hip-hop, rap and even Mezwed are essential.

The collective not only organises itself to encourage young artists and support their production, it also seeks to strengthen the Tunisian artistic scene by highlighting its artists' creations with publicity that tends to be innovative and original.

The DEBO collective, whose main founder was Trappa, is the common point between several Tunisian rappers known as Vipa, Massi, Tiga Black'Na and Katybon, and has over 67,000 views on its YouTube channel. These artists take advantage of the reach a platform like DEBO can provide and vice versa: the audience generating millions of views of these artists' personal channels moves on to the production of the DEBO studio and label.

In terms of status, DEBO distinguished itself from other clans by establishing its own production studio and association. Through these two structures, it ensures continuity and authenticity. The activities of the two overlap, always working towards its "watchwords" of novelty and innovation. Within this framework, members undertake artistic residencies out of which shows grow that tour festivals like "El Banda" (the

${ }^{16} \mathrm{https}: / /$ web.facebook.com/deboworld/ 
band) created in 2016, or the "Tunis block party" evening held several times since 2017. They were the first in Tunisia to participate in Khalli Trace (leave a trace), the first nomadic festival of urban cultures organised in 2018 in several regions, as well as the hip hop and Tunisian Mezwed fusion event Erkez HipHop. They invest in producing DEBO albums and mixtapes like "Debo fou9 E'tawla" (DEBO on the table), which bring together their artists' collaborations.

Always concerned with authenticity, as part of the fight to protect literary and artistic property, DEBO created the concept of "Tahamatas" or the "Bike Sound System", a bicycle with a subwoofer that rides around selling DEBO's music and showing off its graffiti. It is a concept that guarantees the original and fair distribution of the DEBO product $^{17}$.

As such, it has become a highly "formal" clan even while preserving its antiestablishment stance (adopted by underground cultures) and especially its interest in the problems and interests of marginal and marginalised young people (street life, ego-trip, belonging, drug use, rejection of the system and politicians, etc.).

Illustration 6: Debo Headquarter in Great Tunis

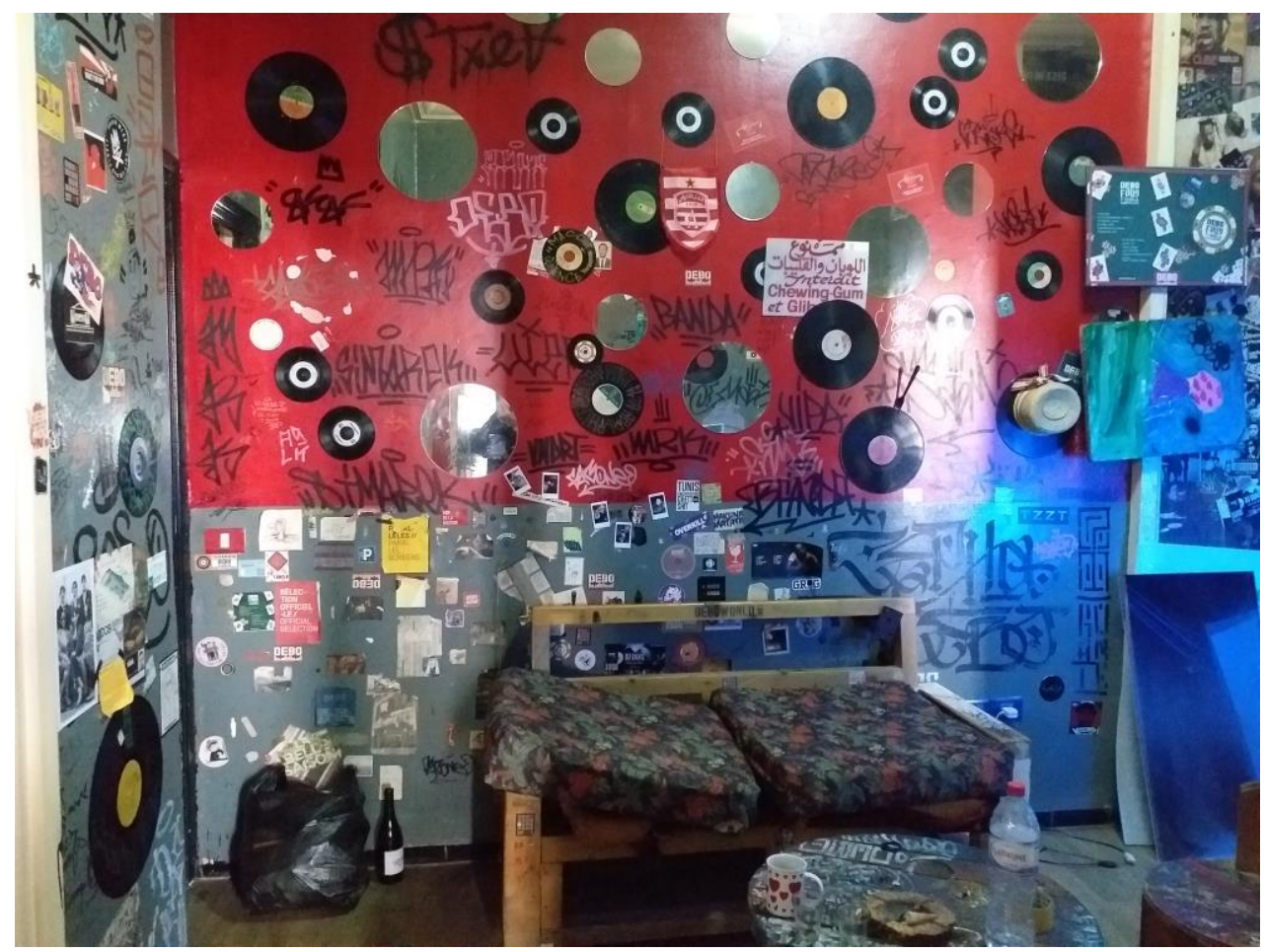

Source: Jose Sánchez García

\footnotetext{
${ }^{17}$ https://social.shorthand.com/ElodiePotente/u2eqtdhLGRY/le-rap-underground-tunisien
} 


\subsubsection{Young people in the informal sector}

Addressing the issue of the informal sector in Tunisia is no easy task. The inclination to summarise this phenomenon as an offence condemned by the state is a shortcut that, in our opinion, disregards the subject's complexity and all the economic and political stakes involved.

Young people in the informal sector are mainly aged between 17 and 30 and live in border areas with Algeria (mainly) and Libya. They leave education to join an established regional or family network where they receive the socialisation necessary to properly assimilate the nuts and bolts of the "profession": the techniques, the attitude to adopt, the formation of a network.

The complexity of the activity within the informal sector means that these young people cannot be seen merely as economic agents. Through their practice they reveal a social world that is their own/a society within society.

We may even note a role reversal in which young people in the informal sector with a monopoly in the market acquire social/economic weight that makes their services necessary for the functioning of the system. Thus, belonging to this community allows the young people in question to stand up to the state and fight against social injustice and marginalisation.

The informal sector is therefore rooted in a "transgressive" social space that disrupts the established social order and various social institutions. Our research focusses on young people who set up in the Moncef Bey market in Tunis, known as "Souk Moncef Bey". Thus, the focus will be placed on informal economic activity among young workers established in one of the largest electronic counterfeiting markets in Tunisia with a network that stretches across the whole country.

We will base our study of this group on direct interviews with group members, on life stories and observation in multiple sites (during purchase, sale and the other activities the group members engage in). At the moment we are able to conduct observations during sales in the Moncef Bey market. However, we cannot a priori commit to and plan observations during the exchange or purchase of goods. This will depend on the relationships we establish with the members of the group and their level of trust in us, in accordance with their internal rules on managing relations with third parties.

\subsubsection{The graffiti artists}

Graffiti is a contemporary artistic language through which the voiceless can achieve free expression through graphic intervention on walls (Bertho, 2015, p. 1). This intervention is generally performed by young people either spontaneously (informally) 
or in an organised (formal) manner. In both cases a message is conveyed that is often dissenting and may be accompanied by a popular uprising.

Since the events of May 1968 in France and the popularisation of the slogan: "murs blancs, peuple muet" (white walls, silent people), graffiti has been seen as a street art which embodies revolt and engagement.

Illustration 7: “White wall, silent people",18

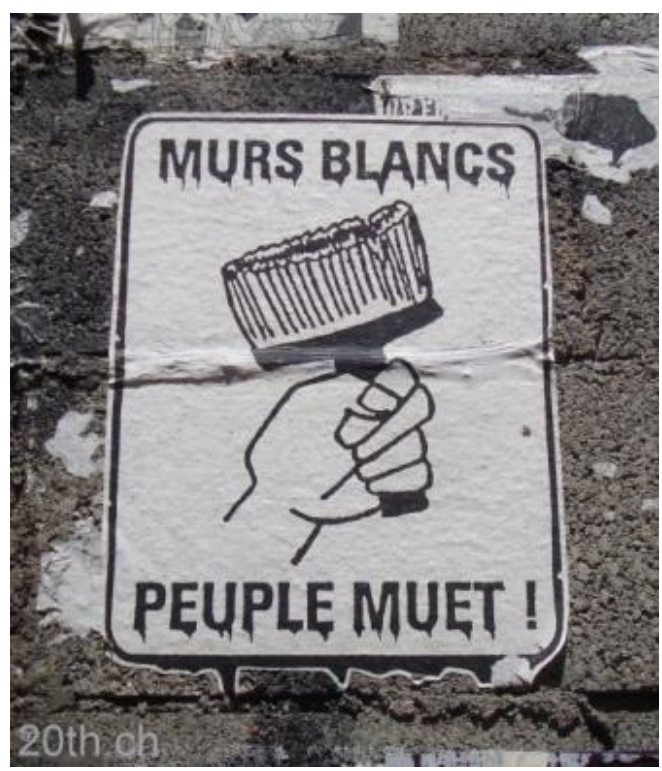

Illustration 8: Graffiti remembering The Jasmine Revolution

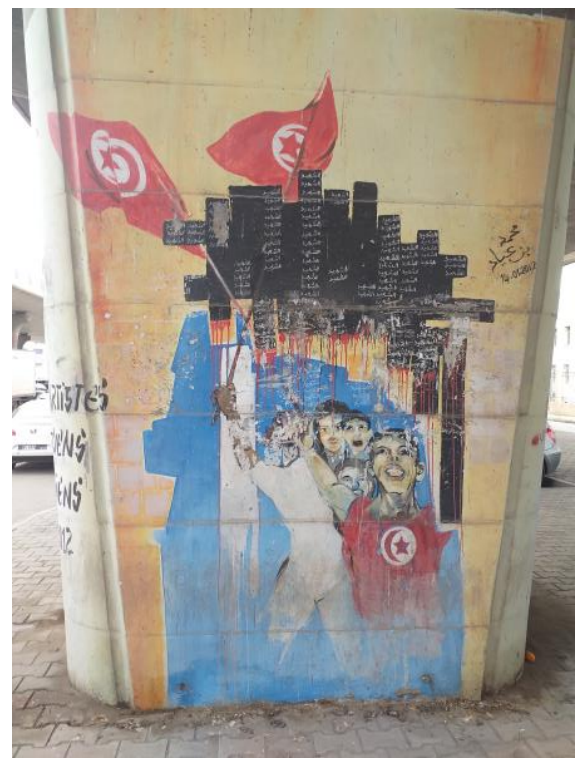

Source: Jose Sánchez-García

In Tunisia, graphic interventions on the walls were characteristic of the 2011 popular uprising. The first tags were seen on the walls of Kasbah Square denouncing the former regime. The movement spread under the influence of a French graffiti artist named "zoo-project" who memorialised the martyrs of the Tunisian revolution in his work. A number of graffiti artists went on to fill the urban space with their work. Notable examples were "I'm tounsi", "Djerba Hood", "Zwawla", "Arab street-art camp", "weldek fi darek" and "Be art" (Karoui, 2010). We chose to focus our study on young taggers in post-revolutionary Tunisia. Tags are a visual artistic practice in the category of graffiti. They consist of intervention through slogans or images on the walls. These slogans are often picked up and spread to other spaces without the author's signature. These are "unauthorised inscriptions" (Vulbeau, 2005). This activity was chosen because of the social dimension it acquires and because it involves young people aged from 16 to 21 years old. Legal, social and even political problems are thereby posed which merit examination. Through this study we will show how, as an artistic

\footnotetext{
${ }^{18}$ Source: http://quandlesmurspalent.blogspot.com/2012/01/poemes-gribouilles-dans-les-toilettes.html.
} 
expression that is basically individual, graffiti can affect the wider group and constitute a representation of the social and the political. We will also attempt to answer the following questions:

Through art, do young taggers manage to exercise their freedom of expression and establish themselves as agents of change or do they remain disruptors of public order? Is graffiti an act of "vandalism" or a means of protest that can even involve civic engagement?

\subsection{Conclusions}

What characterises the street groups we selected is their emergence at the time of the revolutionary turning point, which led to the appearance of new actors who have managed to position themselves on the socio-political scene. These actors are not confined within a defined geographical space, but act in a transnational space that transcends geographical borders by adopting a globalised culture and material space by acting on the internet. As for young people in the informal sector, they represent a group which faces marginalisation and imposes specific relationships on the state and its representatives. Whether in the cultural and artistic or economic fields, we are witnessing modes of social criticism and resistance implemented by actors who could play a key role in post-revolutionary Tunisia.

While the Tunisian context has been marked by specific transformations (postcolonialism, the demise of the welfare state, the protest movement that broke out in the mining basin in 2008, revolutionary process, etc.), the fact remains that the rampant changes experienced at global level (the democratisation of ICT use, the economic crisis, neoliberal policies, exclusion phenomena, social injustice and migratory processes, etc.) take shape in local spaces. Hence, the street groups identified are part of a globalised culture. These groups have experienced multiple hardships: based on injustice, identity, discrimination and stigmatisation, etc. These hardships result from an advanced marginalisation which generates diverse reactions that range from protest to the revolutionary movement.

It is also important to emphasise that the decline of institutions (including the state) has widened the gap between the different social groups that come into conflict, leading to the construction of the public enemy.

At the end of this work, it is important to emphasise the originality of this project, which targets groups of young people likely to play a crucial role in Tunisia in the current setting of socio-political transformation. Does this work's interest lie in examining the extent to which these groups are able to act as mediators? Do these groups have the level of legitimacy that would allow them to play this role? 


\subsection{References}

Asséo, H. (2016). La construction de l'ennemi de l'intérieur en Europe aux XIX ${ }^{\mathrm{e}}$ et $\mathrm{XX}^{\mathrm{e}}$ siècles. In H. Asséo, F. Julien-Laferrière, \& L. Missaoui (Eds.), L'étranger (Etudes et travaux de l'IRMC, pp. 87101). https://doi.org/10.4000/books.irmc.209.

Association tunisienne de défense du droit à la santé. (2016). Rapport sur: Le droit à la santé en Tunisie. Retrieved from https://jamaity.org/publication/rapport-droit-sante-tunisie/.

Audras, I. (2018). Analyse d' « Ateliers jeunes praticiens » de FLS/FLE : un observatoire de la diversité des pratiques et des besoins en formation qui interroge le concept de médiation. Recherches En Didactique Des Langues et Des Cultures, 15(2). https://doi.org/10.4000/rdlc.3053.

Barthelemy, M. (2000). Associations - un nouvel âge de la participation? Retrieved from Presses de Sciences Po website: http://www.pressesdesciencespo.fr/fr/book/?GCOI=27246100126760.

Becker, H. S. (1985). Outsiders: Hacia una sociología de la desviación. Paris: Métailié.

Ben Abdallah S. (2003). Pratiques des jeunes et mobilisation des réseaux sociaux. Processus d'entrée à l'âge adulte. Université de Tunis.

Ben Amor, R. (2007). Parcours des jeunes et précarité dans des quartiers populaires de Tunis : exemple d'Ettadhamen-Douar Hicher. In Berry-Chikhaoui I., Deboulet A. et Roulleau-Berger L. (dir.), Villes internationales. Entre tensions et réactions des habitants, Paris, La Découverte, (pp. 207-222). https://doi.org/10.3917/dec.berry.2007.01.0207.

Ben Romdhane, Y. (1996). Youth culture: emergence, dimensions and significations », Revue Tunisienne de Communication, $\mathrm{n}^{\circ} 28-29$, pp. $41-73$ (in arabic language).

Bertho, A. (2015). Les murs parlent de nous. Esthétique politique des singularités quelconques”, in Cahiers de Narratologie. Cahiers de Narratologie (Online), (29). Retrieved from https://journals.openedition.org/narratologie/7410?lang=es.

Bouhdiba, A., Sebag, P., Camilleri, C., \& Ben Amor, H. (1965). Criminalité et changements sociaux en Tunisie (Cahier du). Tunis: Imp. S.T.A.G.

Bouhdiba, A. (1965). Criminalité et changements sociaux en Tunisie; étude sociologique. Retrieved from https://www.worldcat.org/title/criminalite-et-changements-sociaux-en-tunisie-etudesociologique/oclc/2025246.

Bourdieu, P., Droit, R. P., \& Ferenczi, T. (1992). The Left Hand and the Right Hand of the State. Variant Issue, 32, 3-4. Retrieved from https://www.variant.org.uk/32texts/bourdieu32.html.

Bourdieu, P., \& Wacqant, L. J. D. (1992). Réponses. Pour une anthropologie réflexive. Paris: Seuil.

Center of Arab Women for Training and Research. (2003). Arab adolescent girls. Situation and perspective, Tunis (in arabic language). Tunis.

Coste, D., \& Cavalli, M. (2018). Retour sur un parcours autour de la médiation. Recherches En Didactique Des Langues et Des Cultures (Online), 15(2). https://doi.org/10.4000/rdlc.2975.

Danic, I., \& Valdes, B. (2016). Processus d'autonomisation des jeunes : le cas des étudiants de Rennes. Informations Sociales, $n^{\circ}$ 195(4), 37. https://doi.org/10.3917/inso.195.0027.

Dridi, S. (n.d.). Cybercriminalité et protection des données personnelles. La guerre est déclarée. $L a$ Presse. Retrieved from http://www.lapresse.tn/component/societe/?task=article\&id=146864. 
Dubet, F. (2014). La préférence pour l'inégalité. Comprendre la crise des solidarités. In Éditions du Seuil. https://doi.org/10.4000/lectures.16292

Feixa, C., Sánchez-García, J., Ballesté, E., Cano-Hila, A. B., Masanet, M.-J., Mecca, M., \& Oliver, M. (2019). The (Trans) Gang: Notes and Queries on Youth Street Groups Research. Barcelona: Universitat Pompeu Fabra \& European Research Council https://doi.org/http://dx.doi.org/10.31009/transgang.2019.wp02.1.

Feki, I., Zouari, L., Omri, S., Gassara, I., Maalej, M., Charfi, N., ... Maâlej, M. (2016). Criminalité chez le jeune adulte : a propos de 97 cas d'expertise psychiatrique pénale. J.I. M. Sfax, 24, 42-48.

Galland, O. (2001). Adolescence, post-adolescence, jeunesse : retour sur quelques interprétations. Revue Française de Sociologie, (42-4), 611-640.

Grosfoguel, R. (2011). Islamofobia epistémica y ciencias sociales coloniales. Astrolabio, 6, 43-60.

ILO and the Observatoire National de l'Emploi et des Qualifications. (2014). Transition vers le marché du travail des jeunes femmes et hommes en Tunisie. Retrieved from www.ilo.org/publns. .

Institut National de la Statistique de la Tunisie (INS). (2017a). Enquête Nationale sur le Travail des Enfants en Tunisie de 2017 - Principaux résultats. Tunis.

Institut National de la Statistique de la Tunisie (INS). (2017b). Fundamental Principles and Rights at Work Branch (FUNDAMENTALS). Tunis.

Institut Tunisien de la Compétitivité et des Etudes Quantitatives. (2017). Inclusion sociale en Tunisie: Les enjeux de l'emploi, de l'éducation et de la répartition des revenus. Retrieved from http://www.itceq.tn/files/politiques-sociales/inclusion-sociale.pdf.

Karoui, S. (2010, August 18). Enquête : Le Street-Art en Tunisie (I). Nawaat. Retrieved from https://nawaat.org/2014/08/18/enquete-le-street-art-en-tunisie-i/.

Khaled, S. (2012). La cybercriminalité et la révolution tunisienne. In Archives Ouvertes (Ed.), Journée d'étude sur "Internet, révolution et transition démocratique », (pp. 1-12). Retrieved from www.ihei.org.

Lamloum, O., \& Ben Zina, M. A. (2016). Les jeunes de Douar Hicher et d'Ettadhamen: Une enquête sociologique. Tunis: Arabesques.

Laroussi-Zahar, S. (1994). Criminalité féminine et mutations sociales dans la société tunisienne. Cahiers de La Méditerranée, 49(1), 169-187. https://doi.org/10.3406/camed.1994.1131.

Laurie, A. (2017). International Labour Organization. Working Papers Series $n^{\circ} 104044$. Retrieved from moz-extension://f0096cde-6b01-449b-9b42-8249c6725c56/enhancedreader.html?openApp\&pdf=https $\% 3 \mathrm{~A} \% 2 \mathrm{~F} \% 2 \mathrm{Fwww}$. ilo.org $\% 2 \mathrm{Fpublic} \% 2 \mathrm{Fenglish} \% 2 \mathrm{Fbureau} \% 2 \mathrm{~F}$ stat $\% 2$ Fdownload\%2F16thicls\%2Freport1.pdf.

Mahfoudh-Draoui, D., \& Melliti, I. (2006). De la difficulté de grandir: pour une sociologie de l'adolescence en Tunisie, Tunis, Centre de Publication Universitaire..

Melliti, I., \& Moussa, H. (2019). Quand les jeunes parlent d'injustice: Expériences, registres et mots en Tunisie. Paris: L'Harmatthan, ONJ.

Nasraoui, M. (2011). "Rapports entre délinquance et valeurs vécues : quelques illustrations dans la société tunisienne? Les Cahiers Internationaux de Psychologie Sociale, Numéro 89-(1), 107. https://doi.org/10.3917/cips.089.0107.

Observatoire National de la Jeunesse. (2004). Verbal violence among young tunisians, Tunis (in arabic 
language). Tunis.

Queirolo Palmas, L. (2012a). « Nous sommes ici ! ». Les enfants de l'immigration contre une postérité inopportune . Migrations Société, $N^{\circ}$ 141-142(3), 103. https://doi.org/10.3917/migra.141.0103.

Queirolo Palmas, L. (2012b). The Social Construction of the Youth-Migrant Nexus in Contemporary Spain. A Critical Overview. ITALIAN JOURNAL OF SOCIOLOGY OF EDUCATION, 3. Retrieved from www.yougangproject.com.

Quijano, A. (2000). Colonialidad del Poder y Clasificacion Social. Journal of World-Systems Research, 342-386. https://doi.org/10.5195/jwsr.2000.228.

Ramos, E. (2011). Le processus d'autonomisation des jeunes. Cahiers de l'action, 31(1), 11. https://doi.org/10.3917/cact.031.0011.

Remili, D. (2019). Violences et souffrances en milieu hospitalier: le cas des infirmiers du gouvernorat de Tunis. Conservatoire national des arts et metiers, Université des lettres,arts et sciences sociales Tunis, Tunis.

Rocher, G. (1971). La marginalité sociale : un réservoir de contestation. In C. Ryan (Ed.), Le Québec qui se fait (pp. 41-47). Montreal: Les Éditions Hurtubise HMH ltée.

Sánchez García, J. (2010). Entre la modernidad y la tradición: modos deser joven en El Cairo. EQuaderns, 15(2), 34-53.

Servais, C. (2016). La médiation. Théorie et terrains. Ouvertures sociologiques (pp. 129-163). Brussels: De Boeck.

UNFPA Tunisia. (2016). Défis de la jeunesse tunisienne. Retrieved from https://tunisia.unfpa.org/fr/publications/défis-de-la-jeunesse-tunisienne.

Vulbeau, A. (2005). L'art ou la loi ? Tags et graffs, entre institutions et générations. Territoires, (457).

Wacquant, L. (1998). De l'État social à l'État pénal. Actes de La Recherche En Sciences Sociales, (124), $3-95$.

Wacquant, L. (2008). Urban outcasts: a comparative sociology of advanced marginality. New York: Polity.

World Bank. (2014). Tunisie - Surmonter les obstacles a l'inclusion des jeunes. Retrieved from https://openknowledge.worldbank.org/handle/10986/20693.

Zghal, A. (1984). Note pour un débat sur la jeunesse arabe. Cahiers Du CERES, Série soci(10), 7-41.

Zghal, A. (1985). Violence et jeunesse. Cahiers Du CERES, Série soci(12), 153-170. 


\title{
4 Street Youth Groups Cultures in Morocco: State of the Art and Research Perspectives
}

\author{
Rachid Touhtouh
}

Five-day trainings in "Sidi Moumen" neighbourhood Association IDMAJ in Casablanca, on community against violent extremism opened my eyes to the importance of ethnographic research on the role of CSOs in mediation and conflict resolution in vulnerable communities. I seized the opportunity to have contacts and observe the field for my Transgang ethnographic fieldwork. The training was meant to train parents, educators and CSOs activists on countering and preventing strategies against violent extremisms. This was also a moment of collective remembrance of how it started and what were the results. The neighbourhood now is no longer a shantytown it used to be; many social housing buildings, lot of infrastructure and new roads. However, dwellers of the neighbourhood have new challenges and new problems. Urbanisation and modernization are transforming relationships among the adults and the young generations. Technology, in particular, the internet and social media are impacting transforming the social context. New emerging forms of violence are developing with the urban booming, like Tcharmil and Football Ultras and neighbourhood actors are aware and want to find solutions so as not to repeat the same violent extremism of the 2003.

"Sidi Moumen" is the neighbourhood where the first "Jihadist Salafists" who terrorized Casablanca in 2003 were born and grow up (Hegasy, 2007). The neighbourhood now is transforming from a shantytown into an area populated by affordable social housing buildings. Young people are trying to adjust to a new reality where housing conditions have changed but not social and class statuses have not. It is a neighbourhood where the Ultras of the Green Boys, Islamists and various youth Street groups coexist to produce a social landscape that is hard to decipher without ethnographic fieldwork. I believe this is a good case of mediation that will be researched during the ethnographic field in Morocco. These Street (Zenqa) Youth Groups (SYG) ${ }^{19}$ in neighbourhoods but there are border spaces between the groups. How these various SYG bridge these border spaces among them and vis-à-vis other people and the state are questions I would try to answer. Listening to mothers, educators and activists talking about this digital generation, hard to control and vulnerable if the state and society did not have durable solutions for an integrative approach. They talked about how neighbourhoods are Ultra-bordered, meaning that each Ultra group defend its territory of influence. Not only territory but

\footnotetext{
${ }^{19}$ I will be using the word Zenqa, literally means Street when referring to the youth groups. It is a word in colloquial Moroccan Arabic (Darija). Zenqa in the collective culture of Moroccans has to do with everything uneducated and not well mannered.
} 
also class issue is fragmenting the Ultras and their Fans; one ultra, the Green Boys belong to the lower middle classes and the Winners to the middle-class football in the city of Casablanca. Space, territory, gender and class are key to understand the formation of youth street groups in Morocco.

The Transgang research is being conducted in a very specific time in the evolution of North African Societies; post-Arab spring Societies are going through structural transformations resulting in profound changes in their social organization, polities and economies. Youth as the primary instigators of the revolts that shook these societies have been impacted deeply by these macro-structural changes. In North African Societies and particularly in Morocco, the youth demography weighs heavily on our society, about $30 \%$ of young people between 19 and 25 years old ${ }^{20}$ and even the demographic projection for the year 2030 shows more demographic weight to this age cohort. This demographic weight has been the major cause of all the (non)movements that happened in Morocco from 2003 up until now. (Non)movements here are based on Bayat's notion where he defines (non)movements as "collective actions of noncollective actors; they embody shared practices of large numbers of ordinary people whose fragmented but similar activities trigger much social change, even though these practices are rarely guided by an ideology or recognizable leaderships in organizations" (Bayat, 2010, p. 14). Cases of non-movements, from the most marginalized groups in Morocco are among the youth of the cities of Casablanca and of Sale. These represent the precarious and advanced forms of marginality. The need for social recognition, survival and social dignity pushed diverse street youth groups to use violence (tcharmil), dress and speak differently (Hard Rock bands) or voice the social ills of society in the public sphere (Ultras).

Departing from the perspective of Transgang beyond criminality paradigm, my contention would be to highlight street youth subculture in Morocco as a form of broadening citizenship practices that resist hegemonic state and mainstream culture from a position of marginality and precariousness. Beyond criminalization approach is an alternative to the practices of the State in criminalizing young groups in Morocco where institutional mediation processes are absent or non-existent. State media and security apparatuses criminalize the young people. So how does marginality produce a counter-culture and make the precariat visible in the public sphere? And how do young street groups in Greater Casablanca and in Morocco produce counter resisting culture to what is considered "acceptable" These are guiding questions to this background paper on YSG in Morocco. They are designed to make links between the developments of banditry and criminality in Morocco and the Transgang approach, which is ideally suited to exploring the various street youth groups that are developing at the margins of gangs.

${ }^{20}$ The official website of the last 2014 national census: http://rgphentableaux.hcp.ma. 


\subsection{Researching (Trans)Gangs in Morocco}

Going back to 2003 moment, which is known as the terrorist attacks on Casablanca, illuminates dark sides of urban violence in modern Morocco with a religiously motivated ideology and a way forward to capture the metamorphoses in urban youth subcultures. 2003 is a turning point in youth informal urban violent expressions. A point of departure for the eruption of urban violence in Morocco because of marginality and poverty; 2003 is also the year of a big scandal in which "the satanic musicians" were imprisonment ${ }^{21}$. Urban advanced marginality produced new marginalized young groups fighting to survive in a context of State retreat from the social sectors during the 80's and the 90's engendering marginalized youths unable to lead a stable life with a job in hand. The lost marginalized youth situation deteriorated and produced new forms of hybrid youth existence at the outskirt of urban spaces, leading a life of marginalization and joblessness.

This situation of advanced marginalization (Wacquant, 2016) produced urban forms of violence in both organized mobilizations or unorganized forms. Between 1983 and 1991, mass violent mobilizations against austerity measures led by students and labour unions served as proof of how advanced marginalization could be a push factor for the precarious groups to revolt and occupy public spaces violently (Rachik, 2016). Resistance from below has always been the case in urban violence. In this context and in order to understand the relationship between the eruption of youth violence and advanced marginality, it is important to shed light on various forms of youth violence in Morocco. My attempt is to present various forms of youth subcultures and its link to the public urban violence, mainly I am using three categories, religiously-motivated, secular-motivated, ethnically-motivated and anarchic -motivated with a focus on street youth groups as defined by the Transgang project, "any meeting of young people, according to the definition of youth that exists in each context, who recognize themselves as a group and who use the public space, physical or virtual, to meet". It is their interactions in society and how they use space, conflict and mediation that would interest us. The groups chosen are, "Tcharmil” groups (El Maaroif \& Belghazi, 2017), the "Ultras", the "Hittistes (young people hanging around, occupying neighbourhoods)", "Sub-Saharians", the "Harragas (illegal migrants)" and the "Treporteurs drivers (tri-cycle motorbikes given to released prisoners as a way to earn an income)", street youth groups in Morocco have known a change in formation, discourses and behaviour. Refreshing the research and the look on youth groups in Morocco is an attempt of this paper and applying the Transgang Continuum where the Moroccan case leans more towards hybrid and playful activities in street groups and the

${ }^{21}$ Two Metal groups were accused of satanic worshipping and were sentenced. Civil society rose and protested to pressure the government to release the young people. Angels of Satan (2007) movie chronicles their story. 
youth cultures created by these groups. The idea of the continuum really captures the complexity and the heterogeneity of these groups in the case of Morocco.

Are these new groups or are they hybrid emerging groups handling and resisting from below the effects of neoliberal state policies, a lack of opportunities, and advanced marginality? The failure to integrate marginalized groups in the neoliberal market is creating frustrations and alienation from society (Cohen, 2004). The old ways of education and intermediation institutions are failing to integrate these young new groups and their counter cultures. Failures of state public policies, retreat of the state from the social sectors - mainly education, health and providing jobs - has dismantled the old social contract and left whole generations alone facing precariousness, marginality, and impoverishment. To support my idea and to argue with the Transgang CP, I quote, "it is meaningful to analyse the violence in peripheral urban spaces as consequence of the advanced marginality processes. With the flexibilization of labour, the loss of social support from Welfare, the loss of spaces of common recognition such as trade unions and the growing individualization, a new violence appears that is expressed from the peripheral groups towards other peripheral groups that normally find themselves in an equal or worse situation (Wacquant, 2008).

To my knowledge, there has been no research conducted on gangs in Morocco previously. However, research on gangs is well established on North Africans in Europe including among the Moroccan diaspora mainly in Western Europe and specifically in the Netherlands and in France. There is research on youth in general, although rare, and there exists research on youth violence in particular (Mernissi, 2015) and on youth in social movements (Rachik, 2016) but not on gangs as it is believed if we take the narrow definition of gangs, gangs do not exist in North Africa or Morocco. Some scholars have associated violence with marginality, unemployment and exclusion of youth in public policies. A dominant paradigm on researching problematic tensions among young people, state and society attempts to explain the tensions in political terms either through the focus on authoritarianism or the focus on de-politicisation. During the 60s, 70s, 80s and 90s in Morocco, young people have always triggered urban violence as a form of opposition to the regime; there was mutual violence from young groups and from the state apparatuses (Rachik, 2016).

I argue that it is important to take into consideration the impact of authoritarianism on Transgang as contexts where these young groups interact is different from the rest of other countries where the research is conducted. There are cases where it is the state that pushed groups to produce violence as a weakening strategy against its opponents (Slymovics, 2005). I will give examples of violent uprisings that were caused by the regime to analyse the importance of the authoritarian nexus and its effect on violence against the state and state reaction using "legitimate" state violence. Marginalized youth in Morocco use in either case the public sphere, Street, or virtual spaces to contest hegemonic discourses of state power and institutional practices of exclusion. Youth 
street groups' expressions and acts are forms of performance of marginality and a social critique of bureaucracies and institutions. In resisting the state apparatuses in creating these street youth groups as public enemies, the groups in my opinion contest this hegemony and create a movement imposing its culture and changing the rules of the game.

This section addresses first the literature on youth cultures in Morocco and then the major protests historically in urban and rural Morocco, with a focus on youth roles of youths and the communication tools utilized to mobilize Moroccan citizens to join the upheavals, resist corruption in the government, and take a stand against the state economic and political policies. The literature on youth cultures in Morocco focuses on how some of these policies tarnished the lives of the working classes in central, urban cities of Casablanca, Fes and Marrakech. Unemployment, alienation and lack of social mobility pushed various youths to urban protests or urban violence. In addition, they widened discrepancies between the major Moroccan regions, which resulted in institutionalized division between the so-called rural, unproductive areas left behind in terms of development plans, and urban quasi-productive Moroccan centres engulfed with migratory increases and systemic crises in the forms of slums, corruption, and extremism.

Ten years after Morocco gained independence from the French colonization in 1956, the country went through significant struggles to establish structural and political legitimacy, both based on internal political institutions and with regard to the international order. This legitimacy was completed after placating ordinary and poor people's dissatisfaction with the manipulations of the central government and "resentment at inadequate integration into the newly independent state" (Walton \& Seddon, 1994, p. 176). The results of shifting from "pre-capitalist to capitalist society" transformed the nature of Moroccan protests from urban to rural settings and transformed the mediation of these waves through significant mass announcement liaisons. According to Edmond Burke (2008): "[I]n cities, as the old social forms and economic structures came to be supplemented by new ones, the old styles of urban protests, which had been linked to the mosque as a gathering point and the "ulama as key spokesmen and intermediaries, gave way to forms of collective action linked to the European working-class movement: strikes, boycotts, and other forms of worker militancy. Most importantly, as portions of the Arab world came under the European domination, experiments with new forms of social identity and political cohesion, notably secular nationalism, began to develop (p. 21).

Resistant affiliations were among the encouraging forces, which determined the background constituencies of each group joining these so-called "IMF riots," "bread riots" and/or "hunger uprisings" (Walton \& Seddon, 1994, p. 171-2). They targeted the growing social class gaps and endemic financial distress. For the aim of broad impact, workers whose economy was relatively established turned to their labour unions to 
direct their grievances assertively against state institutions, whereas skilled practitioners had recourse to civil associations, which backed up their demands widely. On the other hand, political parties are supposed to represent the demands of the citizens in general, but it is because of elitist tendencies and representation that their activists' fail to meet the demands of the needy poor (Walton \& Seddon, 1994, p. 171-2).

The Moroccan protest movement in 2011 (called the 20 February Movement) established Morocco as the first MENA country to have encountered the uprisings as a spontaneous reaction to the insufficient economic and societal resources. They were in reaction to state reductionist policies that resulted in spreading economic crisis. Statepublic workers, such as teachers, who were in turn joined by students and the unemployed, took it to the street and organized strikes scattered all over the urban centres. These deadly clashes among civilians and the military forces resulted in the king announcing a state of emergency and dissolving the parliament (Walton \& Seddon, 1994).

These events were referred to as interval turbulent, dysfunctional and passing moments based on the "wait and see" of popular outrage (Madani \& Belghazi, 2001). Madani explained this era by focusing on unions' expression and parties' activities that were impeded by their structural/internal problems proved to be incapable of resolving the status-quo (p. 170). This biased system made it applicable to reproduce the similar structures of dysfunction. A country like Morocco, then, Madani \& Belghazi (2001) describes that situation as a combination between a delayed change, which was transforming, and a no-existent hindrance to its transformation because that change is real (Ibid.). These turbulences were only referred to by the regime once their consequences had been felt and only once the outcomes transform into events and/ or revolts (ibid).

Access to social media and relatively high quality education coupled with socioeconomic difficulties resulted in various emerging social strata, which sought better conditions for fulfilment. This reality caused diverse social burdens as demanding better incomes and services in education and health care particularly in the urban zones. The youth of the working classes made their involvement inevitable due to their search for stable social norms and practices, especially after being able to access and compare their conditions to global experiences (Cohen, 2004). Other consequences of this access were related to massive migratory moves that reinforced the gap and the emergence of neo-proletariat concerning contradictory realities in slum neighbourhoods. In addition, the crisis of the unemployed graduates exposed direct product of the existing mismatch between the education opportunities and labour market. Consecutively, strikes caused by salaried workers complicated the phenomenon of protests in the modern era of Morocco. These complications encouraged a wide range of constituencies to join artists, high school students, slum inhabitants (embedded within more organized associations), brotherhoods, intellectual figures, universities, parties and labour unions who had 
previously made up the movement. New reaction strategies were implemented based on riots, protests and rebellions to evade the sophisticated state repression and spread their calls creatively based on various communiqués.

Another interesting case is the Casablanca riots of 1981. As we have seen, the Moroccan people were among the first inhabitants of the Middle East and North Africa to react against the policies of austerity implemented by the state as economic reforms in the early periods of the new state in 1965. Later, the protests and riots of discomfort re-emerged in the 1980s following the imposition of structural adjustment programs by the World Bank (WB) and the International Monetary Fund (IMF). To begin, the earliest period mentioned above resulted in one of the bloody confrontations between the makhzen and affiliates of the labour unions in what came to be known as the Casablanca bloody March of 1965. Characterized as one of the leading economic cities in Morocco, and as an industrial site inside the country, Casablanca became the major destination of internal migratory workers. The latter marched against the threat that was directed towards the bread prices and the high costs of social services. Hence, the claims were significantly targeting the economy and the improvement of individual access to food and basic services.

In their contribution to Free Markets and Food Riots: The Politics of Global Adjustment, Walton and Seddon investigated the various claims and backgrounds behind the revolts that emerged in the urban Middle Eastern areas and addressed the crucial participants in these events. They stated that: "Given that the urban poor are most dependent on basic goods and services, it is not surprising that they are universally involved. It is also relevant; however, that they constitute the sections of urban society with the least support from, and representation by, organized groups and institutions, and thus has few alternative means of expressing their grievances" (Walton \& Seddon, 1994).

These policies resulted in increased local migratory moves toward big industrial cities. However, many workers encountered higher prices, discrepancies in education enrolment, and livestock ruins that peasant in rural areas suffered from. Therefore, solid protest movement was formed that merged its influence in urban as well as rural areas and managed to organize a more extensive rallying than demonstrations of last 16-years. Some neighbourhoods chosen to conduct fieldwork are spaces where the children of these first dwellers are the ones concerned with the Transgang approach. On June 20th, the Casablanca-based Labour Union of the Trade (UMT) and the Democratic Trade Confederation (CDT) called for comprehensive demonstrations across the country. As a result, "popular discontent erupted in the streets of Casablanca [causing] 12 pharmacies, 23 local branches of banks, 75 private vehicles, 47 buses and two factories [to be] damaged, the Moroccan government claimed."22 Such struggles joined by various

\footnotetext{
${ }^{22}$ http://www.multinationalmonitor.org/hyper/issues/1981/08/imf.html accessed on March 17, 2015.
} 
groups like the students helped to developed a sense of activism that was maintained at schools. Casablanca as a site of turbulent protests will be researched so that the metamorphoses of urban spaces and streets into border spaces that show dissent and social resistance to the failure of State repression strategies or domestication can be understood.

Behind all these cases - and especially the urban ones - are reactions from new groups with different ideology to the regime that want to increase their visibility through violence. This form of legitimate violence was confronted by state violence and gave way to mistrust among the state institutions and the various political groups who suffered from assassination, arbitrary detention and disappearances (Slymovics, 2005). The 1991 bloody students and labour unions general strike is a case in point. The Marxist students who were caught by the police were fighting against the Islamist students inside Fez university campus were portrayed on TV as members of gangs. In fact, it was one of the youth groups fragmented along ideological lines inside Moroccan universities using violence against their opponents.

The cases of urban, ideologically-motivated, (student) union led protests and riots show the importance of youths as a force in these moments. Moreover, it would illuminate our new research within the framework of Transgang on the new SYG in Casablanca. What has changed? Who are the new actors? And how social resistance happens now? All these questions will lead us to rethink notions of youth and street and hence contribute to the Transgang paradigm. A fresh look at these forms of urban groups having recourse to violence on an ideologically-motivated basis is very interesting from the Transgang perspective. The youth in urban spaces in Morocco showed resistance to advanced marginality. The broadened definition of Transgang adopted by the current project makes us think of the various street groups as a "transgang" based on their behaviour, language and rituals.

My conception of these street youth groups in Morocco follows the definition of the Transgang concept paper:

A (transnational) gang is an interstitial group originally formed spontaneously and later integrated through conflict. It is characterized by the following type of behavior: face-to-face (and online) encounters, fights (and fun), movements through space as if it was a unit (and search for intimate spaces), conflicts (and alliances) with similar groups and planning. The result of this collective behavior is the development of a tradition, a non-reflexive internal structure (and the establishment of rules to regulate exchanges with other gangs and institutions), esprit-de-corps, moral solidarity, group consciousness and an identity link territorial (already in their homeland, in their new land or in cyberspace) (Feixa et al., 2019). 
In Morocco and in the rest of North Africa, we use the word "Ishaba". Ishabas are associated to drug dealings, robbery and theft. The concept of "Ishaba" is a relatively recent invention. Historically, it was the notion of "road robbery" that was used to denote people who rob others by blocking roads, "herd thieves" people who steal a village sheep or goats and weekly Markets thieves. However, there existed also other terms, like "Zettata", meaning strong men who are hired to escort trades men in their roads to various villages and cities in medieval Morocco. Interestingly, during the Arab spring revolts, social movements used the notion of Ishaba to denote the ruling regimes in Egypt, Syria, Yemen, Libya and Algeria now. The notion of Ishaba is also used in guerrilla war, mainly to talk about the Rif Resistance against the Spanish Armada in the 20's describing how the leader of the Rif Abdelkarim el Khattabi used the Ishaba warfare strategies to defeat the Spanish army. In 2017, the leader of the Rif Hirak, Nasser Zefzafi used the notion of Ishaba to denounce the Moroccan government in his famous saying, "Are you a government or Ishaba "gang"?". Meaning that the notion of Gang/Ishaba has evolved and used differently and in various social and political jargons depending on the relationships among those in conflict.

\subsection{Beyond Violence: Empowerment, Conflict and Mediation in Morocco}

Generally speaking, researchers and policy makers claim that there is the absence of mediation strategies in matters related to YSG in Morocco instead there is more the repression approach (enemy creation approach and criminalization approach) or "empowerment" approach through social intervention, service-delivery or assistance (direct job provision in public sector, human development policies, affordable housing and vocational schooling). The social intervention/assistance approach is to avoid urban violence uprisings against liberalized market measures by the state demonstrate the fear from the urban proletariat. Urban unrest by the marginalized and precarious groups has always been destabilizing in the MENA countries and regimes react either through repression or co-optation. It is very important to have a historical look at cases of urban violence and its consequences on the formation of youth groups and their resistance to advanced marginality. Within the framework of popular response to the government's measures to reduce public expenditures, which started in early 1970 and lasted to early 1990, Morocco was the first "riots-emitting" country in the MENA region that confronted repressive state strategies. In the form of marches, street demonstrations and popular unrest, immediate, opposing reactions were spread among the population against the rises in daily expenditures and declines in citizens' capabilities to provide for food, especially in urban poor slums. The poor segments, unemployed graduates, students (males and females), and the informal workers supported by labour unions, initiated these street demonstrations across the country. They took place in 1965, 1978, 1981, 1984, and 1990 (Walton \& Seddon, 1994, p. 171-2). 
In Morocco, prior to the explosion of the conflict and the emergence of the youth street group in conflict with the state or society, one could talk of a situation of 'la-hirak', what Asef Bayat calls 'non-movement', where the likes of Tcharmil young people, Harragas (young people who cross the Mediterranean sea to Europe), Sub Saharan irregular migrants, Treporteurs drivers, and university students groups used to go about their informal 'quiet encroachment'. That is to say, the 'non-collective but prolonged direct actions of dispersed individuals and families to acquire the basic necessities of their lives' (2013, p. 35) like numerous marginalized others. But once they are aggressed by state authorities, collective solidary protests follow. This is the moment 'when a common threat turns the subjects' passive networks into active communication an organized resistance'. (2013, p. 24). (El Maarouf \& Belghazi, 2018). Precariousness and marginality can be key push factors towards criminality. However, the 'quiet encroachment" moment, I argue, is a moment of mediation before violence is born. So how can we avoid the "movement" by "non-movement", or how we understand/capture the moment of movement in its embryonic stage before we express shock as to why violence is here and then we have no explanation.

In this fieldwork research, I will try to understand the role of mediators in conflict resolution when it comes to YSG in Morocco. Who are allowed to play this role? When and where? And why are mediation efforts sometimes successful and other times fail. Following this, and based on the Transgang framework on cultural and co-mediation, I will give examples of social movements where mediation has worked in either coopting the leaders of the movement, weakening the movement, or producing policies that tackle the issues at hand. I have worked on three cases that were mostly led by marginalized youth who used urban or virtual space as forms of resistance to state policies. Recent examples have also demonstrated the workings of the logic of mediation in Morocco. For instance, during the 2018 contractual teachers' strikes, faculty of medicine acted in sympathy with staff members and the Rif Hirak ${ }^{23}$. In urban conflicts, where movements and state actors are involved, we are witnessing mistrust and lack of efficient mediation. Institutional mediation is an utter failure in all these cases.

These three cases - the unemployed graduates' movement, the 2016 Rif Hirak and the 2018 online boycott - represent examples of how mediation works in Morocco and have implications for Transgang fieldwork. These recent social movements should be understood as "post-Arab Spring" realisations of societal resistance to newauthoritarianism but also an expression of disillusionments with politics, policies and lack of opportunities. Such conditions have let to the emergence of a social movement culture by a group of young people, ritualizing through public space invasion, chants

${ }^{23}$ The Rif Hirak is a citywide protest by a group of young people in the Rif region in the city of El Hoceima in 2016/2017 after the death of a fishmonger. The Movement attracted attention worldwide because it was peaceful and had social grievances. 
and slogans, demands and creating a durable culture of "hyper activism". The cases I present sometimes have led to violence in the public sphere, mainly the Rif Hirak, the unemployed movement and the Amazigh movement. It is important to situate the research in a broader perspective, looking at the new social movements in Morocco and their characteristics and looking at the new cultures that young generations produce as forms of cultural resistances to the mainstream/state conformist cultures. These young groups have formed a solidarity culture based on conflict and then invading the public spaces. These cases show also the mediation side of conflict, mainly when government or other actors interfere in search for conflict resolution mechanisms.

\subsubsection{The Unemployed University Graduates Groups: Joblessness and precariousness}

The unemployed young graduates are organized YSG movements occupying the public space to protest the lack of stable jobs. It is an example of advanced marginalization. Most young people who join the movement are from poor families and marginal cities and study at the public open universities. Because of their big numbers, institutional forms of mediation worked successfully between the movement and the State.

The Moroccan National Association of Unemployed Graduates (ANCDM) founded in 1991 assembles all graduates with a baccalauréat or a higher diploma consists of some 100 local sections and 3000 members. Today, the ANCDM is not the only actor demanding jobs. From the mid-1990s onwards, different groups of "Diplomés de Troisieme cycle" (Masters and PhDs), engineers and graduates with a handicap appeared on stage (Bogaert \& Emperador, 2011) in various groups called "tansikiyat". In the 90s, the movement was very active in different local branches, organizing sit-ins, hunger strikes and protests; with the first government of Alternance in 1998, the movement started to mobilize its activists in Rabat, the Capital of Morocco. The unemployed argued that Morocco was still a very centralized system and any employment decisions should emanate from Rabat. The movement intensified during moments of engouement of their activism, mainly during the democratic opening moments from 1999 until the start of the Arab Spring. They mobilized strategic discourses of human rights to make their cause appealing to different actors. The battle from 1999 until now has tended to take place in the open space of the Parliament in the capital, Rabat. Mohamed V Avenue has become a symbolic and historical place for the movement. The ANCDM is a national association that is legally recognised. They have branches all over Morocco even in small towns and villages. There is the national coordination in Rabat and the general Assemblies nationally and locally are the structures taking decisions. The founders were mainly from the radical left. These are activists who graduated with BAs in the late $80 \mathrm{~s}$ and started activism to be recruited in the public sector. 
The discourses of the unemployed young people reveal ambivalent strategies of "public persuasion" and "sympathy". The unemployed graduates campaigned for jobs in the public sector with no quota, no exams and wanted to be paid in accordance with their degrees. Their ideas were coloured by a universal discourse of human rights, thereby exploiting an openness towards democratisation and using the 2011 social protests to their advantages. Their actions disclose an urgent need to reform education and to change the design and implementation of public policies, and to frame "reforms" in a discourse and strategy that considers social cohesion and well-being of individuals. The discourse of the unemployed graduates put several pressures on successive governments to find solutions to unemployment. The first transformative moment was the massive recruitment of 2007 by the Istiqlal party who was leading the 2007 government and this second transformative moment was the refusal of the 2011 government led by the PJD of the direct recruitment. Both moments pushed the unemployed groups to be very active in street protests demanding jobs.

\subsubsection{The 2016 Rif Hirak: Marginalization and Incarceration}

The 2016 social movement known as the Rif Hirak that occurred in the North of Morocco triggered by the death of a fisher monger in a garbage truck, sparking a movement calling for social and economic and cultural reforms. The Rif movement is an example of the linkages of both advanced marginalization and repressive incarceration policies (according to Waquant) in one territory; the Rif is a marginal territory where smuggling and cannabis cultivation is part of the discourse that the criminalization process is built on. Young people work either in cannabis plantations, smuggling goods or migration. The rise of this precarious population created a new social movement that erupted after the $20^{\text {th }}$ February movement of 2011 . It has specific objectives, leadership, strategies and tactics. The objectives are mainly economic and but have more recently become political and cultural. The movement calls for socioeconomic projects in the Rif region. From the beginning, Nasser Zefzafi emerged as the movement's charismatic leader. The strategies were mainly street protests designed to put pressure on the government and the king.

The Hirak became not only national but transnational with the Moroccan diaspora expressed solidarity with the Hirak. Repression and heavy/violent interventions from police groups brought an end the momentum of the Hirak and its main leaders were imprisoned. Al Hoceima is in the northern Rif region. It is ethnically Berber and people claim to have been marginalised for a long time. Thousands of Moroccans marched in the northern town of Al-Hoceima to protest against injustice and corruption on Thursday May the 18, seven months after a fishmonger was crushed inside a garbage truck there while trying to retrieve fish confiscated by the police. Waving banners proclaiming "Are you a government or a gang?" and local protest flags, the march made its way peacefully through the center of Al-Hoceima, packing the main square under the 
watch of police and gendarmerie checkpoints. The incident sparked outrage against "hogra", a colloquial Darrija Arabic term for deprivation of dignity.

Right from the beginning, "live messenger" was used to cover the movement and the speeches of the leaders, mainly Nasser Zefzafi. As crowds gathered in one square, Nasser Zefzafi, leader of "Hirak" rallied protesters over a megaphone. He has been the target of attacks in pro-palace media, who have accused him of being a separatist for the Rif region. The anger over Fikri's death, which shocked even staunch supporters of the palace, was a reminder of the broader resentment at the establishment over joblessness and the gap between rich and poor that partly drove the 2011 pro-democracy protests. "Fikri's death woke the Rif up from a deep sleep", said Rabih Boushaaoul, a member of the movement. One of the main strategies used by the leaders of the movement and mainly Nasser Zefzafi was the recovering of the golden past of the Rif leader Abdelkarim Al Khattabi, the nationalist leader against Spanish colonialism. This recreation of the past and its linking to the present social justice movements fuelled the needed energy for the activists and the mob to join the Hirak.

The main cause of the movement was the failure of development interventions to deliver material improvements in the region. On October 17, 2015, the province benefited from a very important development program launched by King Mohammed VI, Al-Hoceima Manarat Al Moutawassit. 6.5 MAD billion is mobilized to provide the province and especially the city of $\mathrm{Al}$ Hoceima large equipment to enhance its attractiveness. When the crisis broke out in October 2016, the economic and social situation of Al Hoceima, with one of the lowest local development indexes, made it easy for discontent and the sensation of abandonment among the population to emerge in the form of social protest. Thus, the lack of opportunities for a population that is mainly young and of working age $(64.1 \%)$, with a rate of unemployment of $16.3 \%$ (above the national average), and with $25.1 \%$ dependent on family assistance, meant that the death of Fikri became a grievance for the whole of local society and that the protests were widely supported.

The Hirak of the Rif epitomized a moment of confrontation between the central state and the region of the Rif, bringing back memories of dissidence from the golden past of the "Rif Republic. Institutionalized mediation failed. Some associations and political parties tried "cultural mediation" in the form of tribal interventions or family mediations but in vain; however, The Rif movement demonstrated that small urban micro new social movements can destabilize the central state and can create its own legitimacy and its own momentum away from formal politics. The young people of the Rif who suffer from poverty, marginalization and lack of opportunities have invested the street and formed a movement that was repressed and most leaders were incarcerated. 


\subsubsection{The Moroccan Boycott Movement of 2018: A Virtual Non-movement}

The 2018, a Moroccan Boycott Movement (Moukatiouan) started through Facebook and Whatsapp and called for Moroccans to boycott the products of three big companies, mainly "Centrale Danone", "Sidi Ali" and "Afriquia Gas Station". The boycott was a success through social media and triggered debates and reactions from government and from the three concerned companies. The online/virtual boycott movement imposed its logic on the political and government actors. The online movement started in 2018 and with no known leadership. It started in social media and triggered by online activism after the heavy repression of Moroccan police against the Rif Hirak and other social movements between 20016 and 2018. There is also the idea of the disillusionment of the middle class after the 2011 constitutional reforms and the failures of the 2011 government policies to impact the wellbeing of the middle class in Morocco. Moroccans boycotted two big national companies (Sidi Ali and Afriquia Gas station) and an international (Centrale Danone) one. It was a boycott against the monopoly of economy and politics by an elite enjoying its connections with the palace.

Since the boycott was online, it created a new form of social activism in Morocco. For the first time of the history of social movements in Morocco that we are witnessing an online form of (non) social movement using social media to escape repression and imprisonment. In this sense, there is a clear need to talk about an online civil society/public sphere activism born out of this movement. This virtual civil society was open to every citizen joining the movement by boycotting these products and then participating actively or passively in the online discussions in Facebook, Whatsapp and twitter. The political context prior to 2018 was very indicative of this campaign.

Social media outlets ran campaigns under the hashtags of "Let It Spoil" and "Say No to High Prices". By late May 2018, the scope of the boycott extended to fish markets due to high prices and hashtags of "Let it rot" and "Let it swim" went viral. The strategic use of social media was an effective tool in the boycott campaign as it makes it diffuse and almost impossible to crack down, as those behind the campaign have remained anonymous, stayed off the streets and been selective in their targets. When the campaign was launched in April, the hashtag "Let It Spoil" went viral on social media, especially on Facebook. Several pages on Facebook were created, sometimes duplicating the same content. Social media was used for mobilization as an effective strategy to make the boycott a success.

The boycott seems to be a youth-driven collective action as almost 93 per cent of people who were aware of the boycott campaign were reported as being between 15 and 24 according to a survey commissioned by the Moroccan magazine l'Economiste. 70 per cent within this category actively participated in the boycott. The number falls to 31 per cent for the older people ( +55 years old). These results can be explained by the strong mobilization of the youth via various social media platforms in the same is the most affected by current politics. They are the most affected category of citizens by 
unemployment, which has turned many of them into serving as the driving force in different forms of activisms. As the youth are heavily connected in Morocco through social Media, about 20 million Moroccans use Internet and about 12 million are on Facebook. The number of Mobile phones users exceeds the number of population; it is about 44 million users of $4 \mathrm{G}$ mobile smart phones. If we consider these youth as consumers, so these critical consumers use this online activism as a strategy for social change.

The instigators of the boycott campaign in Morocco remain anonymous and online. There is a metamorphosis from the invasion of the public sphere to an online/virtual public sphere. The role of the state, political parties and labour unions in the beginning was as if there is nothing going on. What is interesting too is that the boycott was not against the Monarchy or the government but against the symbols of rentier wealth gathering. It is against the lack of distance between wealth and politics and it is more about political connectedness.

\section{3 (Trans)Gangs in Greater Casablanca, Rabat and Sale}

SYG in those cities are invading physical and virtual spaces to impose their sub-culture and resist their demonization and hence produce a culture of SYG. The Transgangs, mainly the Tcharmil groups and the Ultras have come out from advanced marginality, from marginalized neighbourhoods into visibility as groups in city centres and in virtual spaces. How are they producing their cultures? How do they sustain it? And how are they crossing the border space between advanced marginality and social visibility? These are the questions we try to answer in this section.

Our recent history in Morocco showed how the state could play the role of a repressive regime and then appropriate the culture after conflict and mediation happened. This happened exactly with the famous Satanic Hard Rock Bands. On 13 February 2003, the Moroccan state news agency reported the arrest of a dozen "abadat a-Shaytan" ('worshippers of Satan') in Casablanca. It was soon revealed that the so-called Satanists were nine leaders of metal bands and five fans of their musical bands Reborn, Killer Zone, Nekros and Infected Brain. This is the first time in history that Moroccans were accused of worshipping Satan. On 6 March, a court in Casablanca charged the 14 'worshippers of Satan', aged 20-35, with inciting 'moral degradation, debauchery and acts against the Islamic religion' (Garçon 2003). During the politically charged trial, they were asked damning questions like, 'Why do you cut the throats of cats and drink their blood?' One of the incriminated youth, Nabyl Guennouni, recalls: 'The entire case against us was built on CDs, T-shirts, posters ripped from our bedroom walls and generic "satanic" pictures pulled from the internet'. The sentences ranged between three months and one year behind bars. Backed by human rights organizations and the L'Boulevard generation, outraged youth staged protests in Casablanca and held a rock concert in front of the parliament building in Rabat. The 14 middle-class youth were 
acquitted on appeal in April 2003. The heavy metal case showed this youth street group culture in greater Casablanca, Rabat and Sale where young people escape the conformism of societal values, the harsh neoliberal measures of their governments and the lack of opportunities in their social classes. Rabat city centre spots nowadays is coloured with various youth street performances, imposing their music, styles and language on a society that has been showing its back to them.

This case shows exactly the focus of the fieldwork in Greater Casablanca, including the city of Sale are youth street groups in a Transgang situation. The satanic event turned into a national yearly concert called L'Boulvard ${ }^{24}$ where young people gather to celebrate their type of music, performances and the culture they fought for. They also receive a yearly royal cheque from Mohamed VI to organize the festival. The case demonstrates how SYG produced a culture alien to the mainstream, permissible public space culture as a form of resistance to the mainstream and as a way to have a voice in society. These street musicians defied society's norms and officially permitted cultural production. Going through conflict with the state and society and then culminating in a form of a successful mediation that empowered these types of SYG.

Illustration 9: A group of young people gathering to celebrate their bands in Casablanca L'boulevard festival 2018

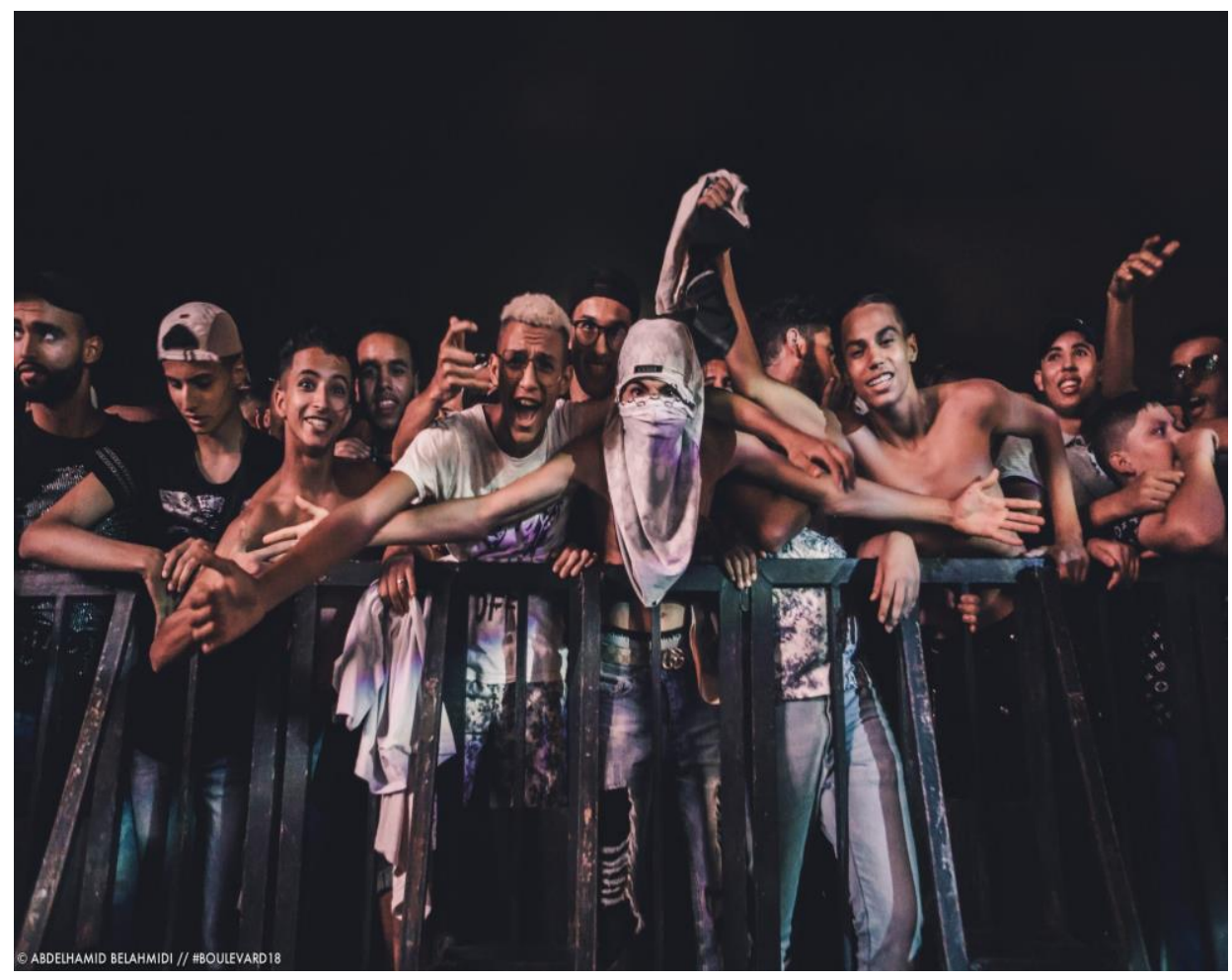

Source: Facebook page of these groups

${ }^{24}$ http://boulevard.ma. 
The second group I am interested in is the group called Tcharmil ${ }^{25}$. They are perceived as young, delinquent, depressed school "drop-outs", jobless, marginalised, as well as aggressive lifestyle of the rich. The way of life they have chosen, according to Ahmed Ghayet (Mernissi, 2015), distances them from their sordid reality and everyday life, which is made even unliveable by contempt, exclusion and rejection. Their lives reveal the failure of the country's educational system and limits of its youth policies. Their experiences are shaped by the external signs of ostentation and opulence that some people hit them in the face with, generating in them both vengefulness and hate (2015, 89).

\section{Illustration 10: Group of Tcharmil group}

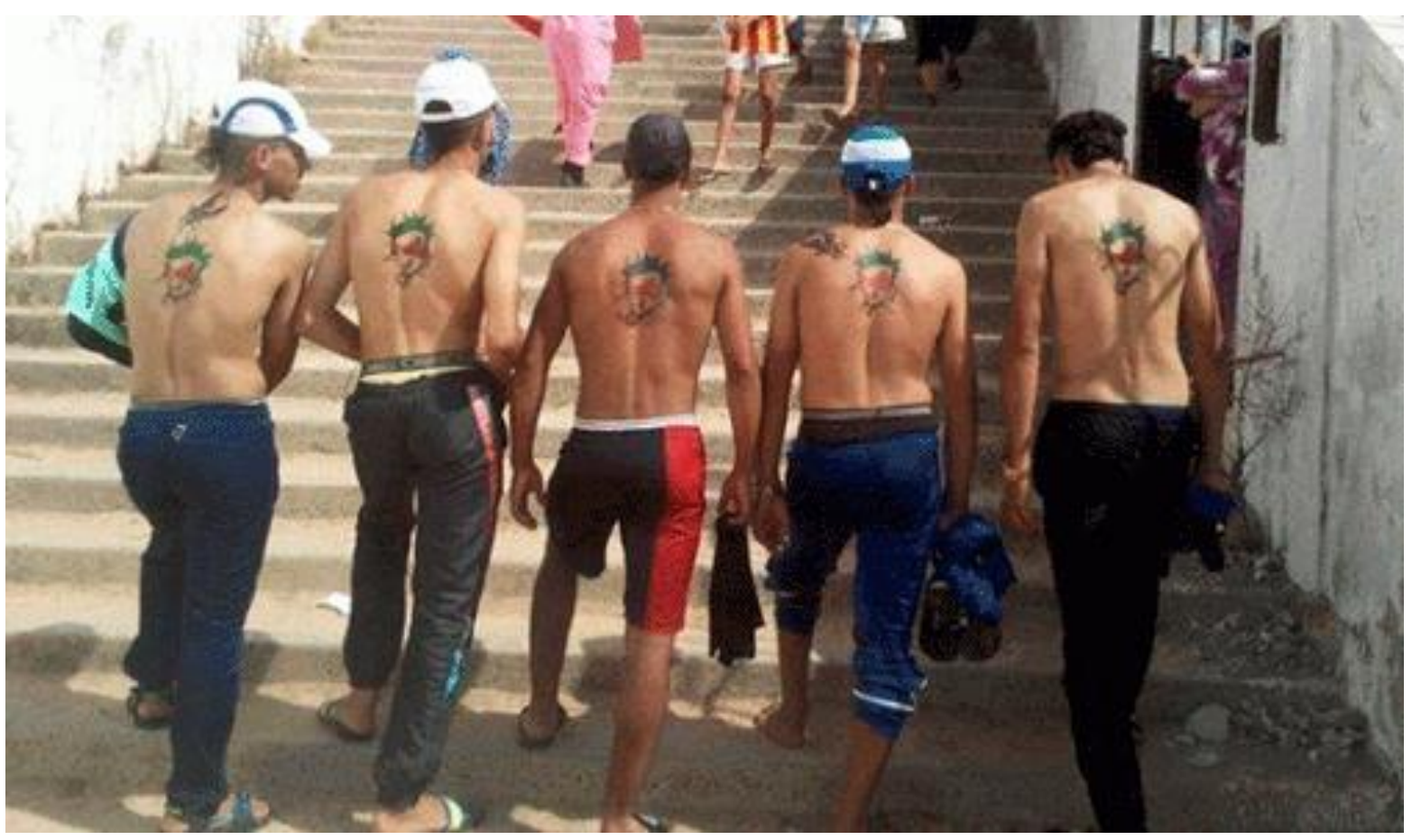

Source: Facebook page of these groups

Due to such suppressive and violent social inequality, they tend to settle accounts by way of the variegated modes of violence available to them. Unlike the traditional image of the thug, who gets born in the street and dies in the street, the mcharmal's life is divided between the street and cyberspace. Hence, they expand their acts of violence by engaging in acts of cyber intimidation and criminality. A web-influencer notes that the mcharmal think that the virtual world swarms with the wealthy, the intellectual, the degree holder, and the poor. Acting within the framework of the last category, the mcharmal runs a counter-show. He avails himself of the social network to boast the

${ }^{25}$ The only book devoted to this groups was edited by the late Fatema Mernissi under the title: Reflextions sur la "violence" des jeunes: Tcharmil in 2015. 
things he can easily accomplish: knock off accessories and a bunch of violent methods. Ahmed Ghayet reminds us that their methods do not necessarily pigeonhole them as originally criminal, because for him this is just a fit of display by a bragging youth who have no idols, a social category which adopts some clothing codes, a language, a haircut, and lives vicariously (Mernissi, 2015). Since the social media is both a real mask for those who want to hide, and enormous zoom for those who want to show themselves, mcharmlin employ the internet as the most efficient instrument of propaganda with which they try to negotiate their marginality. The police crackdown on these groups made them disappear from the public sphere though their styles were adopted by some young people now mainly hairstyles, dresses and group invasion of streets.

In both cases, the street music performers and Tacharmil, the "Zanqa", Street, is the locus of the event, the movement or non-movement performs against all odds in a zanqa rules imposing its own ways of doing social behaviour in cities suffering from uneven development and lack of spaces of freedom and creativity. Zanqa is the space of the transnational, virtual real Transgang culture in a lived manner. Zanqa is the border space where Transgangs resist norms, change culture and impose acceptance. Zanqa as a border space between normalcy and conflict; it is where mediation and empowerment takes place.

The Ultras is the third group this research would cover. Ultras in Casablanca, Rabat and in Sale are groups of football teams supporters associating to express their support to their team in the streets before matches start, inside the stadiums and after matches are done with sometimes violence and vandalism brake at the outskirts of the stadiums.

Illustration 11: One of the Raja's Ultras, the Green Boys, Tifo

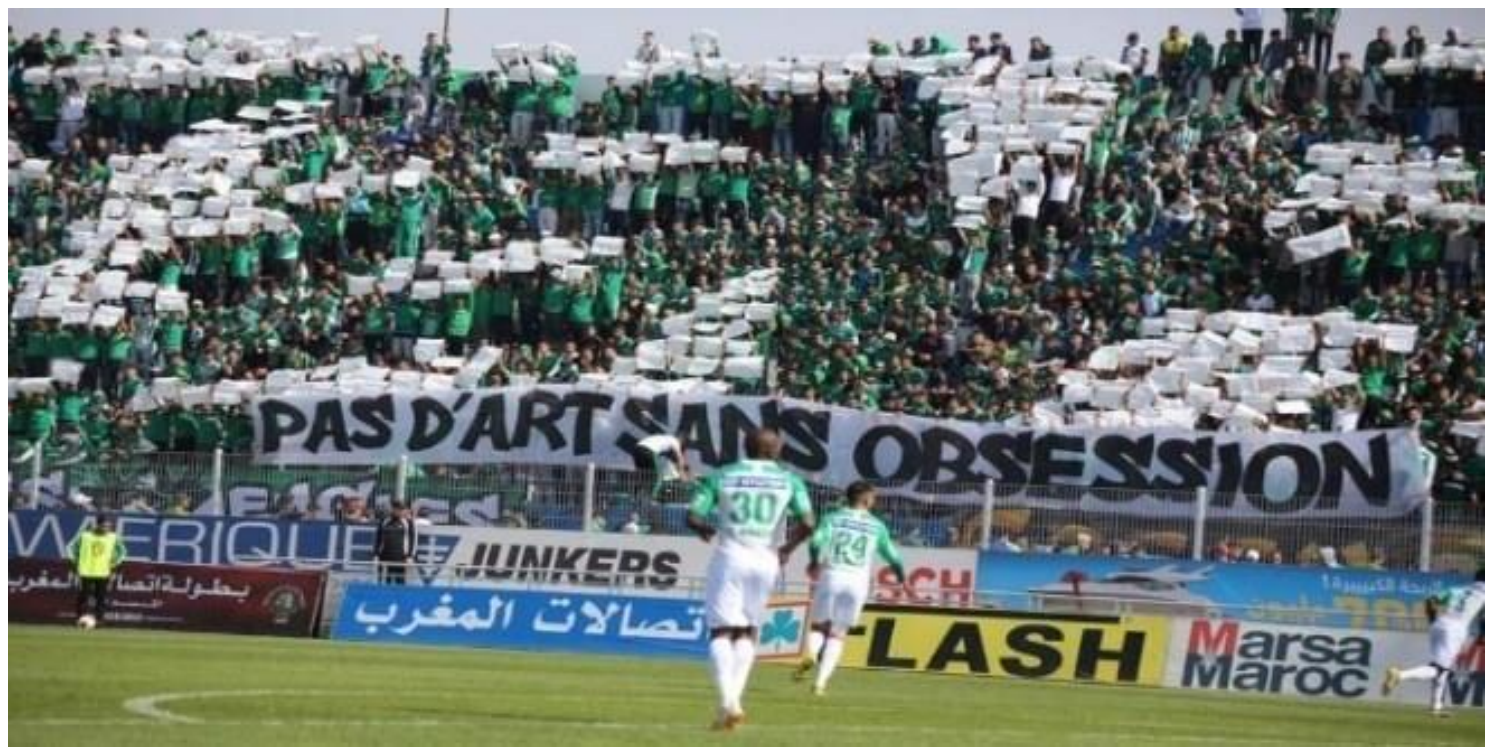

Source: Facebook page of The Ultra 
The ultras first fan clubs were founded in Casablanca in 2005, the Green Boys and the winners of the two successive football teams of Casablanca Raja and Wydad. The only book devoted to the Ultras and published recently in 2018 under the title: Des Ultras Dans La Ville: Etude Sociologique sur un Aspect de la Violence Urbaine by Abderrahim Bourkia is devoted to the sociological aspects of this urban form of violence. The book describes the various groups, their structures, organizations, supporters, slogans and chants. What is interesting is how young the people are who join the groups. Is joining based on where you live? Or the team that you like? Is it class-based or status-based? The most important aspect is the youth culture they create through movement in space, creative street arts and creative slogans and chants and tifos; but also that how it is transnational and virtual, and what are the spaces they invade for their subculture to survive, produce an identity and be accepted by society as a whole, how the process of negotiation is done with State institutions? Why the Ultras lately started to have political views on national and international issues, is it a change in direction or is it the birth of a new social movement away from the stereotypical images glued to the Ultras.

In the Ultras SYG movement, both Zanqa and Stadium are the border spaces of resistance, conflict and mediation. Either through riots and violence or social activism, Ultras imposed their rhythm of social resistance to advanced marginality by bringing social ills to these border spaces through chants, violence and vandalism or through tifos. The cases show clearly the intertwined links among advanced marginality, border space and SYG in Morocco and how they produce a new culture that both State and Society needs to rethink through mediation and empowerment.

\subsection{Conclusions}

After this historical, epistemological and methodological background on the core case of Morocco, the background paper highlights the importance of linking the interplay among history, politics and neoliberal state policies to the metamorphoses happening in Morocco and affecting the young generation. The young groups expressions in the public sphere, whether violent, creative or funny is laden with meanings and knowledge production on the new social fabric in the neoliberal Morocco. Through ethnographic fieldwork, the research will focus on the formations of the new young cultures out of conflict situations and out of social frustrations and disillusionments. The ethnographic work would be done with three young street groups in the Cities of Casablanca, Rabat and Sale and with three mediation NGOs working with some of these young groups. The NGOs chosen are LKWAN Association working with Street musicians in Rabat, IDMAJ neighbourhood Association working in Casablanca and Shemsy Circus in Sale.

This background paper (BP) presented the case of Youth Street Groups (SYG) in Morocco within the framework of the Transgang project. The paper was organized as follows. The introduction remade the objectives of the BP. The second part was devoted 
to researching transgangs in Morocco, which presented the state of the art but exclusively related to Morocco. The third part was dedicated to empowerment, conflict and mediation. It is necessary to discuss the advanced marginality of groups of people in the country.

The discussion of Transgangs in Morocco attempted to apply the Transgang methodology to Rabat case with its implications of advanced marginality in Morocco in the formation of YSG. The fifth presented the Legal Framework. The BP and in order to situate the Moroccan case highlighted the main SYG selected as a local researcher to do fieldwork on within the Transgang framework on advanced marginality, street youth and mediation experiences. In this context, the research would take into consideration the evolution from "Satanic" Hard Rock bands, to "Charmil", to the "Ultras"; street violence is a sign of the visibility of these YSG.

The core case of Morocco focuses on street as locus of youth violence, mediation and visibility and how Zanqa produced a sub-culture of various group through behaviour, dress and discourses and produced an impact on society; the BP presented a historical description of cases where conflict was between various actors, mainly social actors and the Moroccan State to show the specificity of the Moroccan case and the perspective in approaching the Transgang project based on the transgang framework. The BP explored the various lexicons used to describe street youth groups and how they are debated culturally in our society. The BP focused on specific cases of social movements founded by young people through conflict with the state, producing either conflict or violence in the public sphere in the virtual sphere. More importantly, the BP focused on the cases chosen to research in Morocco; a description of three young street groups is given and these are the Street Music performers, Tcharmil groups and the Ultras. 


\subsection{References}

Bayat, A., \& Herrera, L. (2010). Being Young and Muslim. Oxford \& New York: Oxford University Press. https://doi.org/10.1093/acprof:oso/9780195369212.001.0001

Bayat, A. (2013) Life as Politics. How Ordinary People Change the Middle East, Second Edition. Stanford: Stanford University Press.

Bourdieu, P. and Wacquant, L. (1992). An Invitation to Reflexive Sociology. Chicago: University of Chicago press.

Bogaert, K. and Emperador, M. (2011). "Imagining the State through Social Protest: State Reformation and the Mobilizations of Unemployed Graduates in Morocco". Mediterranean Politics Volume 16, Issue 2.

Burke E. (2008) "Theorizing the Histories of Colonialism and Nationalism in the Arab Maghrib". In: Ahmida A.A. (eds) Beyond Colonialism and Nationalism in the Maghrib. Palgrave Macmillan, New York.

Cohen, S. (2004). Morocco: Globalization and its Consequences. New York: Routledge.

El Maaroif, M. \& Belghazi, T. (2017). "The Urban and Virtual Rhetoric of Tcharmil: Display, Violence and Resistance", The International Journal of North African Studies.

Feixa, C. (Dir), Sánchez-García, J. (Coord). (2019). The (Trans) Gang: Notes and Queries on Youth Street Groups Research. TRANSGANG Working Papers 2.1. Barcelona: Universitat Pompeu Fabra \& European Research Council. Doi: http://dx.doi.org/10.31009/transgang.2019.wp02.1

Garçon, J. (2003). Les rabat-joie du Maroc and roll. Libération. http://www.liberation.fr/monde/0101467882-les-rabat-joie-du-maroc-and-roll

Hegasy, S. (2007). "Young Authority: Quantitative and Qualitative Insights into Youth, Youth Culture, and State Power in Contemporary Morocco", International Journal of North African Studies, Vol. No. 1, March 2007.

Madani M., Belghazi T., 2001, Collective action in Morocco. From resource mobilization to speaking out , Rabat, Publications of the Faculty of Letters and Human Sciences.

Mernissi, F. (1997). 'Social Capital in Action: The Case of the Ait Iktel Village Association'. In Voices from Marrakech: Towards Competitive and Caring Societies in the Middle East and North Africa. Ishac Diwan, and karen sirker (eds.). Washington, D.C: The World Bank.

Mernissi, F. (2015) Reflextions sur la “violence” des jeunes: Tcharmil. Casablanca: Editions du Fenec.

Rachik, A. (2016).bLa Societe Contre L'Etat: Mouvements Sociaux et Strategies de la Rue. Editions La Croise des Chamins.

Roque, M. (2004). La Société Civile au Maroc: L'émergence de Nouveaux Acteurs de Développement. Paris : Publisud- IEMED- SOCHEPRESS. 
Slyomovics, S. (2005). The Performance of Human Rights in Morocco, Pennsylvania Studies in Human Rights, Philadelphia: University of Pennsylvania Press.

Wacquant, L. (2008). Urban outcasts: a comparative sociology of advanced marginality. New York: Polity.

Wacquant, L. (2016). Revisiting Territories of Relegation: Class, ethnicity and state in the making of advanced marginality. Urban Studies, Vol. 53(6) 1077-1088.

Walton, J. K. and Seddon, D. (1994) Free Markets and Food Riots: The Politics of Global Adjustment. New Jersey: Wiley-Blackwell. 


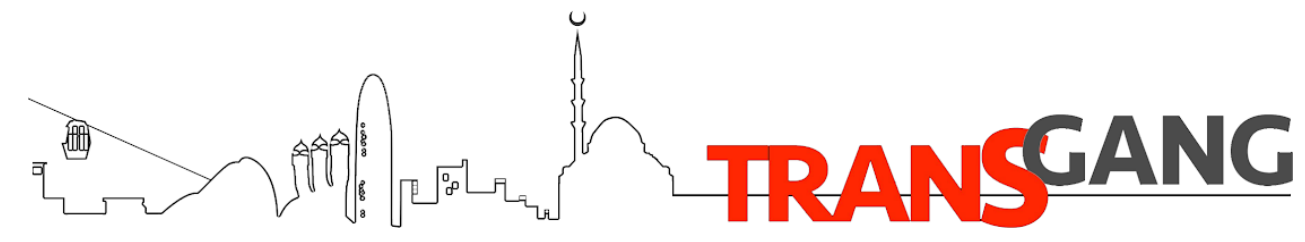

(C) TRANSGANG \& UPF

www.upf.edu/web/transgang

transgang@upf.edu

This project has received funding from the European Research Council (ERC) under the European Union's HORIZON 2020 research and innovation programme under grant agreement No 742705. 